\title{
The World Ends Here, the World Begins Here: Bronze Age Megalithic Monuments in Western Scotland
}

\author{
Gail Higginbottom $^{1,2}$
}

Published online: 28 May 2020

(c) The Author(s) 2020

\begin{abstract}
This paper presents a study of free-standing Bronze Age megalithic monuments across western Scotland: Argyll, Lochaber, Kintyre, and the isles of Mull, Coll and Tiree. The original project was designed to unearth the locational choices of their builders, the reasons for these choices, and what they reveal about the belief systems of these societies. Using statistical analyses and 2D and 3D GIS, it will be demonstrated that vision is the main force behind locational decisions. The GIS analyses revealed that the builders chose a particular horizon shape, defined by qualities of distance, direction and relative apparent height as viewed from the monument (altitude). Significantly, approximately half the sites have the same locational variables as all the sites considered on the isles of Coll and Tiree (labelled 'classic sites': Higginbottom et al. in J Archaeol Method Theory 22:584-645, 2015. https://doi. org/10.1007/s10816-013-9182-7), while the other half are the topographical reverse ('reverse sites'), where the major 'astronomical show' differs due to the topographical differences between the site types. It is relevant to note that landscapes that block views of particular major astronomical phenomena in the south are significantly more common at reverse sites than at classic sites. Specific results pertaining to individual areas will also be highlighted. It will be seen that the interplay between the astronomy and the topographical choices of the builders at each site highlights possible cosmological ideologies that can be observed and that were shared across western Scotland.
\end{abstract}

Keywords Scotland · Bronze Age $\cdot$ Megalithic culture $\cdot$ 3D-GIS $\cdot$ Landscape archaeology $\cdot$ Astronomy $\cdot$ Archaeoastronomy

Electronic supplementary material The online version of this article (https://doi.org/10.1007/s1096 3-020-09139-z) contains supplementary material, which is available to authorized users.

Gail Higginbottom

gail.higginbottom@incipit.csic.es

1 Incipit, CSIC (Instituto de Ciencias del Patrimonio, Consejo Superior de Investigaciones Científicas), Santiago de Compostela, Spain

2 University of Adelaide, Adelaide, Australia 
If everything is relational, mixed, heterogeneous, messy, then analysis must proceed in a bottom-up way, refusing to consider things out of their contexts, always building up from the daily practices of everyday life and the mundane fixes that people find themselves in. ... The approach aims to be thoroughly antiessentialist, building up towards generalization from careful empirical analysis.

(Hodder 2016, p. 10)

\section{Introduction}

This paper reports on research done as part of the Western Scotland Megalithic Landscape Project and concentrates on the chosen locations of standing stone monuments at 59 sites on the Isle of Mull $(n=16)$, and in Lochaber $(n=2)$, Argyll $(n=18)$, Lorn $(n=3)$, and Kintyre $(n=20)$. It combines the observations on these sites with those previously made on the Isles of Coll and Tiree $(n=6)$ (Higginbottom et al. 2015), revealing the reasons for these locational choices and what these show us about the belief systems of the societies that built them (Appendix, Table 1 for list of sites; Fig. 1 for site distribution).

The speculative and non-speculative conclusions about Coll and Tiree were reached by the current author through the examination of the full $360^{\circ}$ visual contexts of these islands' sites, along with the contextualisation of the sites within the greater standingstone astronomical tradition of western Scotland, which had already been conducted as part of the same project, and taking into consideration the archaeological records of standing stone sites in Scotland (Higginbottom et al. 2015). It was specifically demonstrated that there is statistical evidence for a shared interest in astronomical phenomena across western Scotland and across all standing stone types, but with sub-regions (within islands or areas) focusing upon different bodies and cycles (Higginbottom et al. 2000; Higginbottom and Clay 1999, S44). Further, as different monument forms can have the same or different foci within a sub-region, it is clear that the sub-regional differences in astronomical foci are not a question of monument type alone. For Coll and Tiree, the locations of standing stones, while various (near coast, inland, etc.), shared a number of specific landscape characteristics across the two islands (Higginbottom et al. 2015). Initial research suggests that these characteristics may flow over into other subregions nearby, like Argyll (Higginbottom in prep.; Higginbottom and Clay 2016a). It is now crucial to realise that something is being shared in the greater region of west Scotland apart from, but intimately tied to, monument building in stone. Importantly, we now see studies in Europe that also focus on the issue of a shared world, but from the perspective of genetics, looking at the degree of biological relatedness in mortuary contexts, which assists in understanding the biological relatedness between people across places or the genetic topography of populations (Allentoft et al. 2015; Brace et al. 2019a, b; Lee et al. 2012; Olalde et al. 2018). Such work is increasing. The current article thematically connects with such studies as it continues to uncover the cultural topography of populations within western Scotland and helps clarify the degree and kind of cultural relatedness between people in different places that appear to have related traditions that are not yet fully understood. DeMarrais suggests that such concepts of tradition 'can highlight the ways that, through activities, culture is broadly 
shared' (2012, p. 12). This paper will demonstrate precisely how this is evidenced across the Isles of Mull, Coll, and Tiree, as well as in Lochaber, Argyll, Lorn, and Kintyre, revealing the shared values found in western Scotland.

Prior to a detailed discussion of the project itself, this paper will provide an overview of some past considerations and interpretations of standing stone monuments more generally, as well as a short chronological overview of standing stone monuments in Scotland. The project discussion which follows these overviews includes: (i) a description and review of the early quantitative research of the Western Scotland Megalithic Landscape Project (Earlier Research); (ii) a discussion of the assumptions and considerations underlying the more recent qualitative research (Creating a $360^{\circ}$ Visual Context); this includes (iii) a short description of the applied methods of the recent qualitative research (How the 3D Models were Assessed); and (iv) the area results in relation to the standing stone sites on the Isle of Mull and in Argyll, Lochaber, Lorn, and Kintyre, with cross-references to the work previously done on Coll and Tiree. This is all followed by Mull as a Case-Study Exemplar, with detailed examples of findings at individual sites on Mull; and (v) a descriptive narrative that explains how all of the visual elements, highlighted in the results, work together at a specific point in real time at a site on Mull. This is done in order for readers to comprehend how the astronomy and landscape were used to create visual events or 'spectaculars' at these sites by the people that erected them. This is followed by a consideration of how one could go about interpreting such findings (Discussion and Conclusion).

\section{Past Considerations and Interpretations}

That standing stones were culturally significant is already clear, as they were used across Europe and the British Isles in their thousands. Significantly, it is possible they were constructed over a far longer time-frame than any other megalithic monument type in either continental Europe or the British Isles, highlighting their continual relevance for Neolithic and Bronze Age cultures (Beier 1991, 1992; Bradley 2012; Bocksberger 1964; Burri-Wyser et al. 2012; Burl 1993; Calado 2002; Cassen et al. 2013; D’Anna and Pinet 2006; Grau Bitterli et al. 2002; Higginbottom et al. 2015; Kirchner 1955; Müller 2014; Scarre and Oosterbeek 2019; Schulz Paulsson 2017; Wüthrich 2007), and Iron Age cultures (Martinsson-Wallin and Wehlin 2017).

From at least the Early Neolithic, standing stones appeared on their own or with other monuments. The variety of accompanying and associated monuments is great, including megalithic tombs, cairns, cists and earthworks (Bradley 1998, 2011a, 2012; Burl 2000; Fergusson 1872; Kirchner 1955; Müller 2014; Rodriguez and Marchesi 2015; Scarre and Oosterbeek 2019; Schulz Paulsson 2017), and their forms are often well known and/or regionally defined (Barnatt 1989; Beier 1991, 1992; Brophy et al. 2013; Burl 1976, 1993, 2000; Calado 2002; Furholt and Müller 2011; Higginbottom et al. 2015; Kirchner 1955; Noble and Brophy 2011, 2014; Richards 2013a, b, c; Schuldt 1972; Wright 2007). The dates of the accompanying monuments are various, being built before, at the same time as, or after, the standing stones. 
Whilst comparatively little work has focused on the hundreds of extant prehistoric standing stones that appear in rows, pairs or on their own (in particular the smaller or simpler monuments or group studies), stone circles in Britain are another matter. In recent years there have been significant works on and discussion of Scottish stone circle sites, especially the largest circles, recumbent stone circles, and those encircling other monuments like cairns (Barnatt and Pierpoint 1983; Barnatt 1989; Bradley 1998, 2000, 2005, 2011 a; Richards 1996a, 2013a, b, c; Higginbottom et al. 2015; Higginbottom and Clay 2016a, b; Welfare 2011). Quite early works on Scottish sites within this category include Fergusson's chapter on Scotland, which includes different groups of, or individual, circles (1872, pp. 239-274); Somerville (1912) on the stone circles of Callanish, and Spence (1894, p. 123) and Lockyer (1906, p. 132) and Spence (1906) on Stenness. However, (compared to the number in existence) there has usually been a concentration on relatively few encircling monuments within a single project, especially in more recent years (Bradley 2005; Downes et al. 2013; Richards 1996a, 2013a, b, c). Naturally, this is sometimes due to the methodological approach chosen-detailed excavations of single sites, like those at Stenness on Orkney (Ritchie 1976) and Callanish on the Isle of Lewis (Ashmore 2016), are essential for the understanding of site use, construction, lifeways, palaeoenvironmental information and site chronology.

There are some larger group studies though, both in northern and southern Britain. Fergusson's early work on rude stone monuments as a global phenomenon, touched on previously, includes his considerations and preliminary observations on circles, avenues, and menhirs as classes of monuments, with special attention to Britain. More recent larger group studies for Scotland include: Brophy and colleagues' archaeological and broader study of the multiple stone rows of Caithness and Sutherland in Scotland, which includes a compilation of a comprehensive site list (Brophy et al. 2013); this stone-row study regionally overlaps the stone fan investigation of Myatt's (2003) work on the orientation of such sites; Carnes' (2014) work looks at the stone rows of Dartmoor and Caithness and in some respects is an extension of Brophy et al.'s research and some of Burl's discussions of 1993; Welfare's recent work on the Clava Cairns, which are surrounded by stone circles (2011); Barnatt's (1989) work on monument form and distributional analyses; and finally, Wright's (2007) review of standing stone sites on the western Scottish Isles of Arran, Lewis and Mull. Group studies with a focus on the astronomical potential of standing stones include Ruggles' research covering a number of regions in western Scotland (Ruggles 1982a, b, 1984; Ruggles et al. 1991; it should be noted here that Ruggles uses the term North Argyll for the Ardnamurchan peninsula-Lochaber is used in preference here, as North Argyll is also a historic name for Wester Ross in Ross and Cromarty, further to the north and not contiguous with the modern Scottish county of Argyll and Bute); Thom (1979) on the standing stones of Argyllshire; Higginbottom and colleagues' reassessments of Ruggles' work (Higginbottom and Clay 1999; Higginbottom et al. 2000, 2001, 2003); and Barnatt and Pierpoint's (1983) work on the issue of stone circles as observatories or ceremonial centres. Other works by Thom and colleagues encompass Scottish regional studies or individual Scottish sites (Thom 1967, p. 71; Thom and Thom 1978; Thom et al. 1980, 1990). Regional studies south of Scotland include Gillings and colleagues' 
work on the miniliths of Exmoor (Gillings et al. 2010), and then more broadly the miniliths across southwest Britain (Gillings 2015). Burl carried out a study on the Cumbrian stone circles (1988) and produced two gazetteers: one on linear sites of Britain and Brittany (1993) and one on the stone circles of Britain (2000). These gazetteers provide both important details of individual sites and general and regional overviews and notations on work done in archaeoastronomy.

Despite various methodological issues (Higginbottom 2003, pp. 63-66; see also Issues with Astronomy and Landscape Methods below), work by Thom across Britain and by Ruggles and Burl in Scotland and Ireland, made strong steps towards contextualising large numbers of standing stones in their broader environment (Thom 1955, 1967, 1971; Ruggles 1981, 1982a, b, 1983, 1984, 1999; Ruggles and Burl 1985). These large modern, processual field studies helped to re-kindle research interest in the connection between standing stone monuments and the sky and the horizon, asking, can we interpret standing stone monuments as sites that indicate astronomical phenomena, and if so, to what degree? More particularly, they ask, how do the existence and form of standing stone monuments relate to past peoples' knowledge of their environment, in particular the movement of astronomical bodies across the sky and the relationship of this to the edges of the earthly realm (Ruggles 1982b, 1983, 1984; Ruggles and Burl 1985; Thom 1955, 1967, 1973, 1984). Later it was asked, are there certain places as viewed from the standing stones that are seen to be more directly connected to the astronomical phenomena than others (Ruggles et al. 1991; Ruggles and Martlew 1992; Ruggles and Medyckyj-Scott 1996; Higginbottom et al. 2000, 2015)? In these ways, antiquarian interest in astronomy comes once more to the fore.

In Richards (1996a), the landscape context is also key to understanding something of the meaning of stone circles, and Richards interprets both the structure or form of stone circles and the materials from which they are built, as a reflection of the surrounding landscape, or rather of the place in which the Neolithic people lived at the time. However, in 2013, Richards and colleagues appear to have had different goals and a wider interpretive remit, including ethnographic concepts, especially when compared to Thom's or most of Ruggles' works. Whilst Ruggles and Thom look to place their monuments within the visible landscape, Richards and colleagues (Richards 2013a, b, c) adopt a more classical archaeological approach, methodologically speaking, even though their work also includes visual context. In an attempt to move the focus away from preconceived designs, Richards considers the notion and importance of the act of making the circle, and suggests that it 'wraps' or encloses space or things (2013a, pp. 13-23, 29). Whilst the observation that the action of making the monument by the community is one of the most important factors in relation to a monument's considered existence is not new, (McFadyen 2008, p. 309; Richards and Wright 2013, p. 34; also q.v. Heidegger 1971, pp. 42-43, 86); it is clearly a useful and important notion (Richards 2013b; Gillings 2015; also see below). However, the enwrapping quality inherent in the design of the circle may not be relevant to the interpretation of the immediate material quality of stone pairs, stone rows and single standing stones. Nevertheless, the current project argues that the enwrapping horizon at these sites is a crucial factor. The horizon, then, along with the megaliths, is part of the creation and designation of place. This occurs through the enclosure 
and demarcation of visual space, creating close and far away views. It is hypothesized in this paper that such horizons can effectively replace the great stone circles at the smaller and simpler Bronze Age monuments that came later. It will be seen in this paper's discussions on individual site examples from Mull, that the builders of megalithic monuments used horizons to create spaces like amphitheatres. Similar connecting observations can be seen in Bradley's and Richards' works. In his Significance of Monuments, Bradley (1998) specifically argues that stone circles were created with links to the wider landscape, in contrast to the earlier henges, the circular mounds of which would have restricted visibility. The integration of stone circles with the surrounding landscape is further accentuated by the chosen title of a section of this book: 'Theatre in the Round' (1998, pp. 116-131). Richards' observations are as follows:

I wish to draw attention to the constitution of the henge monument in relation to the local topography. The Stones of Stenness and Ring of Brodgar are, respectively, situated on two opposed narrow promontories which separate the lochs of Harray and Stenness. In turn the lochs are surrounded by the hills forming the large natural bowl of western Mainland, Orkney (Fig. 7). Thus, by virtue of their position, both monuments have the appearance of being surrounded by water which is enclosed by the encircling hills. (Richards 1996a, pp. 203, 204, Plate 4; also see description of Deepdale stone, p. 203)

In 2012, DeMarrais states that he and his colleagues had previously 'discussed the materialization of ideology as a means to highlight the active process that underlies the creation, dissemination and manipulation of ideologies' (DeMarrais et al. 1996, in DeMarrais 2012, p. 11). In 2015, Higginbottom and colleagues adopt this same materialist perspective (Higginbottom et al. 2015), maintaining that people's 'concepts are given concrete, physical form, as part of human interactions with symbols and icons, performances, (and) monuments (DeMarrais 2012, p. 11)'. On this basis, we believed it was therefore possible to reverse-engineer such connections, and thus, by studying the material culture we could come to know the conceptual belief systems associated with megalithic monuments. In this way, the 2015 work interpreted something of the cosmological world of the builders of prehistoric monuments in Scotland. These ideas were first presented at the conference of the European Association of Archaeologists in 2005, became available online as a preprint in 2011, and were formally published online in 2013 (Higginbottom 2005; Higginbottom et al. 2011, 2015). In some ways, these ideas echo those of Richards (2013a, b, c) above, as they look towards both the action of creating the monuments and the ritual activities that take place at the monuments, whether these are seen to be conducted by people or other objects/things (like the standing stones themselves, the dead, or astronomical bodies). In this view, the action of making something is both a ritual itself and a materialization of culture, where 'to materialize culture is to participate in the active, ongoing process of creating and negotiating meaning' (DeMarrais et al. 1996, in DeMarrais 2012, p. 16). These are all part and parcel of the materiality of practices (Toren 1999, p. 18). Richards' 1996 work also touches on these ideas: 
If we see cosmologies themselves as being reflexive in that they are both drawn from and explain the natural and cultural world, it is easier to understand how categories of meaning and representation are continually shifting in different social situations. These metaphorical 'shifts' are both observable and comprehensible in the constitution of the Stones of Stenness and Ring of Brodgar (Richards 1996a, p. 205).

However, all these notions have undergone a much longer development outside and then within archaeology, having grown out of the interpretative tradition, moving on from Schleiermacher's 19th century quest to 'illuminate conditions for possible understanding and its modes of interpretation' (Mueller-Vollmer 1986, cited in Johnsen and Olsen 1992, p. 421) to Droysen's 19th century distinction between 'understanding' and 'explanation' in history (Droysen 1986, p. 121; see also Thomas 2006 , p. 22). The latter asserts that the only appropriate approach to history is a hermeneutic one relating the whole and its parts-specifically, 'The part is understood within the whole from which it originated, and the whole is understood from the part in which it finds expression' (Droysen 1977, p. 35, cited in Johnsen and Olsen 1992, p. 421). This is about contextual relatedness and understanding. Such thinkers, along with Humboldt, Herder, Dilthy and others, influenced the work of the hermeneutic phenomenologists of the 20th century, like Husserl (1913), Sartre (1943/1956), Merleau-Ponty (1945/2012), and Heidegger $(1971,1982)$ and humanists alike. The idea of the importance of context led to a questioning of the unnecessary division between nature and culture. In the same way, it was realised that the tangible in heritage cannot be understood without the intangible, for they are all part of the larger system of human experience (Higginbottom and Tonner 2010; Higginbottom 2014). Thus phenomenology's appeal for archaeology often stems from its adoption of the full contextual or holistic approach to human experience. The important thing to recognise here, then, is that many of our salient philosophical ideas about being, ritual and making and our understandings of how these are intertwined and inextricably entangled, along with our acknowledgment that it is through this entanglement that our own belief systems were developed, created and have been understood (who we are), have filtered down from the early interpretive tradition of the 19th century to the hermeneutic phenomenologists of the 20th century and on to thinkers in theoretical and monumental archaeology, like Barrett (1987), Bradley (1998), Richards (1996a), Thomas (2006), and Hodder (2012, 2016), with or without direct reference to these traditions. So, in Heideggerian terms, monuments participate within social processes by showing the community what they know; they allow individuals and groups to identify themselves as a particular group through this association (Heidegger 1971, pp. 42-43; Tonner 2010). Perhaps in this way we come closer to Hodder's idea of entanglement, where as humans we are inextricably and coincidentally intertwined, ensnared and entrapped by the things we make and the things around us and are carried along with them (Hodder 2012, 2016, pp. 8-12). Specifically, having been built by a community, the standing stone monuments themselves gather, focus, direct and manifest the self-interpretations of that same group; engaging with these monuments reinforces, or draws anew, their own world view (Higginbottom et al. 2015, p. 640). As a poetic illustration Heidegger writes: 
The temple-work, standing there, opens up a world and at the same time sets this world back again on earth, which itself only thus emerges as native ground ... The temple, in its standing there, first gives to things their look and to men their outlook on themselves (Heidegger 1971, pp. 42-43, cited in Higginbottom et al. 2015, p. 640).

These ideas are seen directly reflected in Richard's and Bradley's works:

... now (the giant stone rings) become fused and join in union to become a central point, an axis mundi, of the physical and cultural world. From the central hearth within the Stones of Stenness to the monumental complex in the large central bowl of western Mainland, we see a series of transformations operating at different scales, both in the composition of monuments and in people's experience of that cultural landscape (Richards 1996a, p. 206).

Cosmology acts as a way of both understanding and viewing the world; as such it necessarily imposes a categorical order on that world. ... as Richard Bradley (1993) has noted, once constructed, monuments alter the physical world and continue to influence its reading by future generations (Richards 1996a, p. 206; q.v. Bradley 1993, pp. 84-100).

It is possible to connect these ideas with Carnes' (2014) work. He concludes that the long and/or multiple stone rows or cairn-and-row monuments of southern England and northern Scotland are related (2014, p. 149) and indeed "have similar semantic organisations, and therefore look somewhat alike, because they 'represent' (Neolithic) long mounds" (2014, p. 149). In this way, the mounds that were already there have influenced the style of certain standing stone monuments. Further, he deduces their clustering with other monuments was due to a process of signifying and asserting an affinity with those already built. Thus, the monuments and cosmology of the past, influenced the future of both.

Standing stones as a group, regardless of form, have continually had the same two associations and/or relationships across Scotland and elsewhere in the British Isles: the dead (often cremated) and astronomical phenomena (Higginbottom et al. 2015, pp. 587-605). As far back as 1872, Fergusson reports that in the British Isles 'the spade ... is gradually dispelling all these theories (on stone circles as Druid temples or places of assembly). Out of say 200 stone circles which are found in these islands, at least one-half, on being dug out, have yielded sepulchral deposits' (1872, p. 49).

Fergusson then goes on to suggest that in fact stone circles with avenues may well have evolved out of chambered passage tombs, essentially retaining the outer geometric pattern (1872, pp. 51-52). Interestingly, similar to work done in Brittany, Kirchner's 1995 research in central Europe reveals that there is likely a very strong and significant connection between tombs and menhirs. He suggests that there must have existed menhirs in tombs which functioned as a proxy for the dead, and that over time these stones developed an autonomic function, no longer having to be placed within a tomb but being able to stand outside the tomb and maintain their 'religious function', whilst not being confined to one active purpose or practice. Essentially, Kirchner argues that these standing stones still represent the dead and 
the dead live in the menhirs and maintain connection with the living people and their community by existing outside of sealed tombs. Much later, Cooney (2000), Bradley (2011b), Parker Pearson et al. (2008), Richards (2013a, b, c) and Willis et al. (2016) also highlight the issue of standing stones associated with burials or aspects of the dead, like cremations or partial cremated remains (related to, for instance, great stone circles, kerb cairns, ring cairns, recumbent stone circles, and passage graves). In particular, Cooney discusses the idea of earlier decorated standing stones being pulled down and put into different passage tombs in Brittany (Le Roux 1984, 1992, cited in Cooney 2000, p. 131). He also discusses the uses of standing stones inside and outside the passage tomb of Bryn Celli Ddu, Anglesey in Wales (2000, p. 134). He confirms that in the Irish tradition, standing stones were 'used as both external landmarks and as internal features in megalithic tombs', holding some parallel with the anthropomorphic stelae placed inside and on the left of the end of the passage tombs (Giot et al. 1998, pp. 177-179, cited in Cooney 2000, p. 134). We can easily unite these occurrences with Kirchner's ideas and align them with Taçon's notion that standing stones were 'such a widely used monumental form because of (their) anthropomorphic connotations' (Taçon 1994, cited in Cooney 2000, p. 131).

When looking at stelae traditions in European prehistory, Robb examines the methodological potential 'for forging a bridge between the representation of the body and the body's agency' (2009, p. 166) for both decorated and undecorated menhirs without obvious anthropomorphic features (e.g. in Hungary). Moving towards his conclusion on the impact of, and reasons behind, aesthetic styles used during later prehistoric Europe, Robb maintains that:

people formed stelae and installed them in the landscape to act as presences in special places, places in which the dead and the past were invoked or encountered. The salient element was probably the presence of the 'people of stone' themselves in the place, their solidity, fixity, and materiality. But their aesthetic canon also conveyed a powerful social reality (2009, p. 179).

In his 2011 work, Bradley wonders why stones without anthropomorphic features in the British Isles should not be considered statues, as some European Atlantic menhirs have been. Therefore, in a sense, Bradley does not go as far as Kirchner in his interpretation, for he states that the stones could be representations of 'people, ancestors or mythical beings' (2011a, b, p. 52), rather than living parts of a community. Bradley and Kirchner also discuss the mythologies associated with standing stones in the British Isles and Germany, respectively. Cummings and Richards (2013) argue that standing stones surrounding passage graves are there to protectively enclose them. Interestingly, both Richards and Bradley state that such circles around these sites may have been the inspiration for later stone circles. All these ideas have a similar ring to Burl's earlier ideas that stone circles grew out of monuments for the dead. Burl (1982) states that if the origins of stone circles are to be found in the enlarged forecourts of chambered tombs, we might expect the early rings to possess human bone because their ancestry lay with the tombs. Indeed, some of the earliest stone circles either have cremated bones in hearths at their centre (Stenness, Orkney) or once contained burial mounds in one of their quarters (Callanish, Lewis). As discussed above, we know that these stone circles are two of the 
earliest in Scotland, along with Balbirnie (Ashmore 2016; Schulting et al. 2010, pp. 35-36; Gibson 2010). Added to this, 'because of stone circles' links with the (earlier Neolithic) astronomically oriented tombs (to the Sun), their design would include astronomical alignments' (Burl 1982, p. 152). The current author's recent work on Callanish and Stenness supports this (Higginbottom and Clay 2016a, b; Pollard and Ruggles 2001). Interestingly, in Scotland, simple standing stone monuments, like stone pairs and single standing stones, exist in connection with (next to or on top of) burial cairns, or within view of tombs, and then also appear to have been located away from tombs/cairns altogether, but seemingly always in connection with the dead, as partial cremation deposits were often placed in the stone holes or full cremations placed up against the stone hole (Higginbottom et al. 2015, pp. 600-601). An interesting, related point from Cooney is that cremations were placed at the special site of the standing stone, rather than the standing stone being situated there to mark a burial (2000, p. 135; q.v. Noble and Brophy 2015, p. 167). These ideas dovetail exceptionally well with the earlier review, study and interpretation of standing stones on Coll and Tiree (Higginbottom et al. 2015). Here the standing stones may have been regarded as living witnesses to the cosmic order, gaining their local power and supernatural associations from the dead (who were inserted into the holes containing the megaliths themselves, or at the foot of or near the standing stone). Speculatively, it was suggested that through this juxtaposition the stones were given the power to see what the living could, and perhaps it was believed that through the stones the entombed or buried dead could see this as well (Higginbottom et al. 2015 , p. 639). This idea grew out of the conclusions of Higginbottom's earlier thesis (2003), namely that 'part of the monuments' roles ... was to bear witness to (celestial) events and not merely to record or register them. ... The monuments themselves are participating in the events' (Higginbottom 2003, p. 167). This 2003 idea find echoes both in Gillings and Pollard's later work on Avebury, where the megaliths are 'living entities' (2004, p. 69), and in Richards' (2013a) work, Interpreting Stone Circles, where he writes on stone circles as 'animate entities'. Further, the theoretical speculation presented by the current author (Higginbottom 2005; Higginbottom et al. 2011, 2015), about how megaliths could gain their local power and supernatural associations from the dead, along with the discussions on transformation of the body through cremation into an otherworldly force that may become apparent through its association and connection with the standing stone, can also be seen in Richards' (2013a) work on Great Stone Circles. Specifically, he states that:

The juxtaposition of human remains, in the form of cremations and standing monoliths in stone circles is tantalizing. As noted above, the setting up of a monolith into a vertical position draws an analogy with the human body. When monoliths are directly associated with human remains, can we assume some form of fusion where the human remains meld with the monolith and it becomes animated? The idea that standing stones within circles were conceived as 'living things' imbued with an essence is seductive. While potentially taking numerous forms, such animation need not constitute a permanent state and could assume a degree of transience. When animated, however, the stones may have become extremely dangerous and strategies of binding or 
wrapping, as discussed earlier, would be essential. ... Under such conditions, the consistent deployment of architectural devices of wrapping, as manifest in virtually all areas of late Neolithic monumentality, become comprehensible (2013a, pp. 28-29; q.v. Jones et al. 2011).

In this paper we will be dealing with the standing stone tradition that appeared in the late Bronze Age in western Scotland. To enable the reader to follow the arguments related to previous work done on archaeoastronomy on Coll, Tiree and Mull and areas of the mainland of western Scotland, the following section will cover the necessary definitions and explanations of astronomical phenomena and their observation.

\section{Chronology of Scottish Standing Stones}

From the Late Neolithic onwards in the British Isles, forms of megalithic structures that were essentially fully exposed and open to public view appeared-stone circles and 'individual' standing stones (Bradley 1998; Burl 1993; Richards 2013a), with new constructions continuing for more than two thousand years (approximately 3000-900 cal BC: Bradley 1998; Burl 1993, 2000; Higginbottom et al. 2015). Two of the earliest standing stone sites in Scotland are Callanish on the Isle of Lewis and Stenness on Orkney. Callanish circle and central monolith were built c. 3000-2900 cal BC in the Late Neolithic, and its internal tomb during the early Bronze Age (Ashmore 2016). This date range is inferred from the combination of the order or sequence of erection events at Callanish and the 32 radiocarbon-dated samples from excavation (Ashmore 1999, 2016). Stenness has been dated using finds from the henge and hearth (Burl 2000, p. 211; Higginbottom et al. 2015, p. 584; Ritchie 1976, p. 10, Appendix 9; RCAHMS-CANMORE_-under site name). Most recently Schulting and colleagues' Bayesian model of dates, using a combination of traditional dates from Ritchie's excavation and more recent AMS dates, shows that it was likely built c. 3000-2900 cal BC (Schulting et al. 2010, pp. 35-36). Other possibly contemporary sites include Balbirnie, a low stone circle in Fife in eastern Scotland (c. 3000 cal BC: Gibson 2010, p. 63) and Orwell, in Perth and Kinross, a stone pair, possibly part of a stone circle (2890-2630 cal BC) (Ritchie 1974, p. 8; Sheridan 2008a, b, p. 201). Notably, single standing stones are directly associated with, or connected to, monuments dating from the Late Neolithic to the late Bronze Age, such as at Callanish stone circle (Ashmore 2016), or possibly within the cemetery at Forteviot, Stirling, dated to 3090-2638 cal BC. At the latter site there is the possibility of a single standing stone marking a burial (Noble and Brophy 2011, p. 790, 2015, p. 168, Fig. 4). However, at this site, cremations may have been also been placed within an empty stone hole and 'the cremation cemetery was established soon after the decommissioning of a stone circle or setting, with the empty sockets a particular focus for burials' (Noble and Brophy 2015, p. 168). Nevertheless, at some level, the association of cremations with standing stones remains the same.

Recumbent stone circles may date from the Early Bronze Age or the Late Bronze Age (Bradley 2005; Welfare 2011, p. 88). However, the range of dates for linear 
settings, like short rows, and non-Neolithic single standing stones and pairs, appears to be in the latter Bronze Age: Ardnacross, Mull (pair of stone rows) has dates of 1260-900 cal BC and 1130-810 cal BC (Martlew and Ruggles 1996, p. 126); Ballymeanoch, Argyll (a stone row dated by the single standing stone next to it) is dated to 1370-1040 cal BC (Barber 1978, p. 107; Sheridan 2008a, p. 61; RCAHMS - Canmore: sample ID GrA-28613); the single standing stone at Dunure Road in Ayrshire, 1310-1050 cal BC (Duffy 2010, p. 53; Higginbottom et al. 2015, pp. 600-601). The finds that date the simpler standing stones are usually cremated human bone or charcoal from deposits set against the base of the standing stone, often sealed under packing stones, like at Ballymeanoch. The linear settings, and many single standing stones, in Scotland are therefore dated to approximately 1400-900 cal BC. The dating of more complicated monuments is more complex, and the associated literature mentioned so far for such sites should be consulted for this. It is not yet clear whether there are two distinct periods for the erection of standing stones-from the late Neolithic until end of the Early Bronze Age, picking up again in Late Bronze Age - or if they were continually being erected over a period of more than two thousand years.

\section{Understanding Landscape's Connection to Naked-Eye Astronomy}

Some celestial objects' paths will cross an observer's local horizon twice a day (once for rising and once for setting). The exact circumstances of these observed events are a function of the associated object's celestial coordinates, the geographical latitude of the site/location of the observer and the 'local' horizon profile at that site. The declination of the object determines the points on the local horizon at which rising and setting occur (if at all). The right ascension of the object determines the times at which rising and setting occur.

A particular declination path or value always intersects a given horizon profile at the same point, and every horizon point is intersected by one and only one declination path, and always the same one. This implies that there is a unique, one-to-one mapping between points on a given horizon and an astronomical declination, where the latter is the path along which an astronomical body may travel.

The Moon and Sun vary their declinations or paths, and therefore where they cross the horizon, over cycles of time. Nevertheless, these variables can still be calculated. For example, we can calculate what the declination of the Sun should be at its most northerly and southerly rising and setting points (summer and winter solstices) for any specified year. In the northern hemisphere, a cycle is roughly equivalent to the Sun moving away from its most northerly rising and setting points (summer solstice; a declination of $23.5^{\circ}$ north in our current epoch), rising further and further southward, until it reaches its most southerly rising and setting points (winter solstice; $23.5^{\circ}$ south or $\left.-23.5^{\circ}\right)$. The Sun crosses the celestial equator at the equinoxes (declination $0^{\circ}$, around March 20 and September 22). This project used the same average calculations for solstices as Ruggles' 1984 work in western Scotland, namely: $-23.9^{\circ}$ and $+23.9^{\circ}$. These values are representative for the Bronze Age and are slightly higher than those for the current epoch. 
The Moon, which has a more complicated form of movement, takes approximately 18.6 years to complete its cycle in relation to its extreme rising and setting points along the horizon. The Moon's declination also varies throughout its monthly cycle, in much the same way that the Sun's declination varies over the course of a year. Since the Moon's path is, on average, the same as the Sun's, its monthly maximum excursion from the celestial equator is also about $23.5^{\circ}$ on average. However, the Moon's orbit is actually inclined at about $5^{\circ}$ to the ecliptic (the apparent path of the Sun travelling around the earth on the celestial sphere), so in reality the geocentrically observed lunar declinations can vary from about $18.5^{\circ}$ to $28.5^{\circ}$ north and south, where a positive value is to the north and a negative value to the south. In terms of naked-eye astronomy, this will be north and south of the observer. The time at which the maximum northerly and southerly values occur is known as the major standstill, and that at which the minimum values occur is the minor standstill. Therefore $-30^{\circ}$ and $+28.2^{\circ}$ are the average maximum declinations of the Moon's path to the south and to the north of the observer in western Scotland and $-19.7^{\circ}$ and $+17.9^{\circ}$ are the minimum declinations of the Moon's path to the south and to the north of the observer in western Scotland. These slight asymmetrical declinations (around zero) are actually linked to the place of observation, where observing from northern latitudes produces an apparent southward shift of the Moon caused by the phenomenon known as the parallax effect.

Essentially, then, each standstill has two values which are the two 'bookends' of a range of paths that the Moon will take in a certain period (Fig. 2a). At the time of the major standstill, the possible range, or difference, in declination of the two 'bookends' reaches a maximum, whereby the difference between the Moon's most northerly path and its most southerly will be at its greatest within a single month, and so too, the northerly and southerly rising and setting points seen on the horizon. These differences and extremities in the Moon's paths take on the following striking visual qualities, the first of which is attributed to western Scotland's high latitudes:

i. Whilst traveling along its extreme northerly path, the Moon reaches its greatest altitude in the sky as seen by the observer on earth. This then changes quite rapidly, so that within about two weeks the Moon is travelling along its most extreme southerly path, and with this reaches its lowest culmination altitude in the sky, causing it to travel over or along the horizon.

ii. To the observer, it is highly noticeable that at these times of the major standstill, the Moon travels and sets along the horizon further north and south than the Sun ever will. At the time of the minor standstill, the possible range, or difference, in declination of the two 'bookends' reaches a minimum, whereby the difference in the Moon's most northerly path and its southerly will be at its smallest, and so too, then, the northerly and southerly rising and setting points. The striking visual qualities of this event are that the Moon at this time will always travel between the Sun's extreme northerly and southerly paths, never exiting or crossing the solstice Sun's travels. 
Significantly, these regular monthly extremes culminate in a one-time-only maximum and minimum every 18.6 years - the Moon's full cycle. It is to these extremes that we suspect many monuments are oriented. Such things can be easily detected in an environment with horizon markers such as notches, peaks and so forth.

\section{Astronomy in Prehistoric Western Scotland: Previous Technical Archaeoastronomical Research}

The study of prehistoric astronomy in the British Isles and northwest Europe, as well as in other regions, has been primarily based on the assumption that the ancient peoples were interested in celestial bodies as they rose and set along the horizon (Burl 1993, 2000; Criado-Boado and Villoch-Vázquez 2000; Dowd and Milbrath 2015; González-García and Belmonte 2014; Heggie 1981; Patrick and Freeman 1985; Ruggles et al. 1991; Scarre 2005; Mörner 2012, 2015; Ruzicka 2015; Šprajc and Sánchez Nava 2015; Thom and Thom 1978, 1980; Hoskin 2009). Much of the study done by archaeologists and others on astronomy in prehistory therefore specifically focuses upon this connection.

\section{Ruggles in Western Scotland}

Previous archaeoastronomical work in western Scotland has been carried out by Alexander and Archie Thom (Thom 1955, 1967, 1971, 1981; Thom and Thom 1978, 1980) and Clive Ruggles and colleagues (Ruggles 1981, 1982a, b, 1983, 1984, 1985, 1999; Ruggles and Martlew 1992; Ruggles et al. 1991; Ruggles and Medyckyj-Scott 1996; Fig. 1 indicates location of sites considered in Ruggles 1984 and the majority of this project as a whole at the time of submitting this paper). It is important to know that The Western Scotland Megalithic Landscape Project began as a reassessment of Ruggles' (1984) study, Megalithic Astronomy: A New Archaeological and Statistical Study of 300 Western Scottish Sites. The initial aim was to develop new statistical methods and GIS approaches for the study of landscape archaeology, in particular archaeoastronomy, and to create rigorous statistical and qualitative considerations as a basis for landscape work to avoid being misled by the human propensity to observe patterns in visual data. The outcomes of these new methods were then compared to Ruggles' results (Higginbottom and Clay 1999; Higginbottom et al. 2000, 2001, 2003).

Naturally, critiquing all of the methodologies discussed and applied by Ruggles is beyond the scope of this paper. However, this paper will highlight some of the most pertinent points, including some references to Alexander Thom's work. A much fuller assessment of both individuals can be found in Higginbottom (2003), especially the entirety of Chapter 4: Archaeoastronomy and the Experimental Method: The Question of Reliable and Valid Research in the British Isles.

Ruggles' 1984 archaeoastronomical project, which included all manner of standing stones across western Scotland, confirmed that there was firm statistical 
evidence for the deliberate orientation of standing stone sites towards astronomical phenomena in two regions out of five in western Scotland, broadly speaking those of Mull and Argyll. The orientation distribution was made up of either the internal alignments of monument elements, like the axis of a stone row or a thin, wide slab, or the external alignments created by two monuments, such as a small stone circle and a standing stone or even two stones beyond a certain distance apart (see Ruggles 1984, Section 2 for details on site and alignment selection procedures). Furthermore, whilst his entire dataset of 125 sites included single standing stones, stone rows, stone pairs and stone circles, his final results showed that the strongest support for the likelihood of the deliberate creation of monument alignments involved intersite alignments composed of at least one stone row or stone pair (as opposed to on-site orientations; Ruggles 1984, p. 234). These stone rows and stone pairs were likely oriented on the southerly limit of the Moon's monthly motions at different points in the 18.6-year lunar cycle (Ruggles 1988, p. 234). Statistical support was also found for orientations of monuments to the rising and setting Sun at the winter solstice, and weak support for noteworthy orientations that possibly indicated an interest in the lunar standstill limits. Despite these interesting and important findings, it became apparent that the methods used for the 1984 study, and support for Ruggles' other findings, are somewhat problematic. Nevertheless, it should be stated that the methods were the best available at the time, given the large number of sites across a large area, the amount of field work and time required, and the lack of digital landscape data. Nearly all the data for all the sites was collected in the field, but the landscape data (topographical information) was only a small fraction found along the horizon of each site, whereas topographical data as far as a human eye can see, $360^{\circ}$ around every site, is what is required for a thorough and complete analysis of the potential of horizon astronomy at sites.

As we can see from the above, one of Ruggles' main objectives was to test monument alignments in relation to astronomical phenomena, specifically to see if they met at the horizon. The astronomical connection can be tested for by comparing the declination values of the astronomical bodies with those declination values of the horizon points indicated by the orientations of each monument. The declination of the latter is determined by using a monument's alignment direction (azimuth), the elevation of the local horizon in the direction of the alignment (altitude) and the geographical latitude of the monument. We can then see if such calculated declinations coincide with the declination of any known celestial bodies like the Sun or the Moon. If there is statistical support that the coincidences of these two sets of declinations are not random, we can state that the astronomical orientations of the monuments are not due to chance factors. Therefore, Ruggles was testing for the likelihood that the distribution of observed horizon declinations, indicated by monument alignments for each region, was consistent with a distribution of deliberate astronomical alignments rather than a distribution of random astronomical alignments.

The issue for Ruggles when carrying out this test was that, essentially, he did not have access to any sets of random distributions created from a real body of topographic data (expected declination data). Ruggles was aware of this, and he attempted to overcome this problem and the variable dependencies with a number of statistical approaches (Ruggles 1984, pp. 254-261). In a similar way to the Thoms' 
work (Thom and Thom 1978, 1980), Ruggles created his expected declination data ('random') from his observed declination data and then tested his original observed data against this null expectation (Higginbottom 2003, pp. 63-66).

Explicitly, the approach used by Ruggles to examine his 276 observed orientations (monuments can have more than one orientation) was to create three lists: latitude of the monument; elevation of the horizon in the direction of the alignment; and the possible range in degrees of each indicated azimuth (e.g. a possible viewing window of between $0.1^{\circ}$ and $3^{\circ}$-or more, depending upon alignment irregularities, etc.). Two of these lists were then shuffled randomly and recombined with the first entry from each of the three lists 'so as to produce 276 new latitude-altitude-width triplets' (1984, p. 255). Ruggles' next steps were as follows: 'to each triplet we now assign an azimuth at random, and calculate the limiting declinations of the simulated indications. A set of 276 declination intervals produced in this way will satisfy the requirement that orientations have been randomised' (1984, p. 255), as the property he wishes to randomise is structure orientation, and the property he wishes to investigate is the indicated declination $(1984$, p. 254). He did this 100 times to create a probability statistic. He then compared the number of times the observed declination windows from the site orientations hit a particular declination value within a given declination range (ranges from $0.1^{\circ}$ up to $20^{\circ}$ ) and compared it with the number of times the expected random declination windows hit the same declination value within a given declination range. Ruggles tested for declinations running from $+39^{\circ}$ to $-35^{\circ}$. Specifically, he asked: '(i) In how many of the 100 simulations were there as many or more hits upon this target (than the observed)? And (ii) In how many of the 100 simulations were there as many or fewer hits upon this target?' (Ruggles 1984, pp. 254-261). In this way, he created a probability statistic that gives the likelihood that the occurrence of the 'observed events' could result from 'chance'.

It is clear that there is a particular issue with Ruggles' approach, especially when one recognises the importance of the actual horizon profile. As stated above, his approach does not test one set of real or physical data (observed) against another set of real or physical data (randomized expected). So a real randomised situation has not been tested against. The fundamental problem is that the horizon elevation function (the relationship between azimuth and elevation, and therefore to the associated declination) is real and fixed to a specific site; it is not a probabilistic distribution like that created by Ruggles. This meant that Ruggles' tests did not duly consider the actual (physical) landscapes and so his approach leads to results that are unphysical or unreal. In subsequent studies, Ruggles and colleagues made further attempts to deal with the real landscape, given the limitations on data collection/availability.

In 1991, Ruggles, Martlew and Hinge discuss their use of 'control locations' and their collection of a greater amount of horizon data for each site (e.g. horizon prominence, distance and direction). Such data were used for two major approaches, which they called 'global analysis' and 'local analysis'. In Ruggles and Martlew's (1992) paper, they further investigated horizon qualities in relation to an association between particular astronomical phenomena and horizon prominence. All approaches required much extra fieldwork, including horizon surveying and geographical data on nearby locations. However, in carrying out this further work their 
goals shifted from testing the likelihood of the astronomy per se, to testing the choice of the locations themselves, leaving the testing of the declinations unresolved.

More specifically, the applications carried out for the 1991 publication of north Mull (Ruggles et al. 1991), whilst very interesting, make it difficult to make generalisations from the statistics, as the work focused on a small number of sites (seven from the north of the island and 22 real control locations for comparison). Secondly, whilst measurements were taken around the horizon, they were only taken at large intervals, particularly where mountain or hill ranges intersected. So, whilst much more real horizon data was gathered, the lack of easily accessible digital elevation data again had an impact on control and case-study locations. Despite these methodological restrictions, it is clear the results of this study in many ways predict some of the outcomes of future complex topographical GIS analyses. For instance, the researchers concluded that the hypothesis of 'no difference between the distribution of visibility between monuments and control points' was rejected for the $<1 \mathrm{~km}$ horizon distance category at the $p<0.05$ confidence level and for the $3-5 \mathrm{~km}$ and $>5 \mathrm{~km}$ categories at the $p<0.1$, a minor confidence level (Ruggles et al. 1991, S68). The seven sites were also shown to statistically avoid 'distant horizons to the NW and NNW (that is greater than $5 \mathrm{~km}$ )' and 'avoided nearby horizons in the $\mathrm{S}$ and WSW' (less than $1 \mathrm{~km}$; Ruggles et al. 1991, S68). These results imply that horizon distances in particular directions were likely deliberately chosen for these seven sites on north Mull; we anticipate that further work will strengthen this conclusion.

The 'local analysis' of 1991 was a focused study of the site of Glengorm and asked whether 'the mere location of sites in areas of good settlement potential can explain the horizon profiles observed'. However, in the end, only four of the nine variables used to define comparative control sites were consistent across the eight control sites. So, whilst the methodological ideas and outcomes were interesting, the comparisons and conclusions are not firmly connected to the original question for this local analysis.

Ruggles and Martlew (1992) later considered the prominent hill summits and their astronomical potential around seven sites in north Mull. Whilst the collection of data for this stage was clearly intensive, the number of sites is again a limiting factor, as is the issue of a lack of extensive digital terrain data; together these reduce the ability to interpret the findings across a larger number of monuments or to make clear generalisations. In emphasising the intensity of data collection, Ruggles and Martlew proposed future work with GIS (Ruggles and Martlew 1992, S11). In the meantime, they concluded in relation to the placement of seven stone rows in midnorth and NE Mull that there exists (i) a prominent peak to the east of south in a position associated with the rising of the Moon close to its southernmost position at the major standstill, and (ii) a non-local horizon (distant) in the south and west of south (1992, S12). In addition, they state that though by no means proven sites may have incorporated a second southern peak, placed more easterly than (i) above, to incorporate the rising of Moon at the minor lunar standstill. Further, they add that, speculatively, perhaps there was an additional prominent peak set up with the rising or setting of the summer solstice Sun $(n=3)(1992, S 12)$. Again, we can see a hint or a shadow of the outcomes of what will be found here in western Scotland, but at 
this stage, with such a small number of sites, such a conclusion cannot be more generally applied, as stated by Ruggles and Martlew themselves (1992, p. 12).

In attempting to deal with previous limitations, Ruggles and Medyckyj-Scott looked to Multiple Viewshed Analysis in 1996 'to try to identify those natural features and astronomical events that best explain the observed placing of the stone rows' (1996, p. 132). The preliminary visual results, which are a lead-up to the use of multiple viewsheds, appear to support item (i) of their 1992 work as a first foray into using GIS (that there exists a prominent peak to the east of south in a position associated with the rising of the Moon close to its southernmost position at the major standstill, namely Ben More, for some of the seven sites). Ruggles and Medyckyj-Scott then look at five other standing stone sites in north Mull, but these do not contain an astronomical connection with this most dominant peak of Ben More. Then, by referring to the 1992 results of three sites, Ruggles and MedyckyjScott argued that other mountains may have played this role. However, the suggested method of creating multiple-viewshed data to observe or test these ideas (the examination of every possible nominated peak of every single horizon around that site) is actually lacking in the results section. Therefore, whilst we have a very interesting possibility of an approach using multiple viewsheds and the determination of astronomical potential, this paper does not accurately or clearly identify the connection between mountain and astronomy in Mull except in one possible direction and for a single prominent peak.

In sum, despite the excellent data collection strategies connected directly to specific hypotheses, the thoughtful assessment of how to deal with the lack of digital topographical data, and the enormous amount of field work to collect the required monument and topographic information, the major limitation upon Ruggles' work to date has been the combination of lack of computing power and digital terrain data at the time the work was done. The result is that it has not been possible to statistically analyse, or represent, the required data accurately at all times (as demonstrated above), and, finally, the outcomes have not provided visual demonstrations of where the astronomical events happened on the horizons of the actual landscape that surrounded these monuments. The latter is an essential element for understanding the placement of these monuments, as well as how astronomy and landscape are knitted together at these sites.

With the availability of high-powered computers and digital terrain data, new approaches and software applications have since become possible (Higginbottom and Clay 1999, 2016a; Higginbottom et al. 2000, 2001, 2003, 2015: Higginbottom and Mom 2018; Higginbottom 2020, in press). The Horizon software, developed expressly to counter all these limitations, provided firm data for statistical analyses and sound reconstructions of the topographical landscape with the paths of the Sun and Moon clearly mapped on to the model (Smith 2013). Ultimately, for the first time in the archaeology of the simple standing stone of Scotland, the full visual field of both sky and topography, for $360^{\circ}$, was part of the visual considerations of these monuments, alongside the development or application of statistical tests new to this area of research. 


\section{Statistical Re-investigations of Monument Orientation and Connections to Astronomical Phenomena}

This section presents an overview of the results of the current project's initial reassessment of Ruggles' work. To ensure that direct comparisons of methods and results were valid from the beginning of the project, the initial datasets used were those of Ruggles' 1984 project.

Through the new application of more appropriate statistical tests for circular data, our re-analyses of Ruggles' work showed that megalithic monuments as a group, across a wide region of western Scotland, were deliberately clustered in orientation towards what were initially unknown directions (Higginbottom and Clay 1999, S44, tables 3 and 4; Higginbottom et al. 2001, 2015, p. 608). In other words, the monuments were clearly oriented in ways that were meaningful and statistically repeatable, but at the time of Ruggles' project the reasons behind this patterning were unknown, as the test was one that only detected whether or not clustering in azimuth was apparent. This was further statistically confirmed for four out of six sub-regions when the data were sub-divided into geographical areas. The supported sub-regions were: Uist, Argyll/Lorn, Mull/Coll/Tiree, and Islay/Jura (Higginbottom and Clay 1999; Higginbottom et al. 2001, 2015). Upon examination, Kintyre appears to have two separate orientation distributions, one in the more northerly area of Kintyre and a second group of sites in the more southerly parts of the peninsula (Higginbottom 2003 , p. 194). Lewis/Harris did not display any statistical support at that time but is now being re-examined due to the emergence of new methodological approaches and findings. Using comparative testing methods, but an entirely different test that was not as well suited to the circular data (Higginbottom and Clay 1999), Ruggles only found support for clustering in orientation on the isles of Islay and Jura. Other clustering was only found once the data were repeatedly broken down into a number of different archaeological classes and then re-tested (Ruggles 1984, pp. 230-240; Ruggles 1988, p. 234). So by using statistical tests that dealt better with circular data we found much stronger and more widespread evidence for an interest in astronomy within western Scotland during prehistoric times, in particular the Bronze Age, given the evidence presented previously on the likely age of these monuments.

The next step was to investigate the likelihood that these orientations were connected to astronomical phenomena along the horizon. As a graduated step in our declination assessment, a test for the declinations' distribution pattern only was first carried out for each region, basically testing the likelihood that groups of declinations were sought for in the first place (like testing for 'clustering only' in azimuth, it was not testing the likelihood of any specific declination[s]).

This work was particularly bespoke as it was made possible through our newly developed software that created 2D landscape reconstructions called Horizon (Smith 2013). Through these reconstructions it was then possible to generate numerical and graphical horizon profiles for sites on Coll, Tiree, Mull, Lochaber, Lorn, Argyll and Kintyre from digital elevation data obtained from the Ordnance Survey in the UK (digital data based upon the Ordnance Survey 1:50,000 Landform PANORAMA map; Higginbottom et al. 2015). Such 2D site horizon profiles contain information 
on distance, elevation and direction of the visible horizon as viewed from each monument. They were used specifically to test for the likelihood that the distribution of observed horizon declinations indicated by monument alignments, for each region, was consistent with a distribution of deliberate alignments rather than a distribution of random alignments. This digital data facilitated something that Ruggles was unable to do with the form of data he had to work with, namely the creation of random distributions of horizon declinations from a real body of topographic data, which could then be compared and tested against the distribution of observed horizon declinations associated with monument orientations.

Thus, significantly, improved computing power and accessible digital elevation data allowed us to test the null hypothesis in a more rigorous way than Ruggles was able to. Specifically, good elevation data over an area of approximately $100 \times 100 \mathrm{~km}$ is required for determining the complete, visible horizon profile of each site or location in order to create the sets of expected data (i.e. the random distributions of expected horizon declinations).

This was carried out as follows. The observed data is made up of the declinations of the horizon 'points' in the direction indicated by the monument alignments. Therefore, there were 276 declinations associated with the 276 alignments made up by the monuments at our sites. These were divided by region, and declination distribution profiles were created for each region. As mentioned above, Smith's software Horizon (Smith 2013) was used to create the expected data files of entire horizons with which the observed horizons would be compared. These files, then, provided information on the shape of the entire horizon at each site (co-ordinates supplied to program). The program created these files by extracting three pieces of information from the Ordnance Survey digital landscape data every $0.01^{\circ}$ around each $360^{\circ}$ horizon. The pieces of information were: direction or azimuth (from $0.01^{\circ}$ to $360^{\circ}$ ); distance of the horizon from the site in the direction of each azimuth; and elevation of the horizon in the direction of each azimuth. The number of files matched the number of site orientations; therefore, some sites had more than one data file for the expected data. These declination files were then concatenated and the declinations averaged for each region so that now there was a single expected declination distribution for each region, with which to compare each regional observed declination distribution. Using the Kolmogorov-Smirnov test ( $\mathrm{K}-\mathrm{S}$ test) to compare the expected and observed distributions revealed that, for the three regions of 1. Mull/ Coll \& Tiree, 2. Islay/Jura, and 3. Argyll/Lochaber/Lorn, the distributions of the indicated horizon declinations were found to be statistically significant. The $\mathrm{K}-\mathrm{S}$ test gave the following results: for Mull $p=0.00817$ ( $\mathrm{n}=25$ horizon distributions), Islay $p=0.00105(\mathrm{n}=25$ horizon distributions), and Argyll $p=0.00593(\mathrm{n}=17$ horizon distributions) (Higginbottom et al. 2000), where $\mathrm{p}$ is the probability that the observable distributions of the indicated horizon declinations found at our sites are likely to be random. The probability that their occurrence was random, then, is significantly low $(p<0.01)$. This tells us that for these regions the distribution of declinations found within each region is not due to chance. We interpret this as meaning that a thorough search was made for very particular locations at which to create these places; the degree to which this happened will become clearer below. 


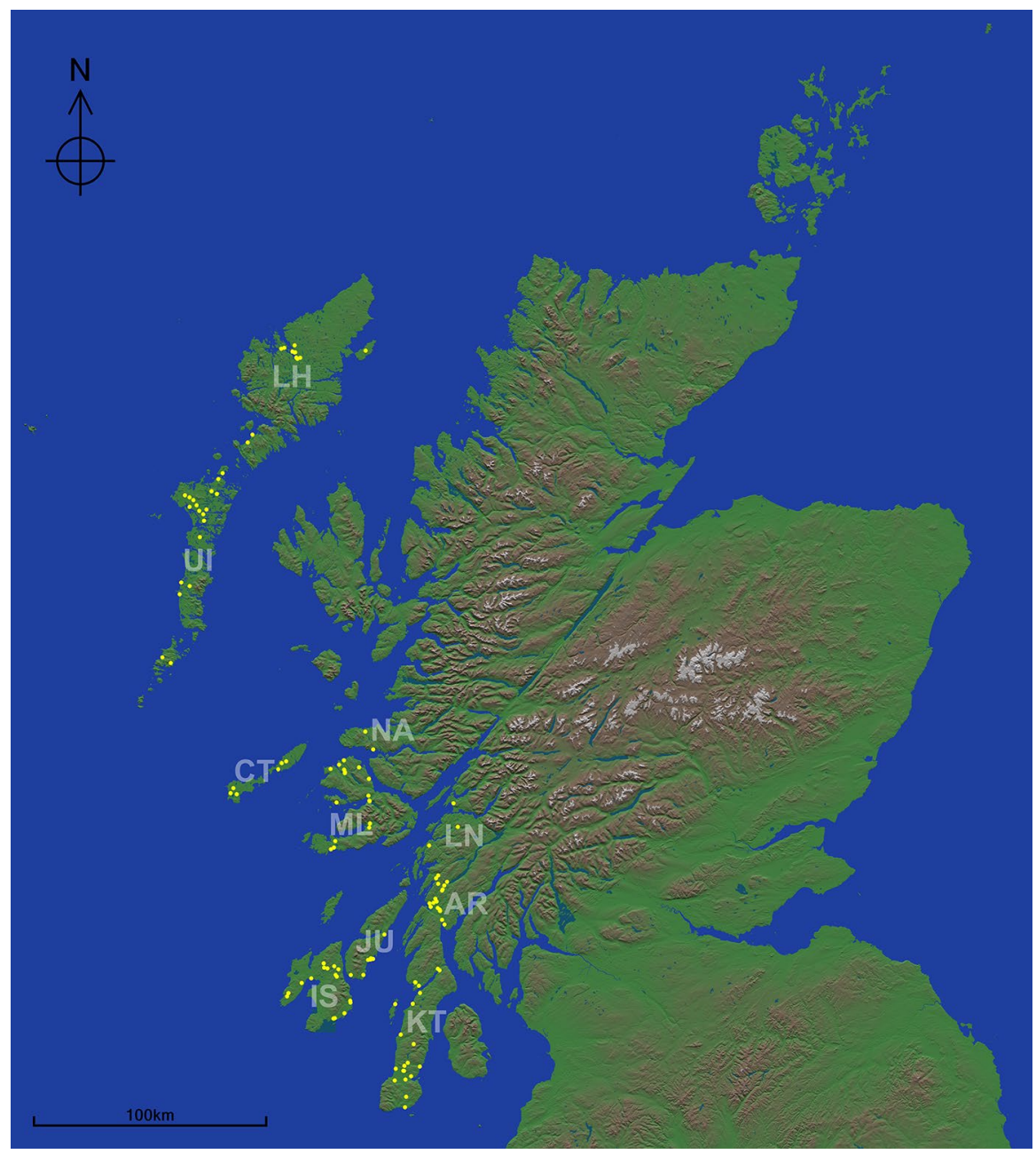

Fig. 1 Map of Western Scotland. This map shows the expansive area of Ordnance Survey elevation data for the area of western Scotland used in our main study. The labels denote the regions in which the study sites are located, namely: LH-Lewis and Harris; UI-North and South Uist; NA-North Argyll [Lochaber]; AR-Argyll; JU-Jura; IS-Islay; CT-Coll and Tiree; LN-Lorn; and KT-Kintyre. This map shows all the sites used in the Western Scotland Megalithic Landscape Project initial comparative study (and Ruggles 1984) for this area. The sites are indicated by dots. Many sites are so close together that the dots could represent more than one site. Software and map created by Andrew Smith. Based upon the Ordnance Survey 1:50,000 Landform PANORAMA map with permission of the Controller of Her Majesty's Stationery Office (C) Crown Copyright

So, at this point, it was not clear what the preferred declinations were and whether they had any astronomical significance. In order to investigate this, it was necessary to see where the differences between the observed and expected declination profiles occurred, and then determine whether these declinations coincided with any astronomical phenomena. Binning the observed and expected (random) data into five 
degree bins for each region (e.g. $0^{\circ}-5^{\circ}, 5^{\circ}-10^{\circ}$ ), a simple probability test $(p)$ was then applied to test whether or not the number within each observed bin differed from that found in the expected (null) bins. This tests the likelihood of any difference in number occurring by chance. Once this test was completed, the statistically supported bins were studied to see if they overlapped with declinations of astronomical bodies or phenomena (Higginbottom et al. 2001, 2003, pp. 140-143). Importantly, the statistically supported ranges could indicate an avoidance of or clustering within a declination range. It should be noted that the comparative declinations used for the Moon and the Sun were the same as those used by Ruggles (1984): solstices: $-23.9^{\circ}$ and $+23.9^{\circ}$; the Moon at the major standstill, $-30^{\circ}$ and $+28.2^{\circ}$; and the Moon at the minor standstill, $-9.7^{\circ}$ and $+17.9^{\circ}$.

Again, the results of this analysis of the orientation data were rather more expansive and specific than Ruggles' (1984) results. These analyses statistically supported an interest in the Moon at the major standstill in its most extreme southerly and northerly setting positions for the combined region of Mull with Coll and Tiree (Higginbottom et al. 2000, p. 47, table 2; or Higginbottom et al. 2002, table 1; Moon at the southern major standstill: $p=0.025$, and minor support for the Moon at the northern major standstill: $p=0.077$ ). For those facing south, half are focused on the rising Moon and half on the setting. However, the orientations were also found to significantly avoid the Sun's position at the equinox, unlike the findings for Islay and Jura which did the opposite (flanking the Sun at the equinox $p=0.035$; Higginbottom, Smith et al. 2000, p. 47 or Higginbottom, Simpson and Clay 2002, table 1). Islay and Jura also exhibited an interest in the Moon at the minor standstill in both a northerly and southerly direction (though the northerly direction is strongly statistically supported: $p=0.005$, the southerly is less strong: $p=0.051$; q.v. Higginbottom, Smith et al. 2000, p. 47; or Higginbottom, Simpson and Clay 2002, table 1). Argyll has firm support for alignments towards the Moon at the northern major standstill $(p=0.026)$ and very strong indications of alignments around $+35^{\circ}$ in declination $(p=0.002)$. At these latitudes, declination $+35^{\circ}$ is circumpolar and if there are any hills towards the north one might see some circumpolar objects briefly dip below the horizon in directions with this horizon declination. So perhaps there is some interest in these phenomena (see Higginbottom and Mom 2018 for details of possible phenomena). As well as these notable events, some sites within Argyll focus on the winter solstice rising or setting $(p=0.062)$. These results at the very early stages of the entire investigation show that the interest in astronomy is both more widespread and more firmly supported than previously deduced by the major work of Ruggles (1984, see above and below). Whilst no statistical support was found for the Sun at the summer solstice by region, a small number of sites were oriented in this direction within $2^{\circ}$ (approximately nine orientations out of 276). However, it will be demonstrated by the improvements in method and the software development of 3D panoramas below that the summer solstice in the Bronze Age was important. These new methods or approaches are also responsible for some of the most original work done in the archaeoastronomy of that period. It is to the theory and method behind these new approaches that we now turn. 


\section{Improving Archaeoastronomical Research: Creating a $360^{\circ}$ Visual Context and 3D Viewsheds}

In this section are outlined the considerations and methods entailed by the inclusion of the entire topographical landscape view surrounding each of the standing stone sites. We turn first to the theoretical debate around these approaches before moving on to the original work done by this author and colleagues.

\section{Considering the Broader Visual Field: Theory and Method}

In the last two decades, there have been very few significant studies of the simpler standing stones of Scotland, such as single standing stones, stone pairs or short rows. Importantly for this project, there is a real dearth of research on standing stone sites of any type in the context of their surrounding visual landscapes, particularly in this region. This is likely due to a lack of innovative application of spatial analysis tools such as GIS, 3D, and agent-based modelling. Geospatial technology has the potential to help us examine and uncover information about the meaning and significance of the placement of standing stones in their landscapes. But to accomplish this, it may be necessary to go beyond most current landscape-archaeological approaches, which tend to use a 'god's-eye' perspective (called the 'global frame of reference' in Kitchin and Blades 2002). In this perspective the model assumes that all agents or individuals in it have complete spatial information. That is, they can 'see' everything around them, there are no restrictions on shared information, and the decisions they make are not limited by their immediate frame of reference. Some very innovative spatial analyses that have given us significant insights into the past are nevertheless situated in a 'god's-eye' or global framework (e.g. Kohler and van der Leeuw 2007; Miller and Page 2007; Dean et al. 1999; Kohler 2012).

By contrast, individual immersion models (from the 'point of view' perspective or 'egocentric' frame of reference: Kitchin and Blades 2002) may be more applicable to discovering how people used their landscape, since they recreate that context from their own point of view. Standing stones are landmarks for people in the past, and they embody information about the landscape as these people saw it. Information is organised in the minds of past people by its relationship to these permanently fixed markers. But that information is specific to the local setting and may not be applicable to any other setting or location. Standing stones are thus proxies for a single point of view, but are a constructed physical embodiment of complex collective information. This may be termed the 'landmark' perspective and is comparable to a 'fixed frame of reference' (Kitchin and Blades 2002). What is missing from the relevant publications and other past studies, then, is an investigation into the local situation of standing stones and their use as fixed frames of reference. By studying these significant markers using a 'landmark perspective' approach we may gain new insights into the shared cognitions of the past, and how people collectively engaged with their terrestrial and cosmological surroundings (Criado-Boado and VillochVázquez 1998; Higginbottom et al. 2015; Higginbottom 2020). 
GIS, agent-based modelling, and 3D reconstructions should be used as an investigative aid for examining and testing archaeological problems (Hermon 2008) rather than only for 'illustrating knowledge already gained once serious scientific investigations ha(ve) been concluded' (Forte 2008, p. 22). Pedagogical attempts at recreating 3D immersive 'experiences' are likewise moot when not accompanied by analytical efforts (Angeletaki and Carrozzino 2017; Tan et al. 2009). Using visual and geospatial tools to investigate archaeological problems 'permits not only reconstruction, but also deconstruction and alternative interpretations' (Hermon 2008, p. 42), and through the use of detailed spatial data 'there is no doubt that a 3D model, be it of a landscape or of a monument, can add information and thus insight to what we already know, at least if the model is correctly built' (Forte 2008, p. 22). In particular, such models can successfully select and highlight certain features of raw 'uninterpreted' data (such as the paths taken by astronomical bodies in the sky), integrate information from diverse knowledge domains, and build visual descriptions into representations of complex experiences. In this way, archaeological data can move from a barely interpreted source to an informative construct (Gooding 2008, pp. 2, 9, 17).

Megalithic studies in Scotland that have considered landscape or skyscape contexts have usually neglected the full visual field, and most do not include quantitative analyses (D. Fraser 1983, 1988; S. Fraser 1996, 2004; Richards 1996a, b; Ruggles 1983, 1985, 1996; Trevarthen 2000; Cummings 2002; Baines et al. 2003; Bradley 2005; Brophy et al. 2013; Jones et al. 2011; Richards 2005, 2013a, b, c; Wright 2007). Few of the interpretations made by these studies have examined how the builders understood their surroundings or why they chose to interact with them through their construction (some notable exceptions are: Ruggles 1984; S. Fraser 1996, 2004; Cummings and Whittle 2004; Richards et al. 2013, pp. 201-223; Welfare 2011). Whilst Bradley's (1998) earlier work The Significance of Monuments was not limited to megaliths or Scotland, it has made a significant contribution to the discussion of how ancient peoples perceived and altered their landscape.

Importantly, too, as discussed previously, what has been missing so far in studies of Scottish standing stones is a deeper examination of the simpler sites, especially from a 'landmark perspective' approach, and as a collective phenomenon. This can be accomplished through a more complete consideration of their situationallyspecific visual context (Criado-Boado et al. 2001), and the created informative constructs provided by digital and geospatial modelling. This presentation of standing stones in western Scotland achieves this.

Whilst it has already been demonstrated that alignments upon certain phenomena exist, it has not yet been shown whether it was necessary to keep observing these displays over the years after construction, or whether the mere connection between the astronomical body and the monument or site was the entire or main point of the construction. The presence or absence of dense foliage in and around the monuments, or even around the regions in general, will assist us in our consideration of these matters, as well as in the consideration of the design of the models themselves. Regarding the latter, tree cover naturally affects visibility, as do the topographic details of the horizon (determined by distance, direction and elevation), variables used in the construction of the project's 3D viewshed panorama models. 


\section{Foliage Cover in Western Scotland}

Despite the number of pollen analyses available from this region and the increase in the number of studies of anthropogenic impact in the Later Neolithic and Bronze Age (e.g. Davies and Tipping 2005), there have been very few detailed studies in recent years. This is in part due to the broader difficulties of recognising such effects in an area where closed forest may have been the exception rather than the rule in its vegetation history.

Fossitt's 1996 study illustrates that vegetation on the Western Isles (Outer Hebrides) was neither treeless nor uniform in the past and woodland was widespread throughout the islands and the western coastal regions in the early Holocene and remained extensive in all but the most marginal areas (specifically western Lewis and uplands) until c. 4000 BP. In particular:

regional variation was accentuated when woodland underwent a sudden decline in western Lewis at about 7900 BP. Trees were replaced by blanket peat and woodland failed to recover on a regional scale after the decline. Woodland continued to diversify in central and eastern regions (of the Western Isles) and, by 6000 BP, Quercus (oak), Ulmus (Elm), Pinus sylvestris (conifer), Alnus glutinosa (Alder) and Fraxinus excelsior (Ash) had become established (Fossitt 1996, p. 171; also see pp. 190, 193, 194).

Fossitt argued that the woodland was open, with birch-hazel woodland dominating lowland regions outside of western Lewis; additionally, Birks and Madsen (1979), Bohncke (1988), Barnatt (1989) and Fossitt (1990) tell us that in the later Neolithic, areas of thin birch-hazel scrub may have been restricted to the thin strip of land on the west coasts of all the Western Isles. Further, on this most exposed edge, trees may have been few and far between (Birks 1991; Fossitt 1990).

Tipping's 1994 review of the palynological evidence for western Scotland supports such findings, arguing that considerable variation in woodland composition can only be demonstrated in those areas subjected to detailed study. Examples include the work done on Skye by Birks and Williams (1983) and the pollen analyses from Little Loch Roag on the extreme west coast of Lewis, where the latter particularly supports Fossit's 1996 idea of western Lewis' marginal character. Specifically, the pollen interpretively indicated that "no trees colonised this region except sparse stands of birch and perhaps hazel, in support of the bulk wood remains' (Tipping 1994, p. 11). Tipping also created a general map of the 'dryland' woodland of this region prior to the earliest agrarian modifications, c. 3000 BC (Tipping 1994, p. 11); naturally simplistic, it nevertheless clearly illustrates the more open nature of these western Scottish woodlands. Further support for this may be seen in the demonstrable lack of pine forests, and in Fossitt's 1990 envisaging of widespread pine from $5500 \mathrm{BC}$, but as scattered individual trees or small stands at any one time (Tipping 1994, p. 11).

To possibly enrich the patterns of the landscape even further in the Western Isles during these times, 'Bennett et al. (1990) tentatively suggest that about half the sheltered valleys of Bhein Mhor on South Uist might have been cloaked in trees' (Tipping 1994, p. 13). Supporting these patterns are detailed palynological investigations 
employing several sites on one island which have shown the complex mosaic of woodland types that could have developed in sheltered localities on Mull, Oronsay and Colonsay (Mithen 2000, Volume 1, p. 27).

On a more general note for Neolithic woodlands, according to Tipping, it is suggested that their fullest development occurred immediately prior to $3000 \mathrm{BC}$ in accordance with earlier reconstructions (Mithen 2000, Volume 1, p. 27) and Fossitt's research (1996). Specifically, Fossitt concluded that open mixed woodland persisted until the second major decline, which began between 5200 and 4000 BP, with woodland contracting gradually as blanket peat expanded. This fits together well with Wilkins' 1984 work, which maintains that towards the end of the Neolithic into the Bronze Age, for a period between 2900 and $1900 \mathrm{cal} \mathrm{BC}$, there is indisputable evidence in the form of radiocarbon-dated stumps (on Lewis and Harris) that pine started to grow on blanket peat (Wilkins 1984). As well as on Lewis and Harris, pine also occurred in eastern Skye and on Rum after c. 2850-2450 BC, also growing on blanket peat. Less than a thousand years later, c. 2000-1800 BC, a dramatic collapse in the extent of pine occurred throughout Scotland, a decline attributed to climatic influences rather than anthropogenic activity (Tipping 1994, p. 27). Specifically, it was likely due to a combination of extreme exposure, low summer temperatures, short growing season, frequent storms and a high incidence of salt-laden spray (Hunt 1987, p. 121). Supporting these general points, Carter and colleagues (2005) concluded that Arisaig, on the mainland coast just south of Skye, had a history of continuous but gradual decline in woodland, starting in about 3200 BC.

In relation to human disturbance, the basic picture is one of 'uneven clearance forays in the woodlands, both in time and scale', suggesting that overall 'no regionally synchronous pattern of clearance is recognisable' (Tipping 1994, p. 28; italics added). The evidence comes from a number of studies attended to by Tipping, supported by the Southern Hebrides Mesolithic Project's outcomes (Mithen 2000) as well as Richmond's (1999) and Macklin and colleagues' (2000) research. The only distinct pattern, if that is the correct description, to come out of this area is that at 2600-2500 BC, the majority of sites 'show some anthropogenic activity. This is so even at sites which failed to attract attention of agricultural communities at other times, such as Loch Ashik on eastern Skye' (Tipping 1994, p. 28).

It was traditionally held that during the Early Bronze Age the woodland began to regenerate, and some time in the middle of this age forest clearance began anew. However, with the evidence above that the Neolithic period was not the grand defining moment of farming and forest destruction by people in western Scotland, the idea of a widespread abandonment of clearings and forest regeneration cannot be strongly sustained. What might be sustained however, is Tipping's interesting proposal that 'the presumed synchronicity of the previous 'regeneration' of woodland phase was greatly emphasised by the degree of synchronicity at its end' (1994, p. 33). This latter synchronicity appeared in the form of 'renewed' clearance in the period c. 2000-1800 BC, which could rather be looked at as the intensification of existing agricultural behaviour (Tipping 1994, p. 33). Further, it has been previously concluded that with 'natural reductions in tree populations through soils deterioration, climate change and the spread of blanket peat ... grazing densities needn't be high, just constant' to influence the constant decline of tree populations (Tipping 
1994, p. 36). Such ongoing processes wear away the fabric of woodland, and so these, along with abrupt anthropogenic events, like the possible felling or burning of trees which are recorded by sudden drops in arboreal pollen, indicate quite a high level of activity. Ultimately, all of this meant that 'the Western Isles were predominantly treeless at 2500 BP' (Fossitt 1996, p. 194).

The evidence above demonstrates that, on the Western Isles and western Scotland generally, during the time when the stone rows and paired stones were erected at least, we can be fairly confident that the majority of the area was either open woodland, without woodland, peat-covered, or deliberately cleared, with the possibility that some sheltered areas on the isles still contained some varieties of woodland.

This means, therefore, that it is quite sensible and possible to uphold the notion that the horizons viewed from the standing stones on Mull were both visible and lacking in consistent lines of thick tree cover.

\section{Topographic Landscape and Water Bodies: Changes Since Deglaciation}

Whilst there are certainly ongoing changes in the landscape (some more dramatic than others at specific times), the issues of rising sea levels and postglacial isostatic movements will also not greatly impact the study as a whole, but may affect studies that consider a single site only. Based on isostatic, eustatic and sea-level studies, the variables and the application of the current project's methodology, it can be argued that what we see today from the monument locations (in relation to topography and larger water bodies only) is essentially what was seen at the time the standing stones were erected, with local variations.

Specifically, it is argued that:

(i) the general order of magnitude of the uplift (relative to sea level) is possibly 0 to 4-5 $\mathrm{m}$ in western Scotland since $6000 \mathrm{cal} \mathrm{BP}$, where the majority of sites sit west of the epicentre(s) of uplift, where the inner isles are relatively close to the periphery, and where the outer isles are almost at the edge (Firth and Stewart 2000, p. 1473; Rennie and Hansom 2011; Smith 2005), or actually beyond the edge, and where isostatic uplift was zero or negative (Smith et al. 2012, figs. 7-9). The same can be said for the Orkney Isles as for the Outer Hebrides (Firth and Stewart 2000, p. 1473; Rennie and Hanson 2011; Smith 2005; Smith et al. 2012, figs. 7-9).

(ii) Such an overall increase will have very little effect on the visibility of the rising or setting of astronomical bodies, because the order of magnitude of error for declinations that four to five metres in height would produce is well-contained by our monument alignment error margins of $\pm 2.5^{\circ}$ in declination, especially for any distant horizons. Essentially, 4-5 $\mathrm{m}$ in the vertical would not greatly affect the angular elevation (one of the three variables used to calculate a horizon declination), where angular elevation is the measured angle of slope of, in this case, a horizon.

(iii) This project primarily assesses patterns, both across the whole of western Scotland, and, principally, within regions, so it is highly unlikely that such local 
changes will affect our overall assessment in the positive (that is, false positives in the rejection of the null hypothesis: e.g. no difference between the observed declinations at the indicated horizon range-via monument orientation-and the random declinations around the same horizons).

(iv) Despite the changing sea levels, the general direction of the sea from a viewing point, including large unconstrained lochs, remains the same now as in the Late Neolithic and Bronze Age. This does not mean that seas were not either closer or further away at some point, or that particular Lochs did not have lower or higher water levels-certainly, smaller water bodies and rivers would come and go or move.

(v) In a similar way, the relative direction of the significant lochs and rivers that travel in the narrower ancient valleys - in particular, in relation to the many sites that are on local high ground and/or usually 'closer' to one side of a valley or the other-has also remained consistent. As a final point for clarity, if the land is uplifted elevator-like together with the observer by a few metres, no effect (zero) on declinations can be expected. Only the water line could shift. For any effect on declinations, parts of the landscape would have to tilt.

Whilst it has been established that there is relatively low to negative isostatic uplift around this project's study area, it is known that northern and western Scotland have had an overall ongoing rising sea level (RSL) since deglaciation:

in the Orkney Isles the fastest rate of relative sea level rise since deglaciation was $\sim 6 \mathrm{~mm} /$ year, achieved between 8 and $6 \mathrm{k}$ calibrated years BP (Shennan and Horton 2002). This resulted in large changes in coastal configuration with substantial submergence, loss of land and the creation of the archipelago that we see today (Rennie 2006). The period since then (at least for the past $4 \mathrm{k}$ years) has been characterised by much slower rates of RSL change in Scotland (Rennie and Hansom 2011, p. 200).

However, as we can see, the most significant events occurred prior to the creation of the standing stones and the slowest rates began prior to the known date range of the standing stone rows and single standing stones (see below). So whilst it is possible that we may well have a greater amount of water surrounding sites like Callanish, being on islands, the sea's general direction from a viewing point generally remains the same now as in the Late Neolithic and Bronze Age, with possible differences in distance and water running into lower-lying areas nearby.

\section{Sand Dunes}

For this paper, there is one coastal site on Mull from which you cannot see the sea because of low sand dunes, and it is hypothesized that these dunes were established after the site was constructed (Wright 2007). If you move not far away from the stone pair you can see the sea through a gap in the dunes or over the dunes. This stone pair site is hypothesized to be Bronze Age typologically. It is possible that a few other sites may also have recent sand dune concerns, as the author is yet to visit 
every one of the 125 original sites. Certainly, in the outer Western Isles, dunes have covered many Neolithic sites, excavation and rising seas have removed the dunes for such discoveries in some places, and likely Bronze Age sites might be covered also. Sand overlaying soil (and then sometimes overlain itself) is primarily associated with the tsunami events related to Storegga (c. 8150 BP and possibly 2 smaller events about 5700 and 2200 years ago). These events coincide roughly with the cusp between the Early and Later Mesolithic, the Early Neolithic and the Middle Iron Age.

Relevantly, places like the Isle of Mull are constructed of Lewisean gneiss. On Mull, the Ross of Mull is also overlain with granite, with the remainder of the island mostly covered in basalt (Jones 1997, cited in Wright 2007, p. 169; Macnab 1995, p. 23). Therefore, the actual mountain ranges in such places are unlikely to have eroded to an extent that would have affected the shape of the horizon between the time the monuments were built and the present day.

Having reviewed the foliage cover, topographic and sea level issues, and until better evidence is gathered to the contrary, we can generally accept the idea that the entirety or majority of the horizons surrounding the standing stone sites in western Scotland were generally visible. Therefore, the elevation models of this land as they are today can be used to construct viable $3 \mathrm{D}$ models of the landscape and use it to assist the study of Bronze Age megalithic Scotland.

\section{Current Method: 3D Panoramas}

Our 3D panoramas allow us to survey a $360^{\circ}$ panorama as if we are turning on a selected spot, steadily revealing the landscape. The models for this paper were constructed using Smith's Earth-celestial program of 2011, Horizon (Smith 2013). What is seen in these models is a calculated consideration of monument location, land elevation, atmospheric variables (e.g. refraction), lunar parallax, curvature of the Earth and the maximum distance humans can see on a clear day. Determining the location of water was also part of this consideration. Calculating the edges of water bodies or locating water bodies in unusual situations is quite a delicate procedure, which was conducted using an algorithm (e.g., in areas where they are located above $0^{\circ}$ altitude). At a later date, the Ordnance Survey layer for water will be added to the model.

The above-mentioned factors determined how an entire landscape would look to someone standing at or near the monument, that is, where mountains or lowlands appear and the line and distances of the horizon. The paths of the Sun and Moon were added as a layer, so that a full visual picture for the builders of the monuments might be in evidence. Whilst rendering 3D data into a panorama image still technically creates a $2 \mathrm{D}$ image, because you cannot create true $3 \mathrm{D}$ on a $2 \mathrm{D}$ display or surface, Horizon uses 3D graphical rendering techniques so that it is not unreasonable to refer to any viewshed panoramas thus generated as '3D' (Smith 2013). 


\section{Information on the 3D Panoramas}

Earlier, in the section Understanding Landscape's Connection to Naked-Eye Astronomy, the reader was briefly introduced to the curved lines on the model landscape; these lines illustrate the paths of the Sun and Moon at particular points in their cycles, as labelled (Fig. 2a). Essentially, as the 3D models are viewshed panoramas of the landscape and sky surrounding each monument, the $\mathrm{x}$-axis denotes the compass direction from the monument location $(\mathrm{N}, \mathrm{NE}$ and so forth; north is at the centre).

Looking at the model, it can be seen that there are four standstill paths for the Moon, two paths for the Sun at the solstices, and one for the equinoxes. Remember that the two standstill events of the Moon, the major and minor standstills, each occur approximately every 18.6 years, and 9.3 years apart.

The lines of the paths of the celestial bodies are drawn $0.5^{\circ}$ wide to represent the apparent width of the Sun and the Moon. All paths have been corrected for atmospheric refraction.

The vertical band indicates the direction of the orientation of the site alignment determined by Ruggles' survey. The lighter part is the outer azimuth range (as labelled by Ruggles; this is $10^{\circ}$ at this site) and the darker part is the inner azimuth range (a $5^{\circ}$ width band).

The chronological parameter chosen, labelled 'Epoch', was 2000 BC. This was initially considered a possible approximate mid-point for the erection of Neolithic and Bronze Age free-standing stone monuments. Also, whilst dates for the majority of single-standing-stone, stone-pair and stone-row sites not associated with conglomerate sites range from 1400 to $900 \mathrm{BC}$, in reality, the effect of the changes in the Sun's and Moon's rising and setting points over a thousand years on our assessments is negligible at the levels of alignment accuracy, on average $\pm 2.5^{\circ}$ in declination, that are being investigated. The value of $10 \mathrm{~km}$ was taken for the variable 'visibility' for the 3D panoramas viewed in this paper. Observer height was taken at $1.5 \mathrm{~m}$. Elevation Range: $-10.0^{\circ}$ to $+30.0^{\circ}$.

Note that more than one panorama was produced for some sites, because some have more than one alignment and each monument alignment was layered on a separate landscape model for clarity.

\section{How the 3D Panoramas Were Assessed}

Simply put, the approach was to examine visible locational variables presented in the 3D panoramas, as well as to note any consistencies and differences between the 3D panoramas, where each 3D panorama represents a different viewing position within a site and/or between monuments. More specifically, the 3D panoramas were assessed using a typological method, that is, a classification system based upon physical characteristics and thus relying on a descriptive, or morphological approach. Using the morphological approach first, the 3D panoramas were examined in detail in two steps: (i) printing out each 3D panorama for an overview of the $360^{\circ}$ views; and (ii) examining any detail via computer preview software. The 
printed landscapes were then all laid out together at the same time and arranged according to apparent horizon shape.

A brief description was also given to each $3 \mathrm{D}$ panorama, noting the landscape shapes and distances and directions of the horizon, as well as the coincidence of astronomical events at the horizon and where on the horizon they occurred (distance and direction and in regards to the shape of the horizon at these 'points'). This information found on the 3D panoramas, along with the position of sites in relation to each other, and their orientation interests, were considered together to form the basis of the results below.

\section{Results}

Among the sites considered so far in our research (that is, those included in Ruggles' 1984 study and therefore this one), there appears to be a regular tendency for a small number of sites to be congregated within a general vicinity (Figs. 1, 3a-c; maps). Such a tendency has been known for some time in archaeological circles (Fergusson 1872, pp. 29, 50, 62; Burl 1993, pp. 55, 78, 170; Burl 2000, p. 176). These sites are often intervisible and we have seen how some of them form alignments with astronomical orientations (e.g. ML2-ML7, ML15-ML16, ML25-ML27, AR2-AR3, AR16-AR17, AR28-AR30, KT3-KT8, KT27-KT39, KT31-KT32). Sites often also have intrasite alignments along the axis of the rows or pairs (e.g. AR2, AR13, AR15, ML1, ML4, ML16, KT10, KT19, KT27) or in line with the widest vertical surface of a slab (e.g. ML31, ML33, AR6, AR32, AR33, KT2, KT12). Whilst these things are intriguing in themselves, by examining the 3D panoramas it was determined that approximately half the sites have the same landscape locational variables as those found on the Isles of Coll and Tiree ('classic sites'; Higginbottom et al. 2015) and the other half are the topographical reverse (simply referred to as 'reverse sites'). Specifically, two general horizon landscape patterns have been found, where, for the first type, the observed southern horizon from a monument is usually both relatively lower and farther than the northern and for the second, the southern horizon is usually both the closer and relatively higher than the northern. Uluvult on Mull (ML25) (Fig. 2a) is an example of the first type, a classic site. Other examples of classic sites include: Campbeltown-K36; Craigs-KT31; and AR13 (2-1-5) (Fig. 2b-d). Examples of the reverse form are Balliscate-ML4; DunamuckIII-AR 29 (baSE); Stewarton-KT37; and Mingary-KT39 (Fig. 2e-h). Whilst there is some variation within these two horizon types, for example, it is occasionally found that a section of the northern horizon at a reverse site may appear to be approximately the same relative height as parts of the southern (that is, their altitudes are similar), the general model holds true (e.g. ML27-ML25; Fig. 2f). It is important to realise that these seemingly simple differences in horizon shape actually create very great differences in what is seen, in terms of both landscape views and astronomical phenomena. Most of this will become clear as the results unfold.

Horizon shapes directly influence the amount of time a body travels above the horizon and where it sets along the horizon (azimuth), as well as influencing how much of the body will be seen. At reverse sites in Argyll and Mull, more often than at classic sites, it was most commonly found that the Moon at the south at the major 


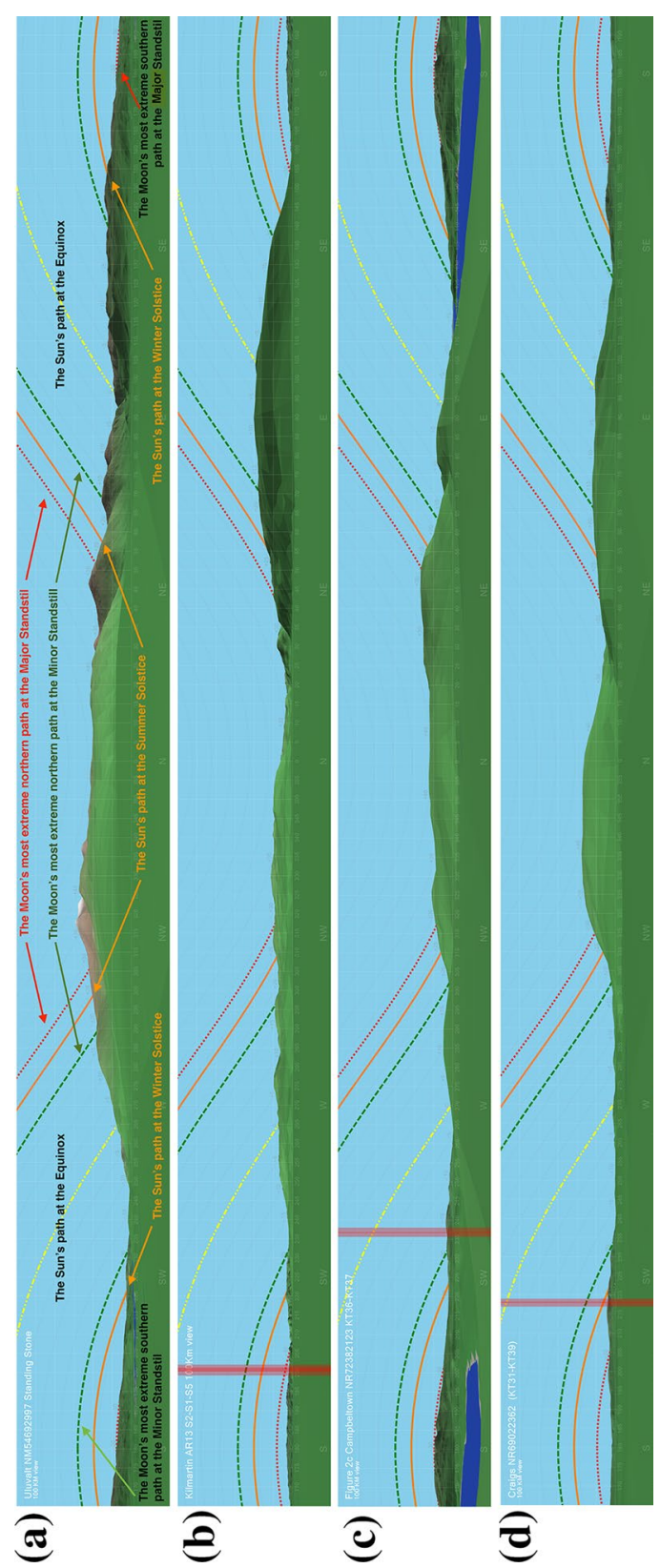

巳 霖

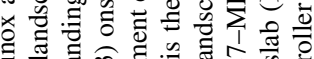

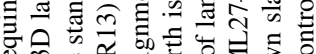
m ले

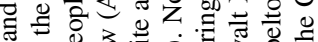
की

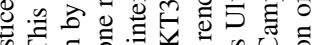

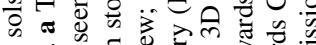

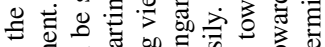

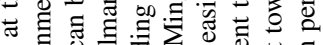

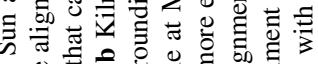

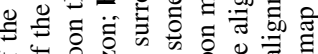
पै 40.000 气

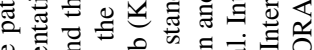

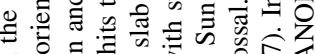

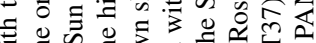

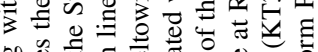
on 0 政 ส

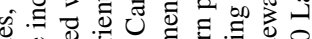

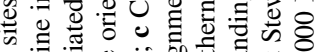

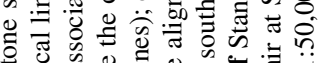
की on

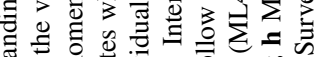

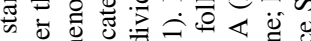

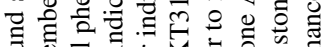

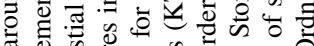

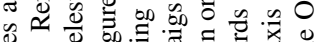

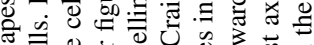

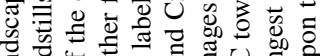

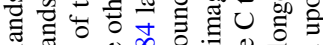

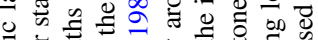

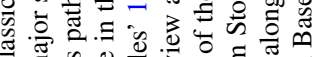

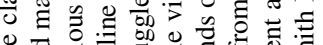

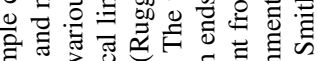

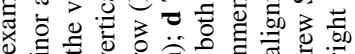
0.

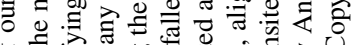
पे

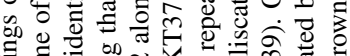

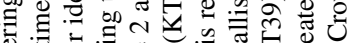
0 एँ

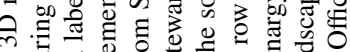

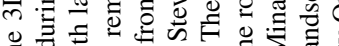
$\exists \dot{3}$ व

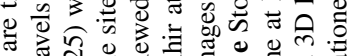
ส

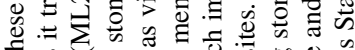
स

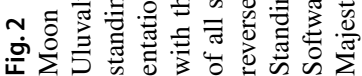




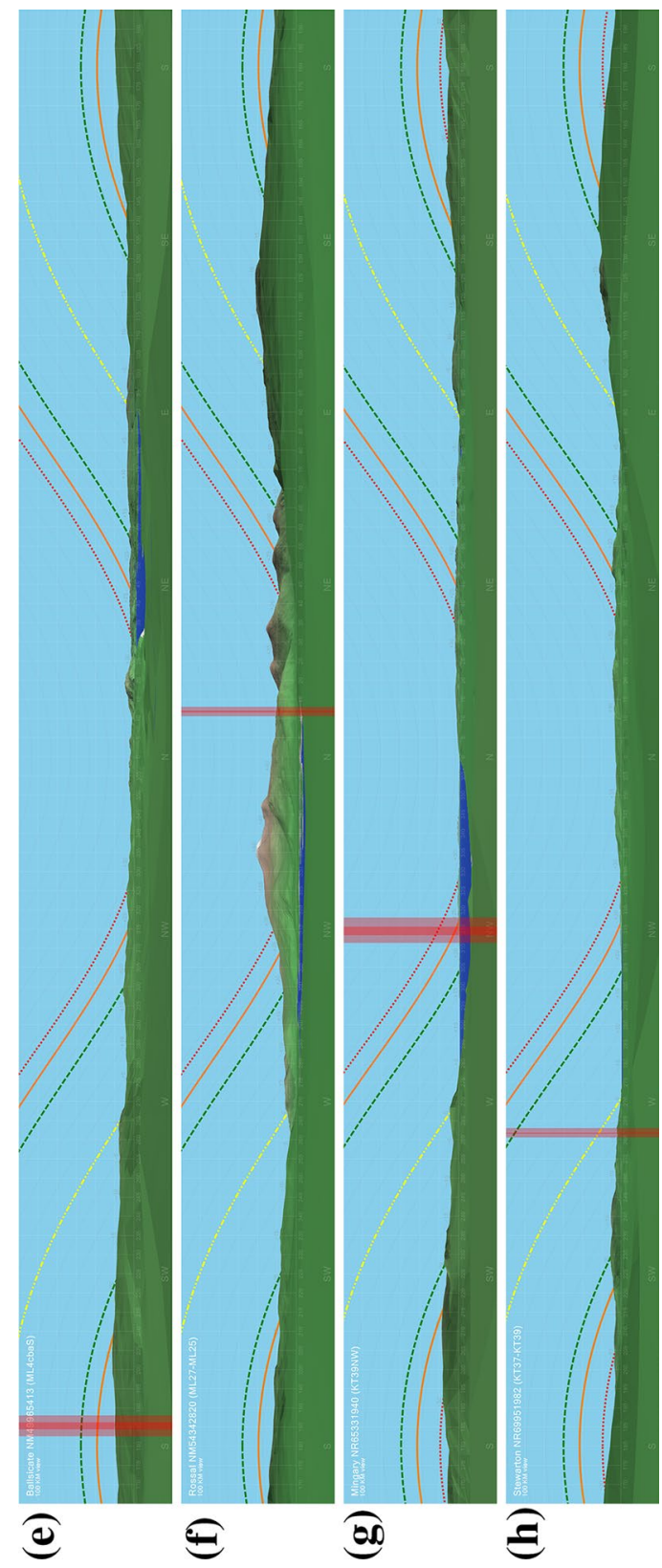

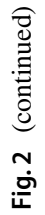


Fig. 3 Site location maps for individual areas and sites discussed in this regional comparison: a The areas are Northern Argyll, Coll and Tiree, and Mull; b North Knapdale, Lorn and Mid-Argyll-labelled in this project as Argyll; c Southern Knapdale and Kintyre-labelled in this project as Kintyre. The name labels follow Ruggles' original labelling in Ruggles (1984). See Table 1 for the names of the sites identified here with an alphanumeric label. Software creation and map production by Andrew Smith. Based upon the Ordnance Survey 1:50,000 Landform PANORAMA map with permission of the Controller of Her Majesty's Stationery Office @ C Crown Copyright

standstill was completely blocked from view and, so too, much of the Sun's path at the winter solstice (Higginbottom in prep.; Higginbottom and Clay 2016a). The former is illustrated by Fig. 2e-f. This will be explained more fully below in the section '3D Panorama Example Sites in Detail', in particular in the sub-section on reverse sites. Note also that mountains, hills or ranges dominate the northern and southern profiles in the ordinal directions (NE, NW, SE, SW), where the Sun and Moon rise and set at the times of the solstices and standstills; similarly there is often a rise in the horizon that the Sun at the equinox sets into or rises out of (Fig. 2a-i).

\section{Things of Note by Region}

\section{Mull}

On Mull the 'classic' and 'reverse' sites appear to group together (though not necessarily at the same immediate location), with at least one site being a 'classic site' and only one a 'reverse site'. Further, so far on Mull, if sites are intervisible, a classic site is intervisible with a reverse site. Basically, the majority of sites considered on Mull occur in broad groupings as follows: ML1, 2 \& 7 (Glengorm, Quinish and Cillchrìosd, very near the north coast, where ML2 and ML7 are intervisible); ML9, 10 \& 11 (Maol Mor, DervaigN and DervaigS, where ML1 \& 9 intervisible); ML15 \& 16 (Killichronan and Gruline, intervisible); ML25 \& 27 (Ulavult 1 and Rossal, intervisible); and finally ML30, 31 \& 33 (Toalsin, Uisken and Ardlainish). The reverse sites for these are as follows: ML7, 9, 16, 27 \& 30 (Fig. 3a; Appendix, Table 2). It should be noted that some stone pairs may even be considered single standing stones in a small cluster, like at ML16 where the two stones are $250 \mathrm{~m}$ apart. Note too, that about $200 \mathrm{~m}$ south of these is a cairn (Carn Bàn). Other sites included in Ruggles' Mull study were those on the Ardnamurchan Peninsula close to the Isle of Mull. These were included by Ruggles for statistical reasons and proximity. They are NA1 and NA3 (Branault and Camas nan Gaell, respectively), where NA1 is a reverse site.

These site groupings become even more significant when we see below that within them, there are at least two different orientations, for example, the Moon at the major or minor standstill and the Sun at the Winter or Summer solstice. This most usually occurs when the sites are either made up of a pair of stones and/or are intervisible. However, any kind of monument could be involved and it can occur within a single monument. 


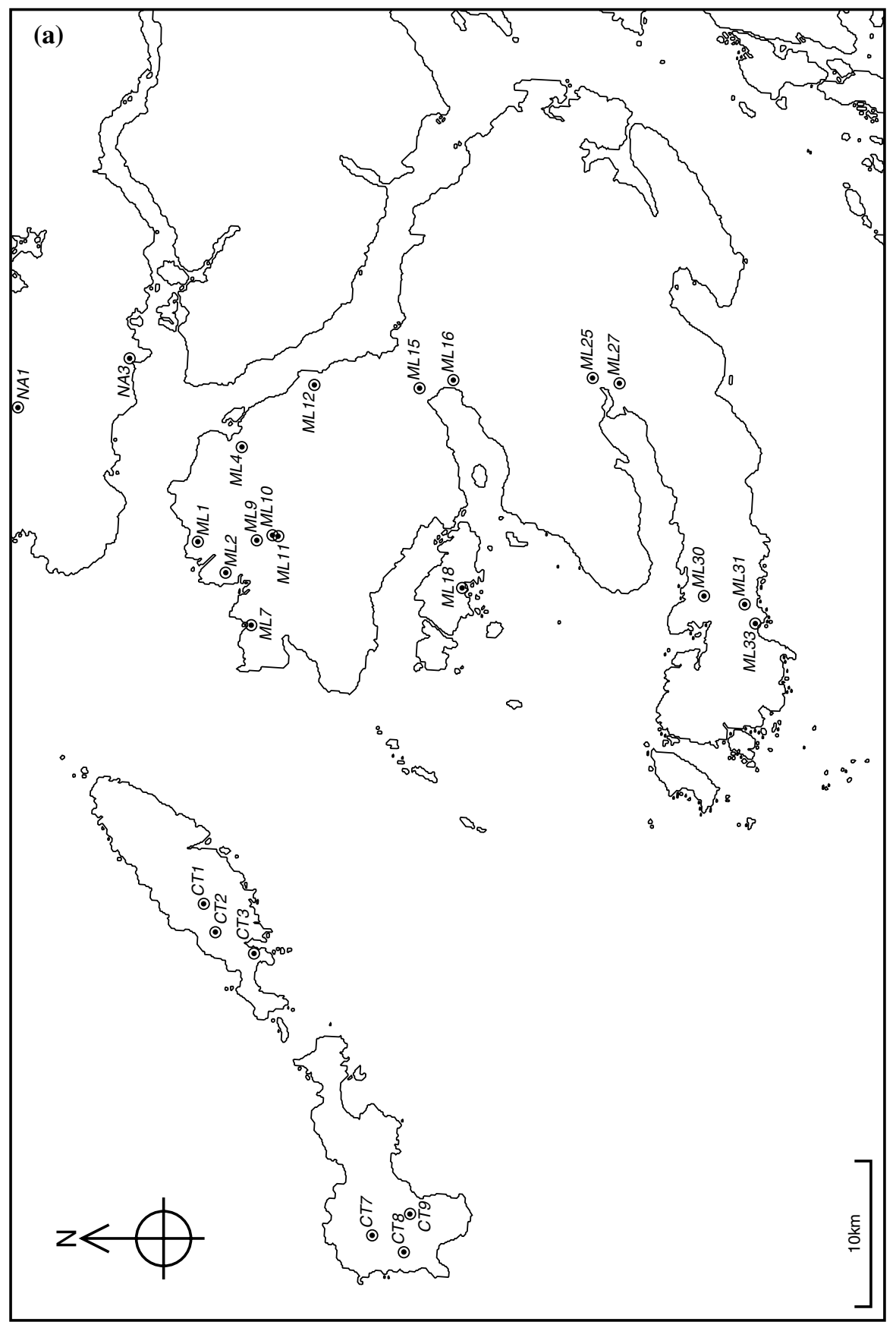




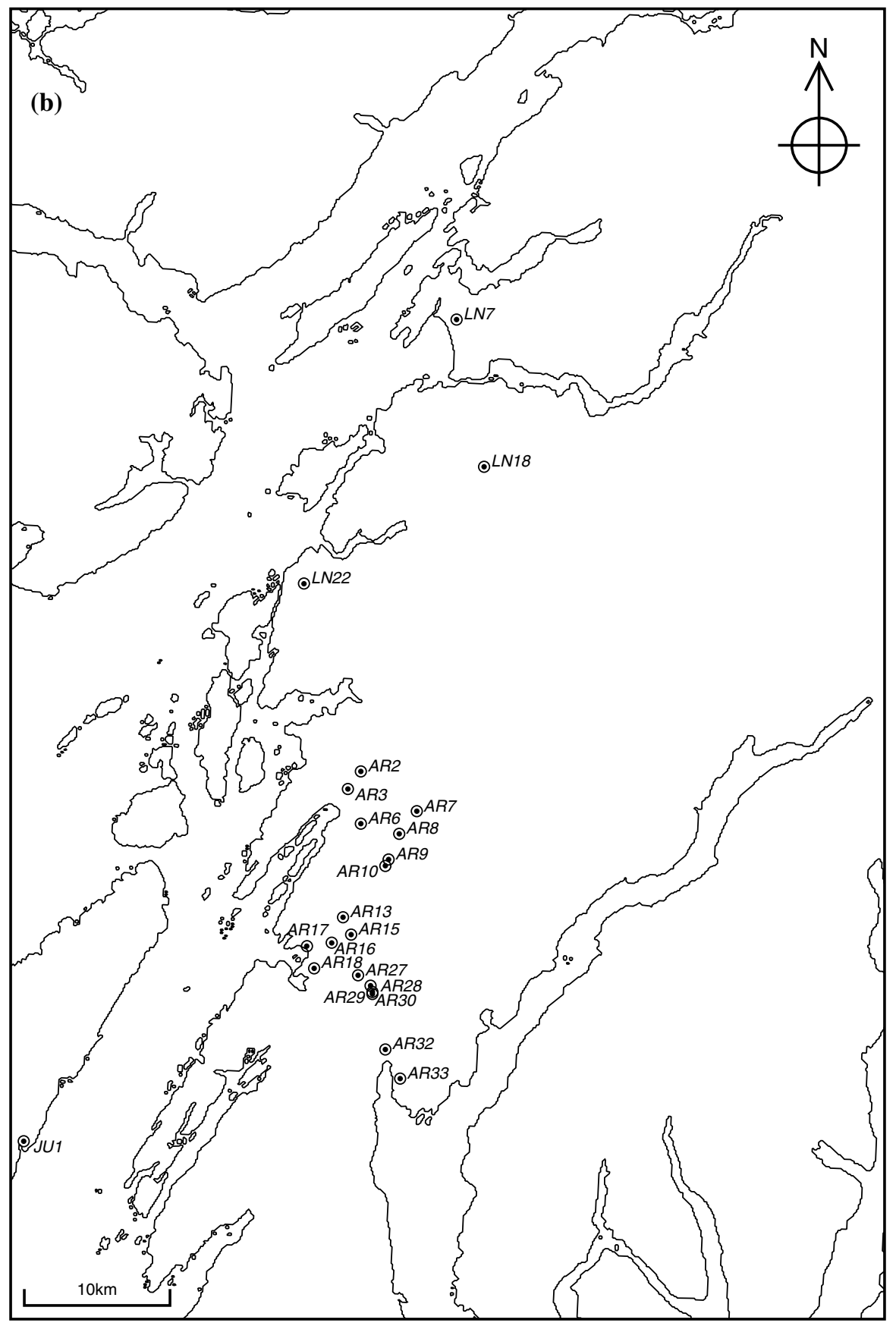

Fig. 3 (continued) 


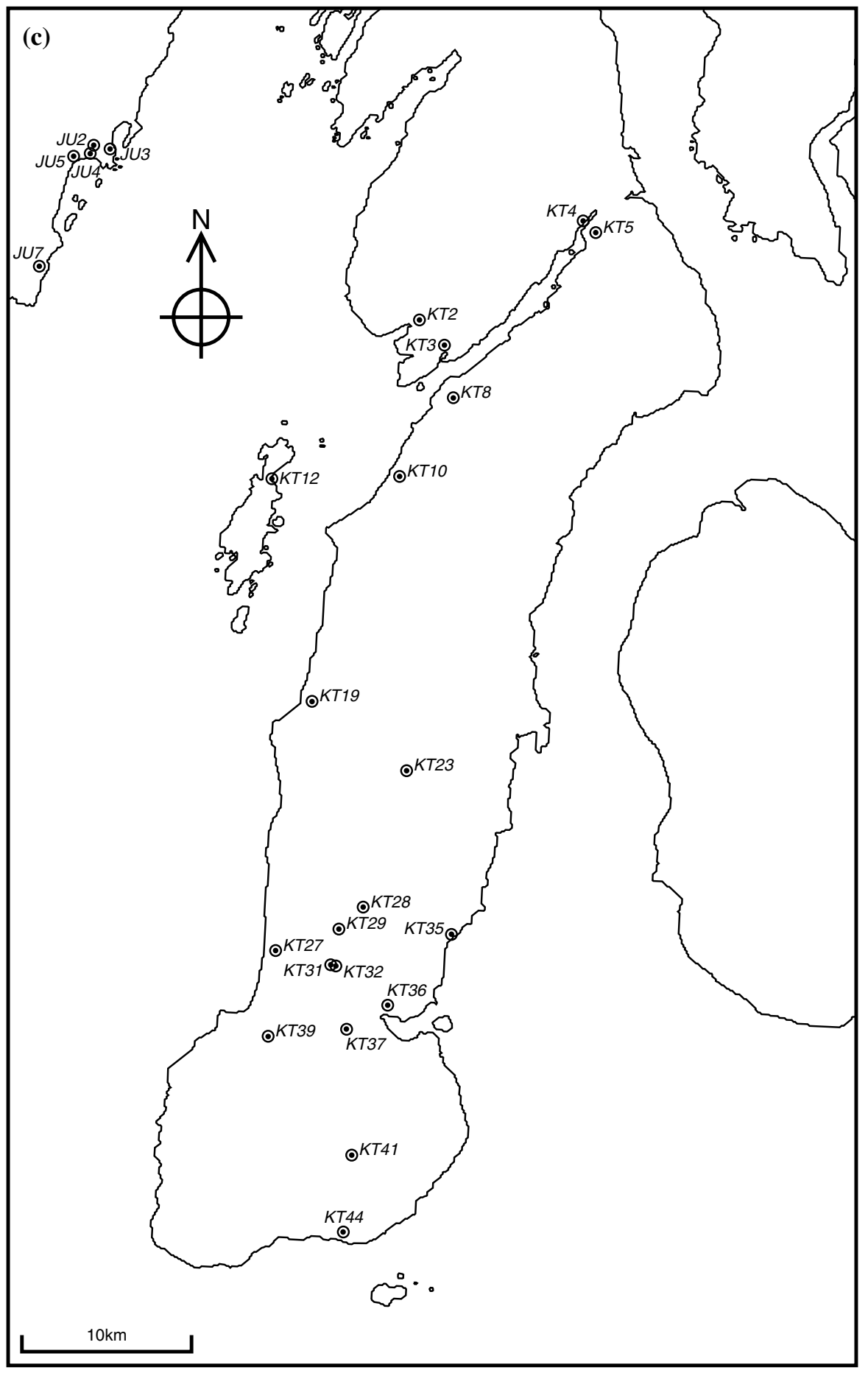

Fig. 3 (continued) 
Ruggles' 1985 work foreshadowed the interest in pairing solar and lunar orientations on Mull when he discovered that, at the neighbouring stones of Dervaig, one was oriented upon the rising Moon at the major standstill in the south (the northern row) and the other was oriented upon the winter solstitial Sunrise (southern stone) (1985, S123).

Note that there are individual sites not found in the close vicinity of other individual sites, perhaps due to loss of monuments, and there are some sites that were not included in Ruggles' study and therefore not initially in this large pilot study. Both of these concerns are currently being investigated in the project. For now it is important to note that two of these lone individual sites are 'reverse sites' located on the east coast (ML4, Balliscate and ML12, Ardnacross). The other lone site in Ruggles' database is located on the Isle of Ulva, ML18 (Cragaig). As Ulva is visible from the Cragaig, it is assumed that the classic site of Cragaig (stone pair) would have been associated with the reverse standing stone site of Ulva, not far to the east, and that the two together (and possibly a missing site) would have been considered an interrelated group. Remembering that Ruggles deliberately left sites out of the final analyses due to various a priori decisions, it is likely that Ulva was not included in Ruggles' study because it has been re-erected or because it was a single standing stone that did not possess the nominated minimum 'length to width' ratio. This ratio would indicate whether or not a stone was of such a length that it might indicate an alignment (Ruggles 1984: see Section 2:3 for all of his a priori field program rules). Considering together the sites on Mull and in Lochaber, as they were for the astronomical statistical analyses, the classic:reverse ratio of the case-study sites of this area is $18: 9$.

\section{Argyll}

Trying to fathom the relationship sites had to each other is generally quite complex, and Argyll is no exception. However, there are some noticeable points. Nearly all of the case-study sites of the current project appear to group near to each other not far from the coast, on coastal plains or in valleys of differing widths, as follows: AR2 \& 3 (Sluggan \& Barbreck); AR7, 8, 9 \&10 (Torran, Ford, Creagantairbh/Glennan North \& Glennan South); AR13, 15 \& 16 (Kilmartin, Duncracaig/Ballymeanoch, Rowanfield); AR17 \& 18 (Duntroon \& Crinan Moss); AR27, 28, 29 \& 30 (Dunadd, Dunamuck I, Dunamuck II \& Dunamuck III); AR32 \& 33 (Oakfield \& Kilmory) (Fig. 3b). As for Mull, some of the project's sites appear ungrouped or isolated due to Ruggles' a priori choices for testing the highly accurate alignment hypotheses of Thom (Ruggles 1982a, b, 1983, 1984). These lone sites include:

(i) LN22-Duachy, not far from the coast (the only listed stone nearby is the now destroyed/removed standing stone of Kilninver, NM82SW 13).

(ii) LN18-Glenamachrie. This is actually near two other extant inland sites in the same valley: Strontoiller stone circle (NM92NW 8), and Strontoiller or Clach $\mathrm{Na}$ Carraig standing stone (NM92NW 2-not a slab), NE of an associated 
excavated cairn. There is one other listed site within $3 \mathrm{~km}$, Kilvaree (NM93SW 4), but it is not clear whether this is a monument or an earthfast unmarked stone. Others much further (3-6 km) north are either destroyed or possibly not prehistoric, such as Connel Station (NM93SW 5) and Dunstaffnage House, Witches' Stone (NM83SE 40).

(iii) LN7-Benderloch (north; which actually has a near neighbour Benderloch south [NM93NW 9], possibly not included since local legend held that it may have been part of a circle (Mitchell 1933 on Canmore: https://canmore.org. uk/site/23258/Benderloch).

(iv) The final lone case-study example is Salachary (AR6). This site takes up a position inland on a plateau with commanding views, similarly to Kintraw (NM80SW 1), which is $1.38 \mathrm{~km}$ WNW of Salachary, 'as the crow flies'.

For Ruggles (1985), the pairing of solar and lunar alignments was more fully realised for Argyll in the area of Kilmartin, where a structure yielding an indication of the winter Sun is invariably situated next to another yielding a declination matching that of the Moon at the major standstill in the south, but he only deduced this for stone rows and aligned pairs (1985, S129; 1988, p. 243). Importantly, whilst there was a significant a priori hypothesis to be tested by Ruggles here, his omission of the northern orientations meant that the fuller pattern of what might be occurring in these regions was still missing. For more on this 1985 study, see section Examples of Other 3D Panoramas in Brief below.

Combining Lorn and Argyll case-study sites, as was done for the astronomical statistical analyses, there are 10 reverse sites out of a total of 21 sites (Table 2). These are: AR2-Sluggan; AR3-Barbreck; AR6-Salachary; AR9-Creagantairbh; AR10 - Glennan Sth; AR18-Crinan Moss; AR27-Dunaddand; AR29Dunamuck II; AR30—Dunamuck III; and LN7—Benderloch North. In Argyll, similarly to Mull, 'classic' and 'reverse' sites appear to group together. However, unlike Mull, where at least one site is a 'classic site' and only one is a 'reverse site', no particular pattern could be determined in relation to the number of classic sites versus reverse sites in these groups. Perhaps, as for the general situation on Mull, this could be due to the number of known standing stones sites left out of Ruggles' (1984) statistical analyses. Nevertheless, the clustering of monuments and groupings of sites in specific locations is notable, and certain monument clusterings have been well known for centuries (Fraser 2004; Graham 1977, p. 187), such as the cluster of monuments in the Kilmartin valley. In this area the following standing stone monuments make up the case-study site labelled as Kilmartin (AR13): two stone circles (Temple Wood: NR89NW 6); an individual standing stone (Nether Largie: NR89NW 44); two groups of standing slabs (Nether Largie: NR89NW 3); and a possible standing stone stump, no longer locatable (Slockavullin: NR89NW 73). Importantly, as in other regions, other monument types, including rock art, are found with or near to standing stone sites in Argyll, and many are intervisible (Burl 1993, 2000; Bradley 1993, 1997; Higginbottom et al. 2015; Jones et al. 2011; Sheridan 2012). At Kilmartin there are also cairns and rock art (Burl 1993, p. 5). Nearby, at Ballymeanoch, there is a site made up of an alignment of four slabs, which is only about $40 \mathrm{~m} \mathrm{NE}$ of a roughly parallel alignment of two slabs, along with a single standing stone, and 
near to all of these are two cairns, with a henge only $130 \mathrm{~m}$ to the SSW (AR15, Ballymeanoch, NR89NW 14; RCAHMS 1988, p. 128, no. 199 [see fig.]. So here we also have a case of two major sites (AR13 and AR15) quite close to each other, both made up of a number of, or cluster of, monuments. It is relevant that, despite their proximity, these two sites are not intervisible due to the gently undulating landscape, yet they are quite close. All such considerations highlight the ongoing difficulty of categorizing or defining a single site or the possible relatedness of sites in archaeology, and this is naturally recognised by this study. This can be further illustrated by places like AR29 and AR30. These may well have been thought of as a functioning single place when they were created, as they are very close together and intervisible, yet they are formally listed by the authorities as separate sites. Finally, the author suspects that, for those sites where it was not possible for Ruggles to do an intervisibility study in the field, some might well have been intervisible if the current dense pine forest cover was missing or a more open tree cover was in evidence (like AR32 $\& 33$ ), and these ideas will be tested as the project is expanded.

\section{Kintyre}

Kintyre illustrates that an interest in orienting monuments to astronomical phenomena does not mean that an entire geographical region, such as a peninsula, has to focus on only one or two astronomical targets. It may focus on a number of them, whilst still favouring the same astronomical bodies, like the Sun or the Moon, as was found here. Initially for Kintyre there was no statistical support for clustering in astronomical orientations (Higginbottom and Clay 1999), but on further inspection it was discovered that the sites to the north ( 9 out of a total of 20 , i.e. $n=9 / 20$ ) appeared to have slightly differing orientation foci to those of the south $(n=11 / 20$; Table 2, note dotted line separating northern from more southerly sites; Higginbottom 2003, p.194). The northern sites displayed orientation foci or clustering in orientations similar to the sites found in Argyll, whereas those sites in southern Kintyre had a greater degree of clustering on other phenomena, as well as some matching Argyll (Higginbottom 2003). On closer inspection, the majority of orientations that we have for sites in the north focus on the Moon $(n=8 / 11)$ rather than the Sun $(n=3 / 11)$, whereas the orientations are equally distributed between the Moon $(n=9 / 18)$ and the Sun $(n=9 / 18)$ for the southern sites. The greater number of orientations in the south is primarily due to the fact that the southern sites have intersite orientations as well as onsite, whereas the northern sites only have one intersite orientation listed by Ruggles and it does not hit either the Sun or the Moon. What is most intriguing here is that, in terms of Sun:Moon ratio, the orientations in the south of Kintyre have the highest number facing the Sun of any region studied so far, barring the combined data set of Islay and Jura, where a distinct majority favour clustering around the Equinox or possibly the mid-solstitial points (also see below). In fact, due to the number of solar orientations in southern Kintyre, and with the addition of the few from the north, this comparatively greater weight of solar orientations can also said to be true for the entire region of Kintyre. Note that the majority of the northern Kintyre orientations are favouring or looking towards the south compared 
to the north (North 4:South 7). The orientations of sites in southern Kintyre are also barely comparatively different (North 9:South 8). When considering the sites themselves we find this pattern holds true, which did not have to be the case when there are multiple alignments at some sites (two-way for slabs and a row for instance) or due to the intersite alignments in southern Kintyre. The breakdown is as follows: for northern Kintyre, seven sites are aligned to the Moon $(n=7 / 9$ sites), four are aligned to the Sun ( $n=4 / 9$ sites), and two are not clearly aligned to either phenomenon when rising or setting ( $n=2 / 9$ sites). These numbers are not mutually exclusive because alignments are two-directional, remembering that the term aligned means you can stand at one end of the axis at a site and look along the axis (of the slab or the row) and see the phenomenon-so effectively one faces the phenomenon along the axis. Of these northern Kintyre onsite slab and row alignments, four are luni-solar and involve four separate sites. Here the Sun is seen in one direction and the Moon in the other. Notably, there are orientations on the cardinal points of north/south (KT2 Carse) as well as midpoints, including that between MinSS south set and Equinox Sun rise, as is found at KT19-South Muasdale. In the north, three sites face the winter solstice and one faces the summer solstice.

As one would expect, the situation in the south is rather more complicated because many sites participate in both onsite and intersite alignments. For the onsite alignments, four sites face the Moon $(n=4 / 11)$ and five face the Sun $(n=5 / 11)$; of these one is luni-solar $(n=1)$. Where solar phenomena are tracked, four sites face the winter solstice $(n=4)$ and two face the summer solstice $(n=2)$ - these are not mutually exclusive, for at two sites we have dual solar alignments. There are six sites participating in intersite relationships. Here five face the Moon $(n=5 / 11$ sites $)$ and two face the Sun $(n=2 / 11)$, and there are two luni-solar alignments and one dual lunar alignment. Altogether then, we can see that the sites in the south have a very different relationship to, and focus on, the Sun and the Moon than that seen so far in the north, for here we have nine facing the Moon $(n=9 / 11)$ and seven facing the Sun $(n=7 / 11)$. Thus when we take into account the number both of orientations and of sites, it could be argued that in the south the Sun may be of equal or greater interest than the Moon. Note that we have three summer solstice orientations and seven winter solstice orientations in Kintyre as a region. Overall, there is a great spread of preferences for specific alignment choice, but there is absolutely no doubt the Sun and the Moon at their extreme rising and setting points were the focus of these alignments. Remember that there are eight targets to choose from for the Moon at its extreme rising and setting points and four for the Sun, plus two midpoints, making a total of fourteen targets. The actual numbers of astronomical targets 'hit' in the region of Kintyre as a whole are as follows: the Moon at the major standstill rising in the north, $\mathrm{n}=3$; the Moon at the major standstill setting in the north, $\mathrm{n}=1$; the Moon at the major standstill rising in the south, $n=2$; the Moon at the major standstill setting in the south, $n=2$; the Moon at the minor standstill rising in the north, $n=3$; the Moon at the minor standstill rising in the south, $n=3$; the Moon at the minor standstill setting in the south, $\mathrm{n}=1$; the Sun at the summer solstice rising, $\mathrm{n}=1$ and setting, $\mathrm{n}=2$; the Sun at the winter solstice rising, $\mathrm{n}=4$ and setting, $\mathrm{n}=5$; and finally, one equinoctial Sun rising, or mid-point between solstices, $n=1$. Such a fairly evenly spaced variety of orientation foci creates low numbers for any single 
target and goes some way to explain the lack of statistical support for Kintyre as a whole.

As with Argyll, trying to figure out the relationship between sites in Kintyre is quite complex. This is especially so when sites have been destroyed and could not be included in Ruggles' study-for instance, Low Margomagach (NR63NE 19) just SSE of KT19; and Drumlea (NR62NE 19) and Drum Farm (NR62NE 8), the latter very close to, and north of, KT27 and both generally east of KT28 and KT29. What is noticeable here, then, is that the majority of known sites missing from Ruggles' Kintyre assessment are from the south and the locations of the missing sites tend to be near those included in this project to date. Nevertheless, when looking at all the sites included in Ruggles' study, we can still find that (as with Mull), both classic and reverse sites are grouped together in both the north and the south of Kintyre $(\mathrm{n}=7$ reverse sites and $n=13$ classic sites; Table 2; Fig. 3c). Intriguingly, each pair of intervisible sites contains at least one reverse site, with the majority of pairs composed of one classic and one reverse site $(n=5 / 7$ pairs; Table 2). Whilst in Argyll most case-study sites appeared to be near the coast or in a valley, in Kintyre, more like on Mull, the locations were more frequently varied such that, as well as being near coastal edges (KT3, KT35), they also appeared on high ground overlooking the sea or coastal lochs (KT8, KT36), distinctly higher ground around the edges of valleys (KT31, KT32, KT37 \& KT39), and on top of lone, large plateau-like situations (KT29, KT28, KT41) (Fig. 3c). Despite this variety of locations, the builders engineered the same kinds of interest in landscape and astronomy in the form of the classic and reverse landscapes as was found on Coll, Tiree, Mull and in Argyll (Fig. 2a-h).

\section{Orientations on Cardinal Points}

Interestingly, there are orientations on the cardinal points of south and north in each region of Mull, Argyll and Kintyre, and the adjoining areas of Coll and Lorn, indicating the times of midday in the south and midnight in the north $(\mathrm{n}=12$ sites). The four intersite alignments are ML1 looking towards ML9 (ML1-ML9); ML9-ML1; KT27-KT39; and KT39-KT27 $(\mathrm{n}=4)$. These sites are made up of stone rows and single standing stones. The onsite alignments $(\mathrm{n}=8)$ are made of rows, pairs and single slabs. These are CT1, ML4, AR2, AR3, AR6, LN7, KT2, and KT12. Interestingly, the majority of these sites are reverse sites $(n=9 / 12)$. These possible indicators of the times of day may be linked to activities that occur at or are connected to the solstices or standstills at midday or midnight as described for sites on Coll and 
Tiree in Higginbottom et al. (2015, pp. 625-626, 632 and discussion), and thus may work and have associated functions in a similar way to those midday solar markings noted in Fajada Butte in Chaco in northwest New Mexico, USA (Sofaer et al. 1982, pp. 170-173, 177, Figs. $2 \& 3$ ) and the astronomical architecture of Palenque's Temple of the Sun (Mendez et al. 2014, pp. 63-65).

Whilst the Sun may never reach the zenith at these latitudes of Scotland, as the Sun's path moves closer and closer to the time of the summer solstice, the Sun appears higher and higher in the sky, until one day at midday, at the solstice, it reaches its highest point above the earth at these places (culmination), similar to sites in the Tropics. One has to clearly look up to see the Sun at this time. In summer, the Sun can be seen to rise and set north of the observer. It also appears to spend its time below the horizon in the north, as it sets in the northwest and reappears in the northeast. At the winter solstice, looking at the midpoint of the Sun's path in the south, one can see the Sun at its lowest midday point in the sky for that year. The winter solstice is also the time that the Sun spends most of its time below the horizon, or visually 'below the earth', and in this case it will spend all of its time below the earth in a southerly direction. It should also be noted that because the Sun is only just below the horizon at and close to the summer solstice, twilight lasts longer and is of greater intensity than at the winter solstice. Thus at the summer solstice people can carry on everyday activities out of doors the entire night. In winter, the sunlight is seen to 'drop away' quickly below the horizon, twilight vanishes after a short time and darkness falls quickly. The Sun does not reappear for many hours until just before the late dawn, indicating that the Sun has 'fallen' further away from the Earth than it does in summer. So here we can see a link and possible reasons why Scottish monuments might also be aligned to the cardinal points of north and south.

Sometimes non-astronomers think that the Sun always rises and sets south of places at high latitudes, but this is incorrect. Essentially, the Sun is so far away its rays are parallel when they hit the Earth. This, combined with the tilt of the Earth through its polar axis, ensures that the Sun will rise and set north of the observer in the northern hemisphere at high latitudes in summer and south of the observer in the southern hemisphere at high latitudes, also in summer. The incorrect assumption is likely a confusion between the Sun's amplitude and the actual position of the Sun in relation to the observer on Earth. The Sun's amplitude is a measurement along the horizon, which tells us the horizontal distance of the solstice points from the equinox point. This changes from $23.5^{\circ}$ at the equator and increases as one goes to higher latitudes. So, for the great circle Stenness on Orkney, for instance, we calculate the Sun's amplitude by knowing that the latitude of Stenness is approximately $58^{\circ}$ north, roughly as follows: $23.5^{\circ} \div(\operatorname{cosine}(58))=44.3^{\circ}$ approximately. Therefore, this approximate amplitude is merely the difference in degrees between the Sun's rising and setting positions along the horizon compared to those at the equinox. Note that after the March equinox (northern astronomical spring/southern astronomical autumn), the Sun rises north of east (wherever you are on the Earth) until the September equinox. 


\section{D Panoramas and Orientations}

One of the major points to take away from the investigations of the 3D panoramas in this work above and below, is that the same two astronomical bodies and the five major phenomena linked to these (solstices $[n=2]$, equinox $[n=1]$, standstills $[n=2])$ are used both as orientation targets and for the creation of landscape settings for sites across western Scotland. It is important to remember that these five phenomena create a total of 14 rising and setting targets in the north and south of the sky (Fig. 2a). Further, it should be remembered that whilst some regions contained statistical orientation preference within them for two or more of these targets, as demonstrated in the initial statistical tests (Higginbottom et al. 2000), nearly all of these targets can be found in each of the case-study regions discussed in this paper (q.v. also Higginbottom et al. 2015; Higginbottom and Clay 2016a, b).

\section{D Panorama Example Sites in Detail: Mull as Case-Study}

Following from the methodological approach taken here, we can argue that to gain a more complete comprehension of any cultural artefact ultimately requires an archaeological-phenomenological narrative or description in terms of contextual relatedness or a holistic context of significance. To create such a narrative requires one to discover as much as possible about the qualities and context of the artefact and the connection between these. In this paper, then, we now turn to the revelation of the detailed accounts of the holistic visual context of each example site (ML1-Glengorm; ML2-Quinish; ML7-Cillchrìosd; and ML16-Gruline). The details of ML16 will later be used to create the archaeological-phenomenological narrative of how the sites work in the region of Mull. Together, these detailed accounts, the information discussed above and the narrative act as an illustration of all the sites investigated so far in western Scotland.

Firstly, those sites with the classic landscape pattern will be described and their similarities discussed (ML1 and ML2); after which, the 'reverse sites' (ML7 and ML16) are described and discussed. The narrative will follow on from the detailed example accounts.

\section{The Classic Sites}

\section{Glengorm-ML1}

This stone row is set near the base of a small open local valley-or bowl as Wright (2007, p. 198) likes to think of it - that slopes gently towards the south to southeast; it therefore slopes gently upwards towards the north coast where you can look out to the Sea of the Hebrides. The slope northwest is relatively steep and close though not high (Fig. 4a, b for site photographs and Fig. 5a for the 3D panorama). The stones 
(a)

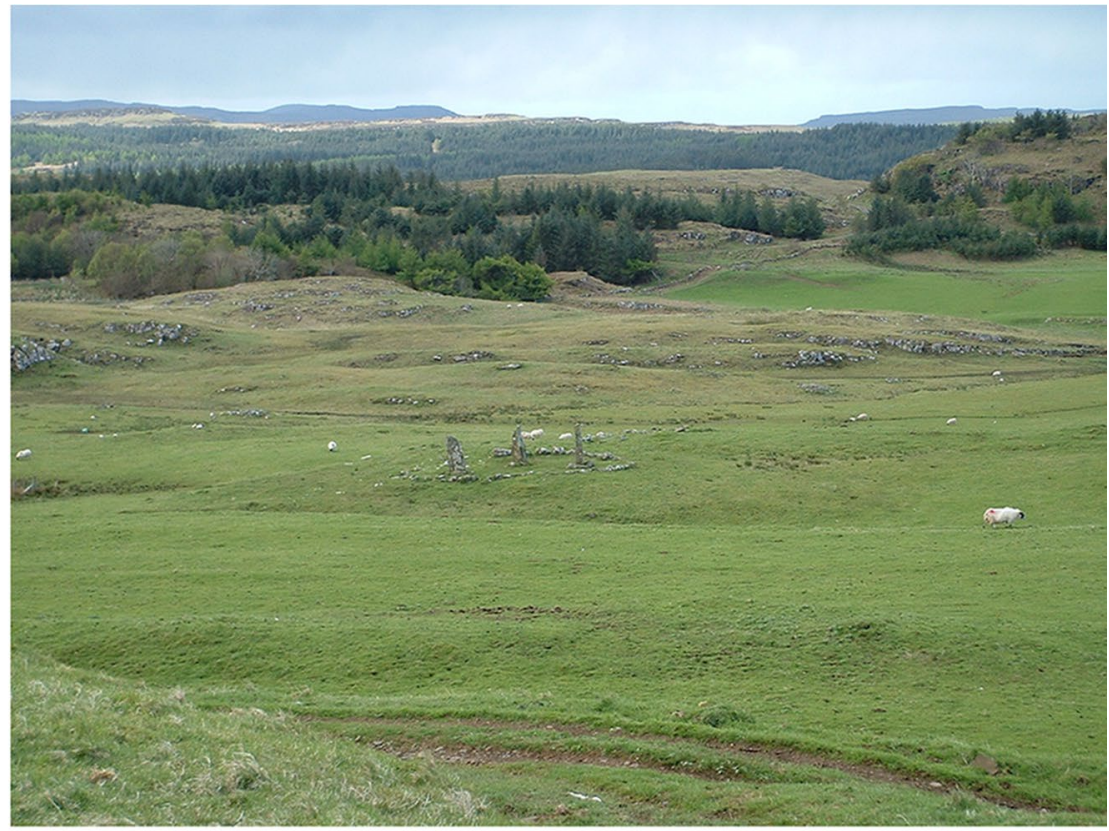

(b)

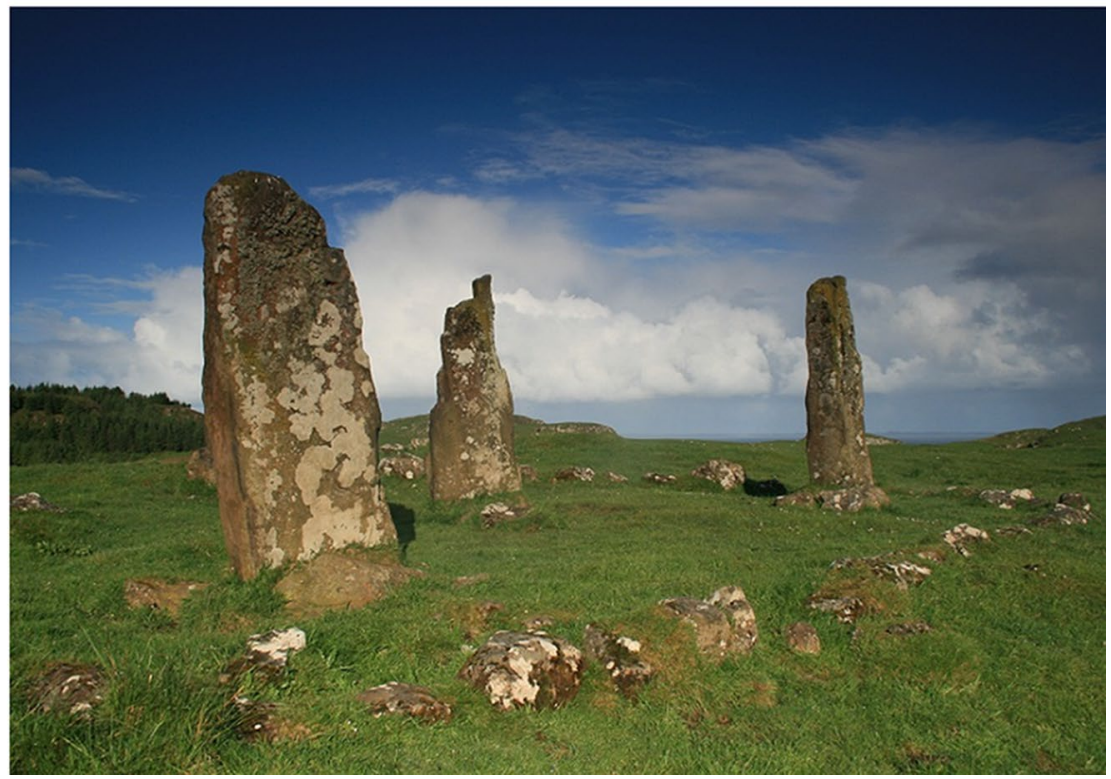

Fig. 4 Glengorm. a Taken from a northwesterly direction upon the top of the hilline that creates a partial amphitheatre effect around Glengorm. Two of the three stones were re-erected by 1942 (information from V. G. Childe MS notebook, held in NMRS; RCAHMS 1980, p. 68, no 105). Martlew and Ruggles' excavation showed that these two were not in their original positions. Photograph taken by Joanne Wright. Copyright $\odot$ Joanne Wright. Note that at this site Ruggles and Martlew excavated the stone row and found a cremation burial, but no dates have appeared in publication (Ruggles and Martlew 1989, S147). b This shows the form of the megaliths of this site more clearly. Photograph taken by Chris Bickerton. Copyright () Chris Bickerton 


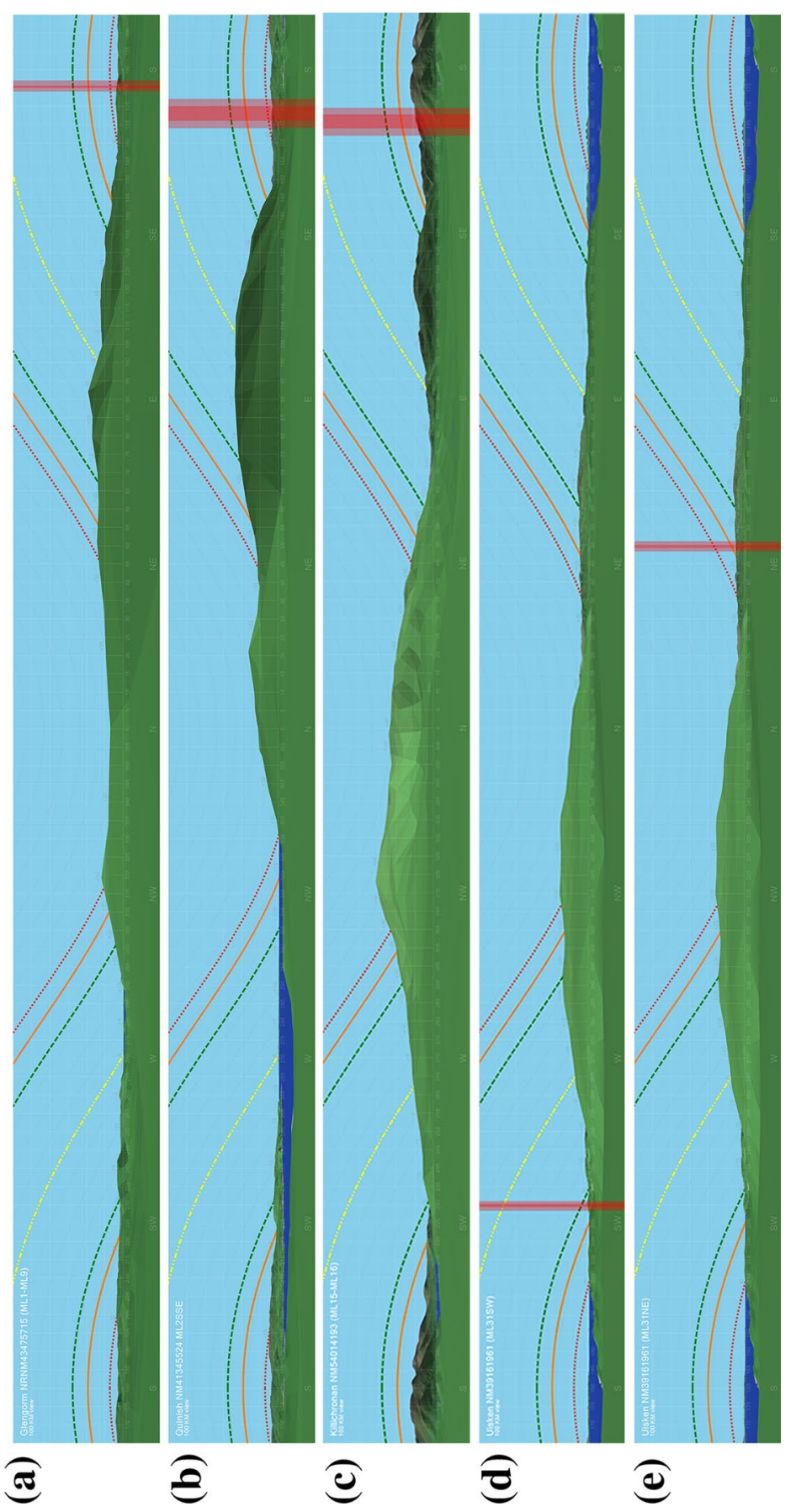

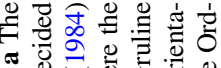

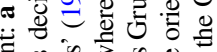

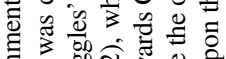
品.

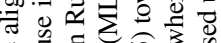
의 证 $\bar{m}$

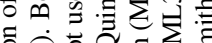
О人ㅎำ

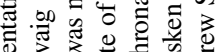

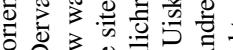

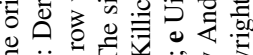

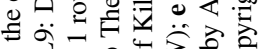

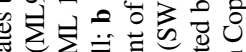

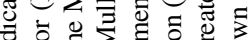
$\equiv \sum^{\circ} \sum^{2}$

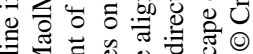
毛葑. 可

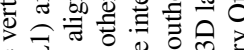
o 0 을 政

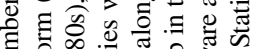
言

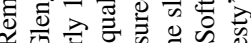

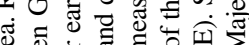
ष

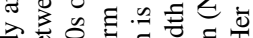

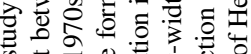
类 要 尊 ․ㅡㅇㅢ

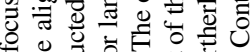

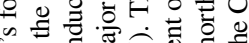

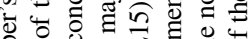
空

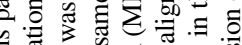

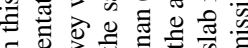
동

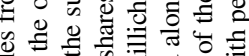
on 0

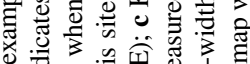

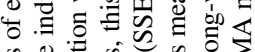
o : :

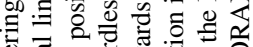

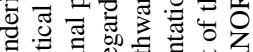
एँ o के o के

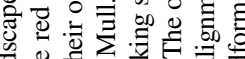
을 프며의 लि 읻 过论

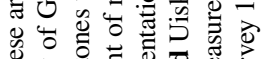

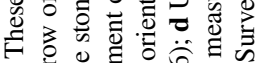
过

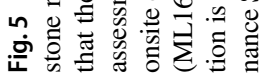


of this row were re-erected and Ruggles and Martlew's excavation confirmed the stones were originally in line.

On first viewing of the 3D panorama, comparing north with south, we can see that the closest ranges occur in the northern horizons and the most distant ranges in the southern (the actual distances have been confirmed for all horizon profiles [HP] through digital readouts of the horizons for every $0.1^{\circ}$; program by Smith). It is apparent that water is almost absent from this set-up, except in the west, where the westward horizon towards the south contains the most distant section of the entire horizon line surrounding the site. However, regarding the horizons as a whole (not just the apparent ranges), the southern to southwestern horizons are still far more distant than the northwest to north to east, and thus the general concept still holds: that the southern horizons are generally more distant than the northern. The northern horizon lines, from west to east, are connected to the dominant peak in the east. The horizon profile of ML1 is visually most like the site ML10 (DervaigN). It can been seen that at ML1, all three southern phenomena appear to rise out of the dominant southern chain of mountains, or near the eastern foot, in the southeast. In fact, whilst the Moon rises out of the foot of this dominant chain, the Moon at the southern major standstill rises next to a distinct distant peak. This is not easy to see in the 3D panorama figure reduced for print publication. These phenomena then travel over the lowest and more distant sets of ranges in the south. Both lunar phenomena set into the tops of the ranges in the southwest around the same altitude, the Moon at the major standstill, into a peak, the minor into the edge of a notch indicating the change in slope of the highest ground in the SW. The Sun sets into a point that is the same altitude at the cardinal point of south.

The northern phenomena all rise out of the northeastern slopes of the dominant range and all set into the slopes of the range in the NW, which is also the first high horizon line north of west. The equinox Sun rises out of the southern flank of the apparent highest point in the east and sets in the water. Intriguingly, the orientation of the alignment between Glengorm (ML1) and Maol Mor (ML9) is on the horizon just below the major standstill Moon as it moves away from skimming along the horizon (close to the southern cardinal point).

\section{Quinish-ML2}

Directly southwest of Glengorm and across a long, thin inlet is the damaged stone row of Quinish. Only one stone now stands erect (Figs. 6, 7). The points to note here are that the general shape and distances of the horizon are like those of Glengorm, though with more water in view running from south to NW (Fig. 5b). If we look at the horizon line only, the southern rising phenomena exhibit the same rising and setting patterns as ML1, except that the exit point for the winter solstice Sun at ML1 is a distinct peak. Essentially, though, two southern phenomena rise out of the dominant southern chain of mountains in the southeast, with the major Moon rising out of a more distant range. These then move over the lowest section of the southern horizon to primarily set into the relatively higher ranges of the southwest. Specifically, we have both lunar phenomena setting into the highest points in the SW. The 


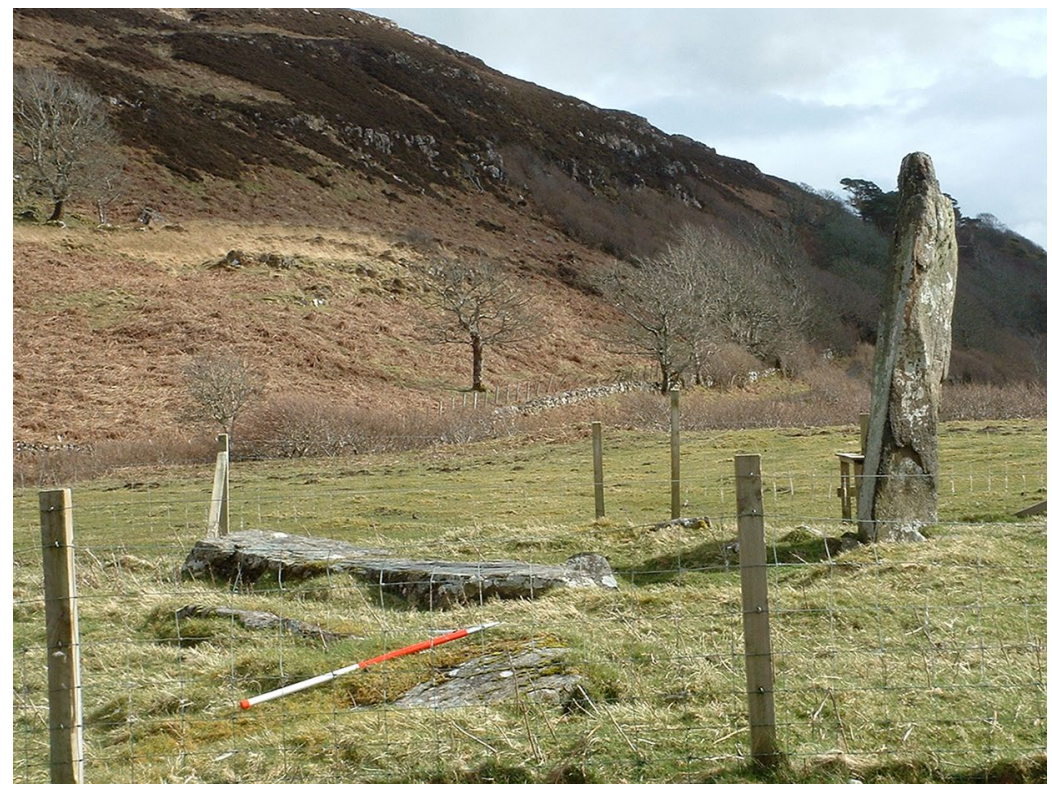

Fig. 6 Quinish. The stone row stands on a relatively level terrace. Here we can see the southeastern beginnings of the hillock that creates the sense of amphitheatre at this site 'behind' the stones. In the opposite direction is the view of the water (see Fig. 7). Photograph taken by Douglas Scott. (C Douglas Scott

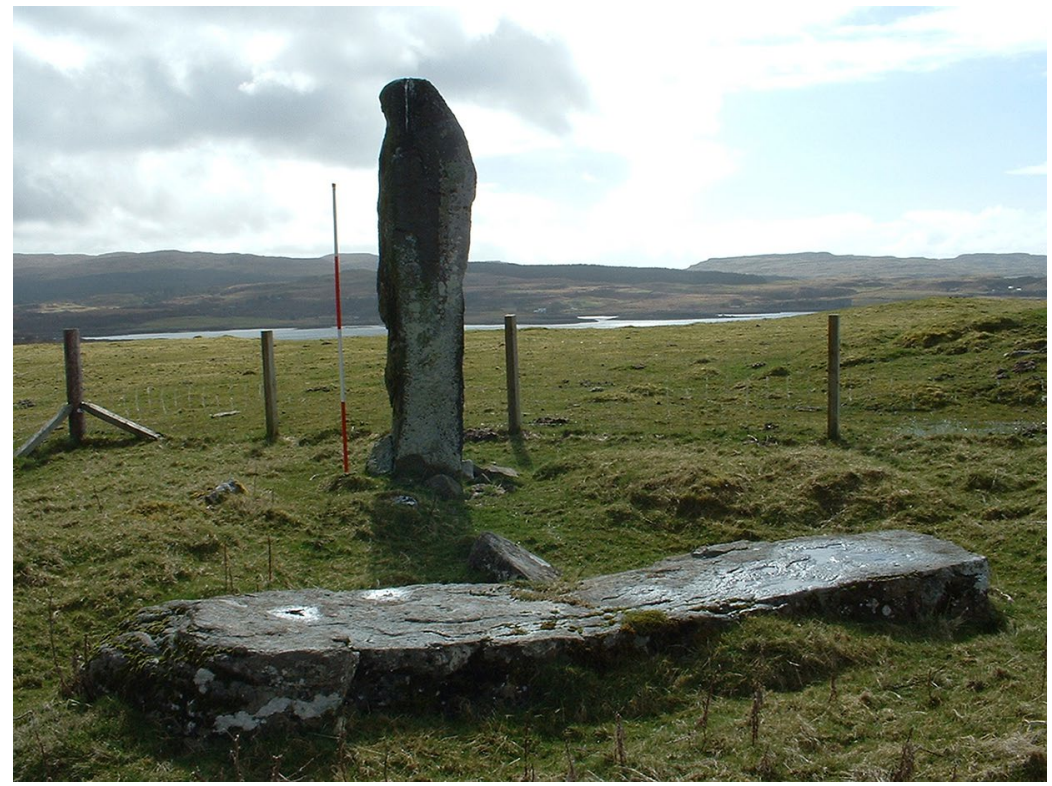

Fig. 7 Quinish. Here we can see both the placement of the site on a terrace and how the land slopes very gently down and outwards towards the water. As elsewhere, the most distant, lowest horizon, in terms of its perspective as viewed from the site, is usually placed directly opposite the 'highest' looming horizon (see Fig. 5b also). Photograph taken by Douglas Scott. (C) Douglas Scott 
winter solstice Sun, like that at ML1, sets at a lower apparent altitude than the Moon at the major or minor standstill.

Further and similarly, in the north, the astronomical phenomena all rise out of the dominant range in the northeast. Only the Moon at the major standstill manages to set into the range in the NW, and, just like at ML1, the equinoctial Sun is seen to rise out of the highest peak in the northeast and sets into the water in the west. The orientation of this stone row is towards the rising of the major standstill Moon in the south.

\section{Examples of Other 3D Panoramas in Brief}

Killichronan (ML15): The horizon profile has the classic shape of a large hump-like chain of mountains dominant along the northern horizon with the horizon line dropping significantly lower over the southern area creating a trough in profile. In Coll and Tiree, the entire trough in the southern profile is also usually at, or nearly at, sea level. Instead of a complete trough in altitude at sea level in the south then, we have a low chain of peaks with water running in front and there is still a significant amount of landscape in the southern direction that is near, or at, sea level, as evidenced by the water in this direction. Importantly, too, as at other sites (e.g. ML2, ML11), to the west of the trough we have a prominent range and to the east the large, close, dominant northern range begins to rise. Importantly for this site, the orientation of the alignment of this single stone with the stone pair of Gruline (ML16) faces the edge of southerly rise of the Moon at the major standstill (known through astronomical calculations but not demonstrated by these figures yet). However, one can deduce from the 3D landscape panorama that only the glimmer or glow of this rise will be seen. It is possible that the glimmer of light from the southerly setting of the same Moon will be seen also.

The stone slab at Uisken (ML31; Fig. 8a-c) has a dual orientation and is precisely oriented on the rising summer solstice Sun in the north and within $2^{\circ}$ of the setting Moon at the minor standstill in the south (Fig. 5d, e). Notably, the alignments acknowledged by Ruggles for Ardlanish (ML33) and Camas nan Geall (NA3) did not indicate any astronomical phenomena. Interestingly, if we look in the opposite direction along the standing stone or stone slab for both ML33 and NA3, we see that ML33 is within $5^{\circ}$ north of the equinox rising in the east and NA3 is within $0.5^{\circ}$ of the rising Moon at the minor standstill in the south (these new orientations are a reasonable estimate and are calculated simply by adding or subtracting $180^{\circ}$ in azimuth). Significantly, both of these orientations are within the defined possible azimuth range for these sites' axes (q.v. Ruggles 1984, chapter 2, which explains how an azimuth range is calculated) and thus, for NA3 especially, it can be considered to be distinctly aligned with these astronomical phenomena. Note that Ruggles did not consider these sites and these opposite orientations in his (1985) study. Lochaber was not reconsidered and ML33 was not of interest as there was not a southerly facing alignment. 
(a)

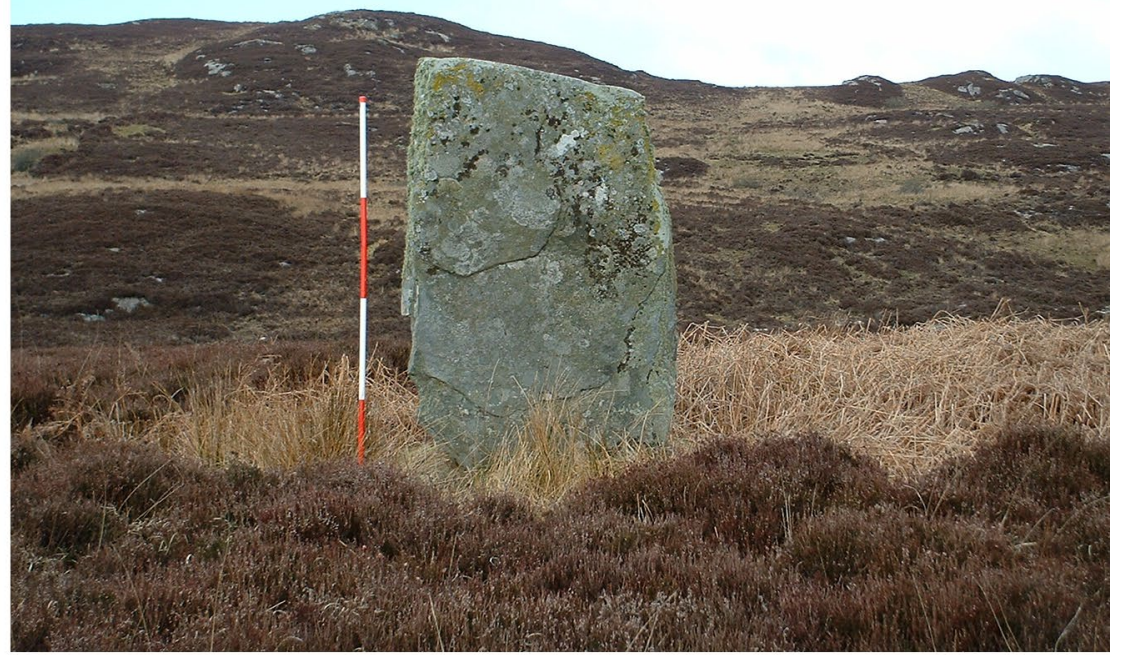

(b)

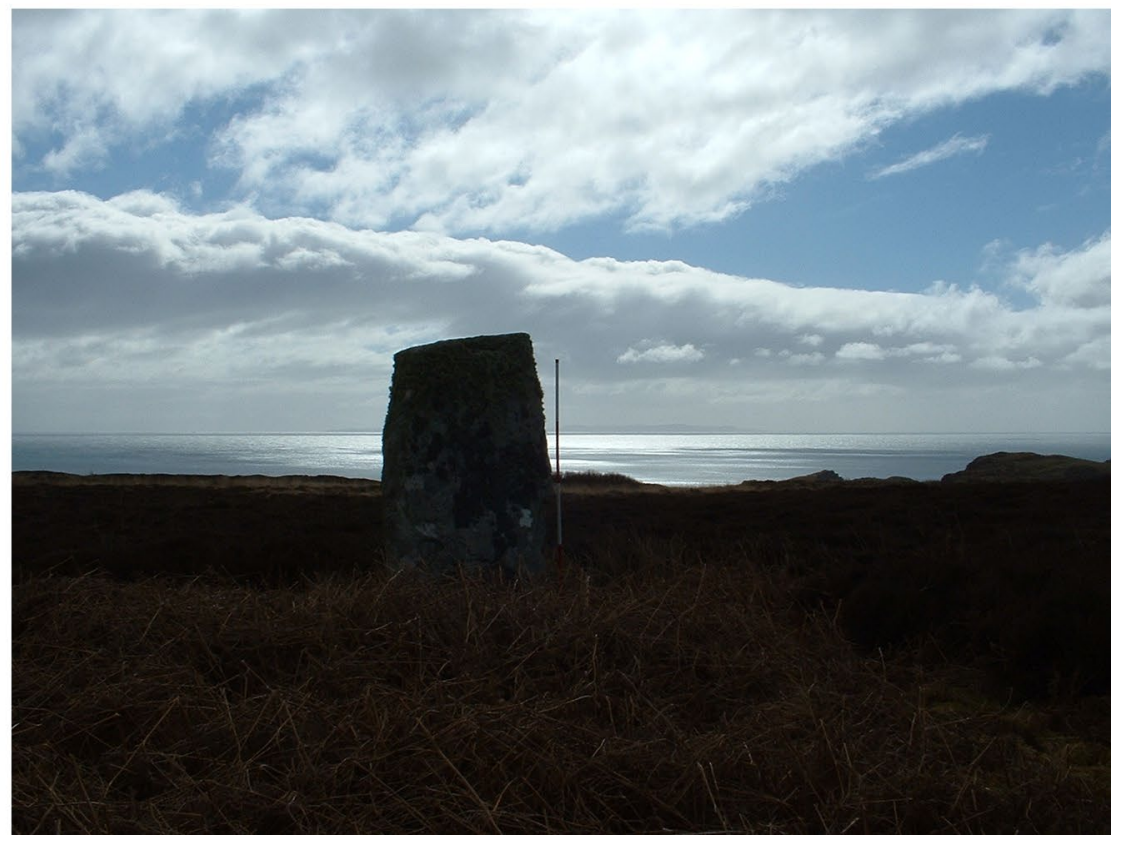

Fig. 8 Uisken Druim Fan (ML31). Figure a illustrates the repeated pattern of the site sitting on a flat terrace within a natural amphitheatre. The area opens out in one direction over water $\mathbf{b}$. Figure $\mathbf{c}$ shows the alignment view to the distant hilline in the NE out of which the summer solstice Sun can be seen to rise (see Fig. 5e). Photographs () Douglas Scott 
(c)

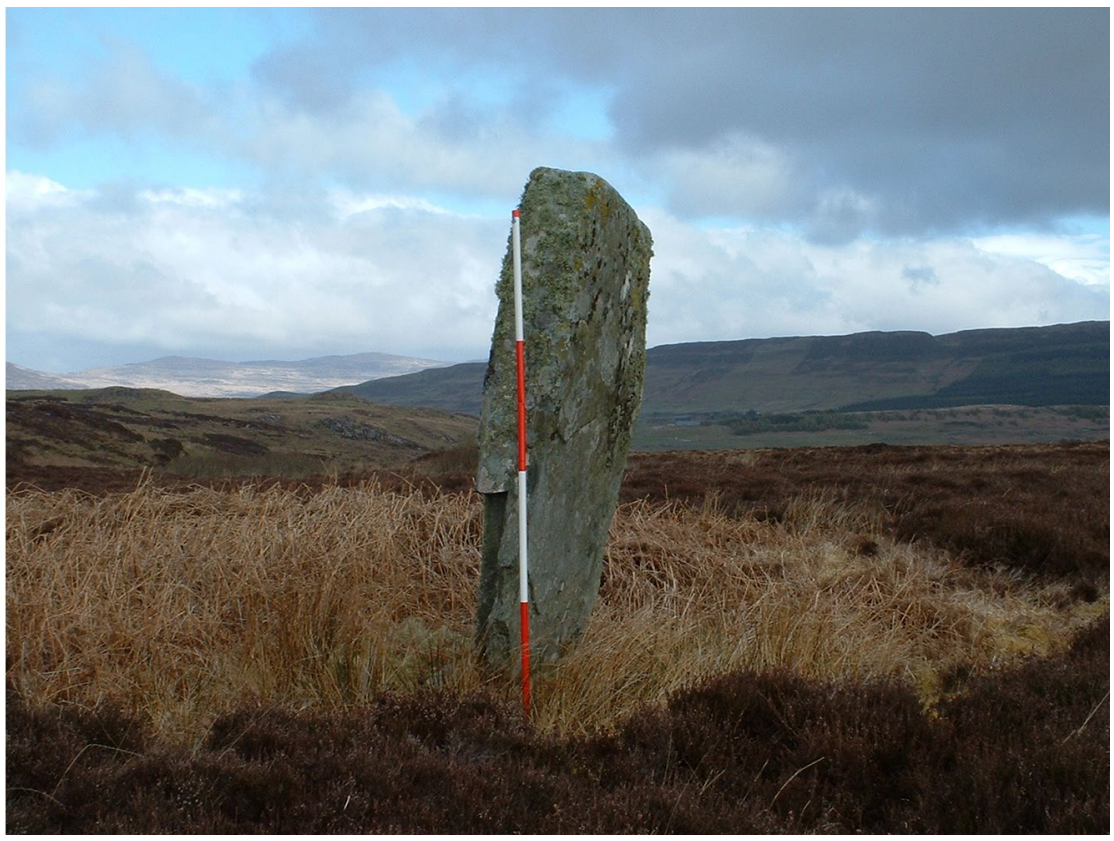

Fig. 8 (continued)

Importantly, both of these orientations were facing the sites' closest horizons. The current project has discovered that the closest horizons of each site appear to be as integrally involved with the sites' locations as is each site's most distant horizon. Therefore the project will continue its study of the orientations in both directions across chosen sites in western Scotland, and, as can be seen, it is so far reinforcing the theme of every site being oriented upon the Moon or the Sun. These points are important, for, as part of a carefully constructed project testing the possibility of highly accurate astronomical orientations to within $0.1^{\circ}$, we know that Ruggles' (1984) work left out those orientations with horizons closer than $1 \mathrm{~km}$. His (1985) work points out that his (1984) work-directed by assumptions and methodologies that differ from ours-was unable to differentiate clearly specific orientation preferences, or narrower possible clusterings, within the wide range of orientation preferences to within one degree (in declination) in the south. Specifically, we remember, this range equalled the rising and setting points of the Moon over its entire 18.6 year cycle in the south: $-30^{\circ}$ to $-19^{\circ}$, which encompasses the winter solstice Sun $-24^{\circ}$. In 1985, therefore, Ruggles chose to survey or extract from Ordnance Survey maps, such close or other horizons in the south. Stones which in themselves did not have a linear feature (i.e. which were not slightly wider than their depth or which were irregular, like Gruline stone b [1985, S114]) were omitted. This qualitative study established that, in the south at least, when including very close horizons, these extra sites also fit the general pattern of orientations between $-30^{\circ}$ and $-19^{\circ}$. Ruggles also found that, for stone rows and aligned pairs, the distribution of these indicated declinations 'is far from that to be expected if sites were merely oriented upon 
(a)
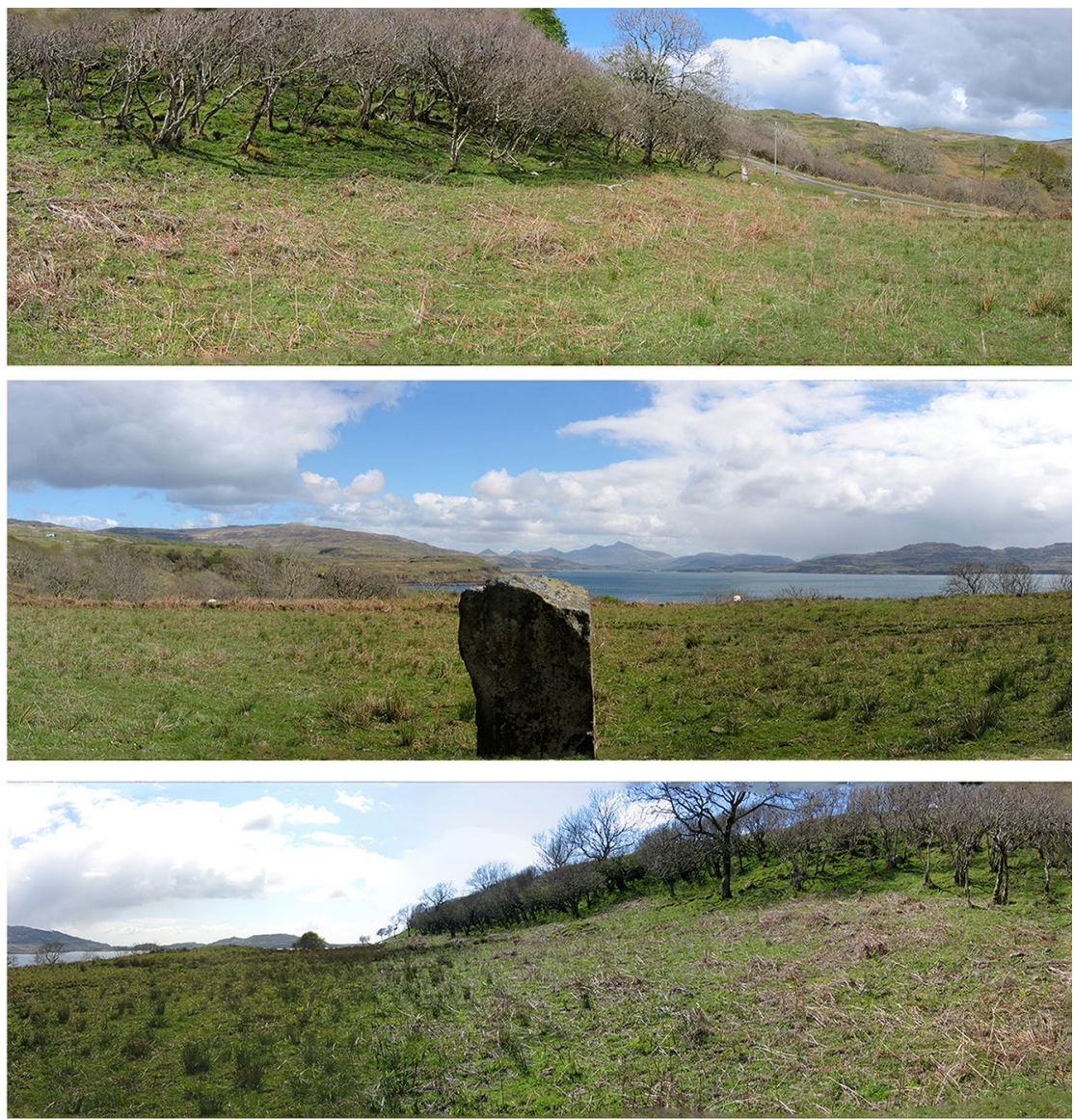

Fig. 9 a The panoramic view whilst standing at the stone of Tostarie (ML14). Like most other sites, this basalt stone sits on a level platform in the hillside offering extensive views across the water. Here we can see across Loch Tuath, towards the isle of Ulva and possibly Gometra. The setting is one of an intimate amphitheatre form like that found at Ardalanish, Uisken and Ardnamurchan. Roughly rectangular in section and aligned NE and SW and 'facing' roughly westerly; it measures $1.8 \mathrm{~m}$ in height and $0.6 \mathrm{~m}$ by $0.4 \mathrm{~m}$ at the base; the top is a slightly jagged curve. This stone was once listed as being a stone circle but visits to the site by the RCAHMS in 1972 could not find any evidence of this (RCAHMS 1980). This site is labelled as a 'Loner site' by this study until researched further. Photograph (C) Gail Higginbottom. b The panoramic view whilst standing near the stone of Ardnacross. This is the wider, more openedviewed version of the same pattern of curved hills surrounding most of a site, higher and local on one side and open to the water in the other. Uluvult (ML25) is very similar except that it sits very low in a wide, glacial valley that opens out to the water in the distance surrounded in part by high, impressive mountains; a spectacular view. Photograph (C) Gail Higginbottom. Both of these photographs are spliced into 3 where the top is the left of the panorama

the limiting monthly Moon at arbitrary points in the 18.6-year cycle' (1985, S129), and maintains that there is irregular clustering at $-30^{\circ}$ (with $1^{\circ}-2^{\circ}$; Moon at the major standstill) and $-23^{\circ}$ (wider band; winter solstice) for sites in northern Mull and the Kilmartin area of Argyll. However, there is no clear quantitative support for this statement. 
(b)
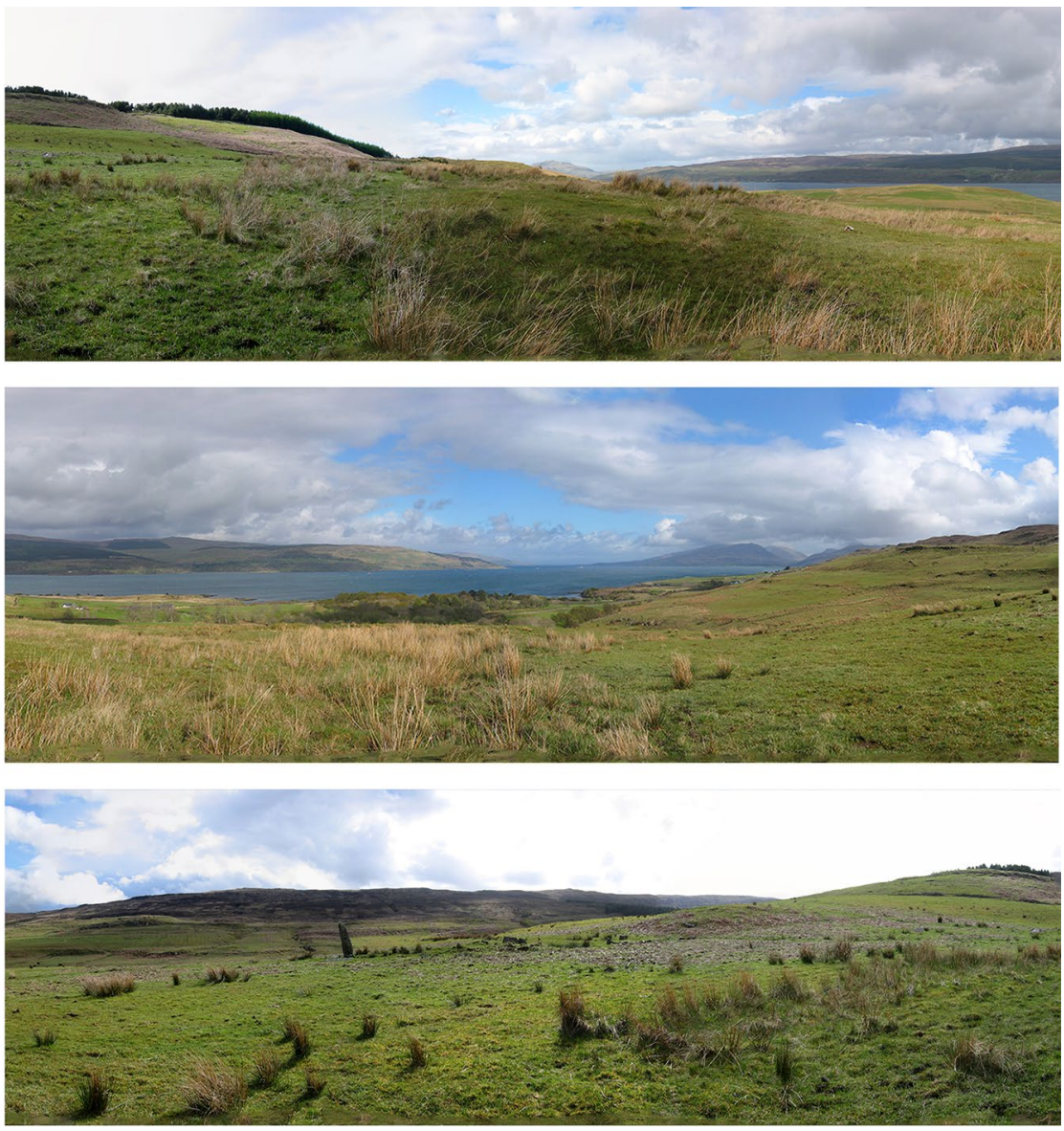

Fig. 9 (continued)

\section{Classic Site Observations on Mull-A Summary of Exemplar Sites}

What is already clear is that the main landscape choices are the same regardless of the basic form the individual sites take (stone row, single standing stone, stone pair). At all of the sites on Mull, the monuments are set in what is now immediately open ground, usually flat or gently sloping. Much of the research into this period in Scotland is showing that open ground may well have been a reality in the Bronze Age (see conclusion on 'Foliage Cover in Western Scotland' above). From viewing the $3 \mathrm{D} 360^{\circ}$ profiles and visiting the sites, it can be concluded that at most of the sites an individual has the sense of being surrounded by a curved wall of mountains or local hills placed at varying distances from the monument, with a unique and very long view usually only in one direction. This can be observed further by examining the panoramic photos of Tostarie (Fig. 9a, b) and the close-up of Ardnacross (Fig. 10; ML14 \& ML12 respectively). 


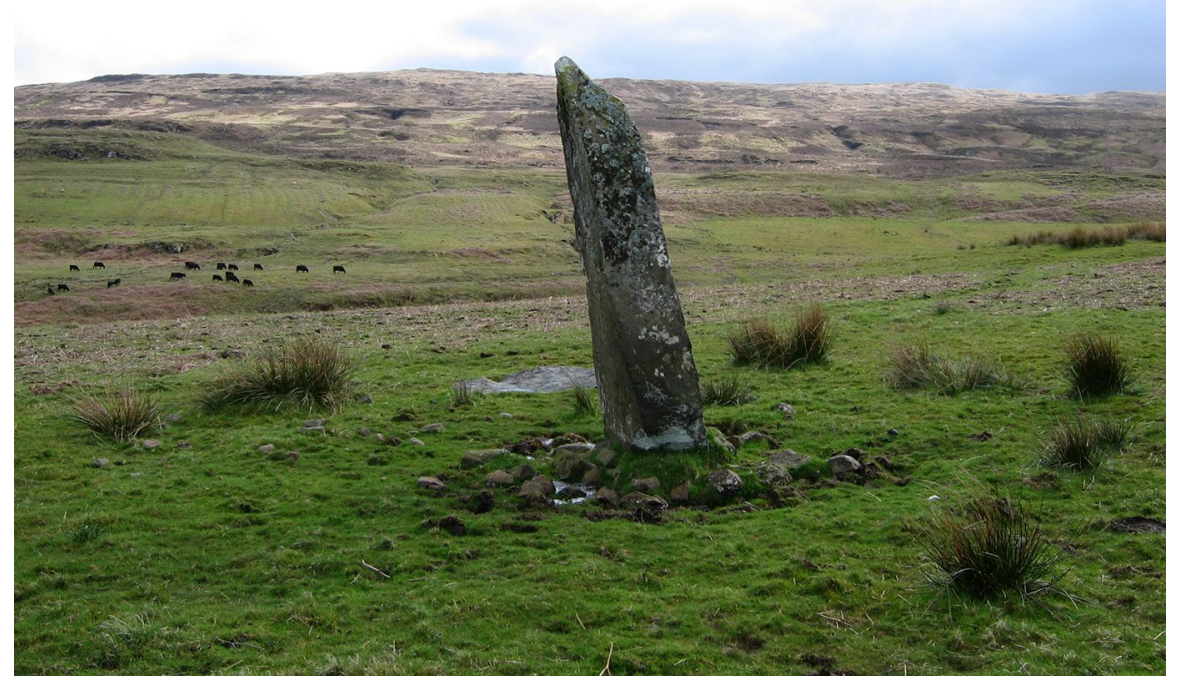

Fig. 10 Ardnacross. Here we see the one remaining standing stone of two parallel stone rows that flanked three kerb-cairns all situated on a platform in the hillside above Ardnacross. Photograph (C) Gail Higginbottom

Other shared characteristics involve the basic horizon shape found at classic sites: (i) a large hump-like chain of mountains dominant along the northern horizon with the horizon line dropping significantly lower over the southern area creating a trough in profile; and (ii) a significant amount of landscape in the southern direction which is near, or at, sea level, as usually evidenced by the water in this direction (and the altitudes that can be observed both on the landscapes within the interactive Horizon software (Smith 2013) or the author's original copies of the graphical output of the 2D horizon profiles for each site; q.v. above section Statistical Re-Investigations of Monument Orientation and Connections to Astronomical Phenomena). More specifically, the horizons usually swell and dip to create a distinctive rise in the SE and SW as well as the NE and NW, with the dips often coming between these. Alternatively, there may be two separate chains in the north and south that contain prominent features in the SW/SE and NW/NE. The horizon also often dips around the eastern and western cardinal points.

Northern horizons are the closest and the southern are the farthest, often with water most in view in the south. If hills actually make up the distant south, the northern horizons are still relatively higher than those in the south (e.g., ML15 and ML2). When we stand at the monuments and look northwards, the northern astronomical phenomena all set into, or close to, the dominant range in the west. The phenomena usually all rise out of the dominant range in the east (this can be part 
of an overlapping series of chains that travels from the NW to the NE); this is summer for the Sun and can be any season or time for the Moon. Looking southwards from the monuments, the Sun and the Moon rise out of mountainous horizons (or a mixture of 'out of' and 'over', as in Tiree: Higginbottom 2003; Higginbottom et al. 2015). Most of the phenomena at each site also set into the dominant chain in the SW. This is in winter for the Sun and any season or time for the Moon.

Remembering that Ruggles and Martlew discovered that 'sites were preferentially placed to associate prominent peaks with particular astronomical phenomena, regardless of their orientation' when investigating seven sites in north Mull, (Ruggles and Martlew 1992, S4; emphasis added), it can be seen that Ruggles and Martlew's work supports the general outcomes presented here. Specifically, evidence was found that at some sites use was made of a second peak or group of peaks, associating them with the southerly limit of the minor standstill rising of the Moon or the setting of the solstitial Sun (Ruggles and Martlew 1992, S6-S8, S12). Therefore, their work also supports the deliberate creation of some kind of repeated numbers and outcome for the area of Mull. In this way, the current work advances our knowledge more securely.

Site visits and the 3D panoramas created from digital terrain models (DTMs) have shown that in the past water was potentially visible in the close vicinity of each site, that is, when standing within $2 \mathrm{~m}$ of every monument, with the number of sites only changing by one, M15-Killichronan (q.v. Wright 2007, p. 183). This potential is dependent upon tree cover in the past and it was argued above that the tree cover was likely light enough to allow good views of the horizons in later prehistoric times. Current views of Killichronan are affected by sand dunes as discussed above.

At those sites with water, the largest spread of water is most commonly found in the south, regardless of where the site is located on the islands or the mainland (as in the case of Lochaber). In relation to the sites with water in the south, both the solstitial Suns (midwinter and midsummer) and the major and minor standstill Moons that rise and set in the north travel over the water and set on the other side. The rising and setting Sun in midwinter often flanks the body of water; the Moon at the southern major standstill would do the same; however, the time of year is not set, unless we link it to a particular lunar phase. Ultimately, in winter the Sun travels nearer to the water and spends less time in the sky.

Interestingly, due to the chosen landscape forms of the south, the minor standstill Moon usually arises from, and sometimes sets into, elevations higher than the other two southerly phenomena. Further, the builders always chose to have the three southern phenomena travel over a low area of ground/water with higher elevations at least to the east (and often to the west). Note too, that the equinoctial Sun, as part of the celestial dynamics, will always rise over and encompass all of the southern phenomena and landscape features in its continuous curves and the path of the Moon at the major standstill in north encloses every path the Sun and the Moon will ever take during this epoch.

The 3D panoramas have enabled a much clearer and more specific identification of many patterns than could be attained solely by visiting the sites, especially in understanding the connections between past astronomical phenomena and specific landscape features. All of the sites discussed above share a series of landscape characteristics that shape ultimate visions. 
(a)

(b)

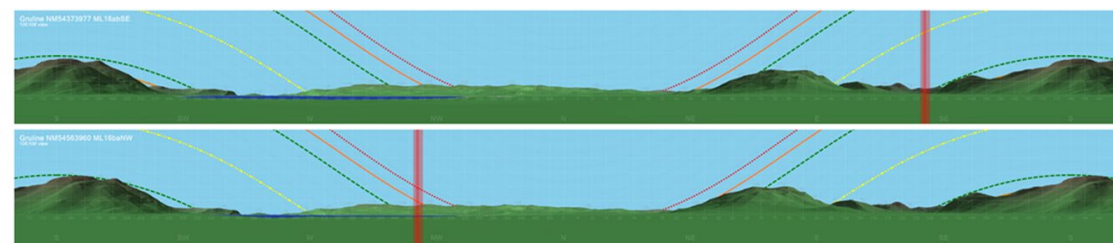

Fig. 11 Two 3D renderings of the landscapes found around ML16a and ML16b, along with the paths of the Sun at the solstices and equinox and the Moon as it travels during the time of the minor and major standstills. a Shows the view from ML16a. The orientation is measured along the alignment between two stones (from Stone A towards Stone B) in a southerly direction (SE). b Shows the view from Gruline Stone B. The orientation is measured along the alignment from Stone B to Stone A in a northerly direction (NW). Software and 3D landscape created by Andrew Smith. Based upon the Ordnance Survey 1:50,000 Landform PANORAMA map with permission of the Controller of Her Majesty's Stationery Office (c) Crown

\section{The Reverse Sites}

These classic sites above represent the slight majority of sites investigated on Mull and Lochaber to date $(n=9 / 16)$. As explained above, the remaining $7 / 16$ sites exhibit an interesting version of this majority, where the main landscape variables are placed in the opposite cardinal directions. These sites are ML7, 9, 16, 27, 30 as well as two on the east coast (ML4 \& ML12) and NA1 in Lochaber. ML7 and ML16 are discussed below as representatives of reverse sites. Due to space considerations, there will be a detailed discussion of the 3D panorama of one site (Gruline, ML16) and a short review of the other (Cillchriosd, ML7).

\section{Gruline ML16}

Gruline is a pair of stones, approximately $250 \mathrm{~m}$ apart. One of the pair is a thick slab $2.3 \mathrm{~m}$ tall by $0.8 \mathrm{~m}$ by $0.3 \mathrm{~m}$, oriented across the line joining the two stones (Stone A). The other is usually referred to as a lozenge-shaped stone, $2.4 \mathrm{~m}$ high (Stone B) and from the side looks very much like an axehead. Whilst no excavations have occurred at Gruline stones themselves to identify cremations, cairns are positioned nearby the monuments (Gruline, RCAHMs no: NM 547,393 \& 546,393; Canmore).

Naturally, whether at Stone A or B, the most distant horizons are the WNW to N (NW specifically) and SE (Fig. 11a, b). Gruline has the main horizon shape and 'look' of all the sites in Mull: in one main direction the horizons appear higher and closer and in the other they appear much lower and more distant. As with other 'reverse sites', the 'highest' is in the south and the 'lowest' in the north. The longest close stretch of horizon runs SE almost to SW (with short length in the east being $0.5 \mathrm{~km}$ closer) and the most distant horizon exists in the NE with the most generally distant stretch occurring from the WSW to the NE. Water runs from NW to SW.

From Stone A (Fig. 12a): The summer solstice Sun is seen to rise out of a small peak next to the most prominent chain in the north and the Moon at the minor standstill rises out of the top of this same chain (Fig. 11a). The Moon at the northern major standstill rises out of the peak of a very distant mountain. All these set into 
(a)

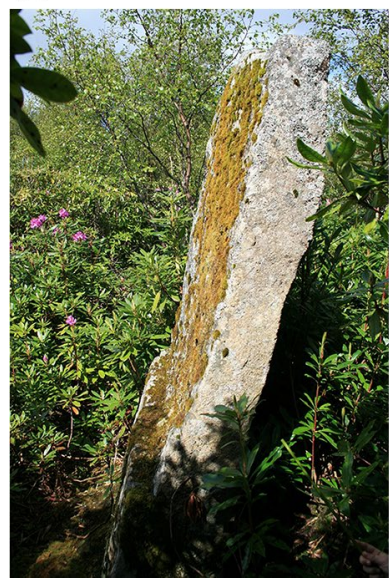

(b)

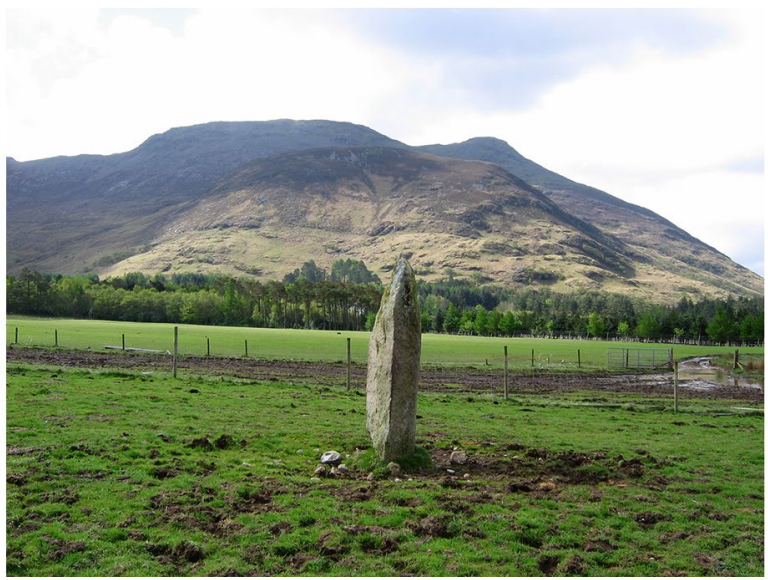

Fig. 12 a Gruline Stone A, almost lost in the rhododendron forest $250 \mathrm{~m}$ away from its mate, Gruline Stone B. Photograph (C) Chris Bickerton. b Gruline Stone B. In many ways this stone was the most striking one found on the island. It had clearly been deliberately shaped with more care than any other stone seen and looked like an axe head or lozenge and was paired with a long thin rectangular stone (Stone A). It was positioned on open ground again, surrounded by relatively close hills in the south and is thus a 'reverse site'. It is across the tops of these hills that the amazing phenomenon of the Moon rolling across the horizon can be viewed and the winter Sun just peeks out around the times of the solstice. Today the views to the water are cut off by the rhododendron forest, in which you can find Gruline Stone A. Photograph (C) Gail Higginbottom

the lowest chain of mountains that sits on the other side of the body of water, running from the west towards the north. The most fascinating view at this site is in the south. We have the Moon at the southern minor standstill rising out of a very distant chain in the south so that as it moves up into the sky it rolls along the western flank of the closest horizon in the south; it then continues over the trough feature in the chain (usually created by two mountain chains either side of cardinal south at other sites on Mull) and then rolls along the top of the western side of the same chain, moving to the western flank, before continuing on to set into a low distant chain. For approximately $98 \%$ of its travels, the body of the Moon does not actually appear to touch the horizon, though its glow will. The alignment of Stone A to B is oriented $3^{\circ}-5^{\circ}$ north of the rising of this phenomenon, where the range width is likely linked to the uncertainties in the alignment intentions (such as the slight leaning properties of Stone B).

The equinoctial Sun is seen to rise out of the eastern flank of the eastern range and sets into the western edge of a low range. The winter solstice Sun peaks and rolls for a very short distance across the top of the trough of the southern chain; possibly appearing for about 8 minutes. The entire Sun then reappears towards the end of the day on the western flank of the southern chain and travels for about 12 minutes before setting into a more distant set of mountains in the SW. This would be a very dark and cold place in mid winter. The Moon at the southern major standstill is never seen, completely blocked by the southern ranges. 


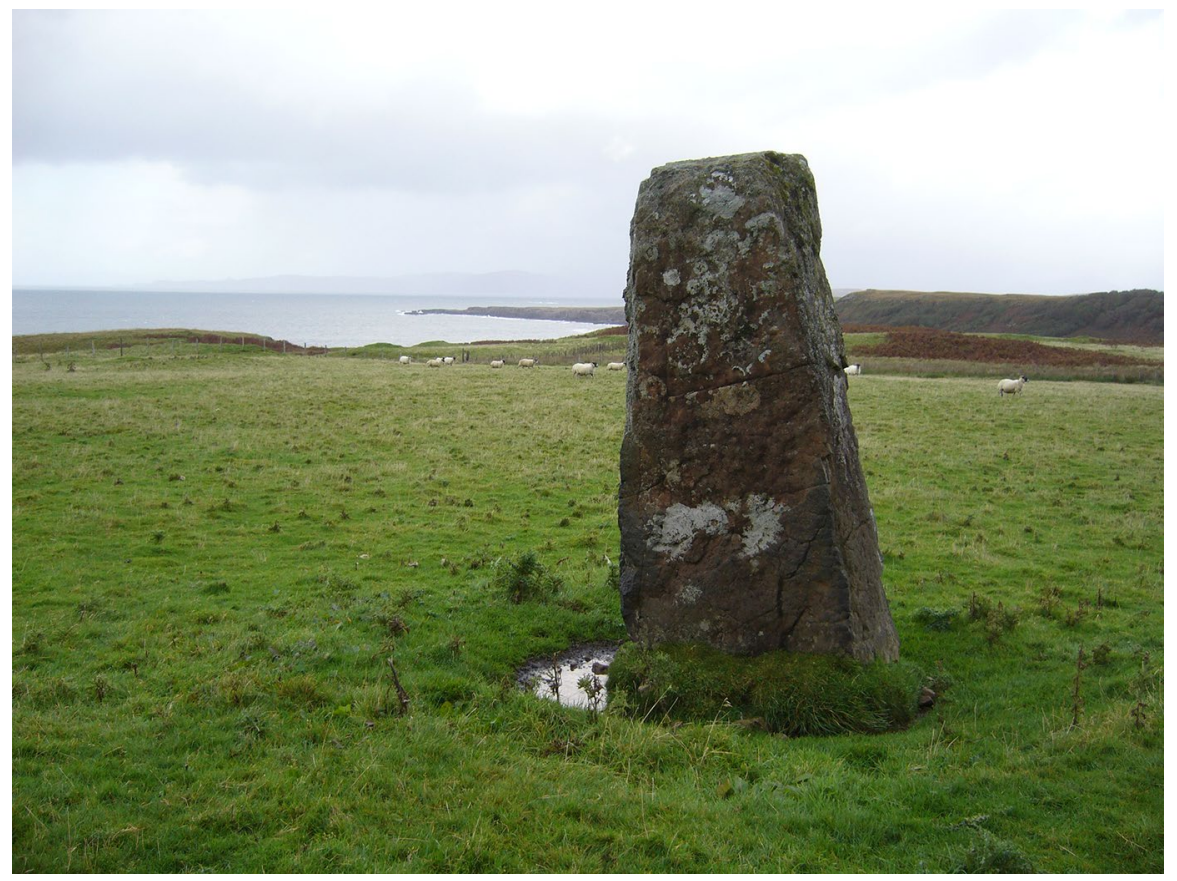

Fig. 13 Cillchrìosd. Sitting NNE of Mull about $1 \mathrm{~km}$ from the beach, this stone measures $2.6 \mathrm{~m}$ in height and $1.4 \mathrm{~m}$ by $0.65 \mathrm{~m}$ at the base. It is aligned NW and SE and stands in an open terrace in front of a local hill; the terrace slopes downwards towards the sea. Photograph (C) Drew Parsons

(a)

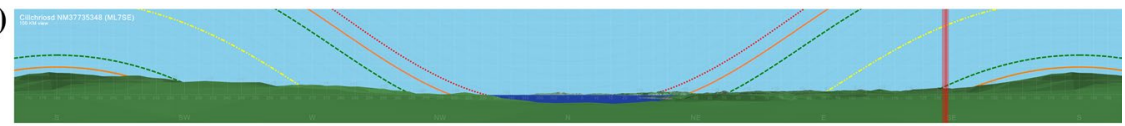

(b)

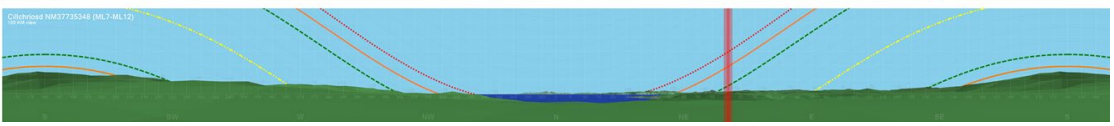

Fig. 14 Cillchrìosd (ML7). Cillchrìosd is the classic reverse landscape site in toto in relation to its surrounding horizon shape and other features. Here the most distant horizon is in the north, instead of south, and here is also the location of a large spread of water positioned such that its radius falls equidistant east and west of north. The summer solstice Sun, flanked by the minor and major northern standstill all rise out of the most distant peaks, where the peaks are barely visible. Crucially, these bodies' rising and setting basically flank the edges of the body of water. Thus, unlike the sites discussed above, the rising and setting Sun and Moon never travel over the water. a The orientation is measured along the alignment of the long-sides of the slab in the southerly direction (SE); b The orientation is measured along the alignment between Cillchrìosd and Quinish (ML2). Software and 3D landscape created by Andrew Smith. Based upon the Ordnance Survey 1:50,000 Landform PANORAMA map with permission of the Controller of Her Majesty's Stationery Office (C) Crown Copyright 
Stone $B$ (Fig. 12b): The general pattern of the landscape itself is the same, what differs is the placement of the celestial bodies rising and setting and the orientation of the alignment from Stone B to Stone A (Fig. 11b). The orientation is aligned to the NW, the setting of the summer solstice Sun into a peak of a chain across the water. Unlike the view from Stone A, the equinoctial Sun rises out of a large notch in the east and the minor standstill Moon in the south, once it has rolled along the top of the western side of connecting horizons, temporarily disappears behind them. Also the Sun does not reappear from the eastern flank but has set prior to midday. Once again, the Moon at the southern major standstill is never seen, being completely blocked by the southern ranges.

\section{Cillchrìosd, ML7}

Cillchriosd is a single standing stone measuring $2.6 \mathrm{~m}$ in height and $1.4 \mathrm{~m}$ by $0.65 \mathrm{~m}$ at the base. Its sides are vertical and the top is almost level (RCAHMS 1980, p. 66, no. 98, plate 7F; Fig. 13). This site is one of three of the first group, along with ML1 and ML2.

Looking at the 3D panoramas (Fig. 14a, b), the southern range of mountains is closest and dominates the horizon. The winter solstice Sun and minor standstill Moon rise and set over the most prominent peak in the south. Their mid-transit point equals that of the highest point of the peak almost due south. Cillchrìosd participates in two alignments, one on-site alignment oriented to the Moon at the minor standstill in the south (Fig. 14a) and one in conjunction with Quinish (ML2) on to the Moon at the minor standstill in the north (Fig. 14b).

\section{Comparing the Sites and Views on Mull: Final Observations}

By viewing the 3D panoramas designed for the project it can be seen that sites on Mull share many of the major landscape and astronomical cues. These astronomical cues, to which the sites were oriented, were initially examined separately to see if their patternings could have occurred by chance, and this was shown not to be the case. On examining the series of cues all together, it is clear that there is a pattern of opposition being set up: for instance, the pairing of distant southern with close northern horizons or the pairing of distant northern with close southern horizons.

The great variability found in the detail of the site locations on Mull is suspected to be a combination of the number of sites on Mull along with the vastly variable terrain. Naturally this brings the consistent patterning of the majority of sites into sharper focus. The basic horizon shape stays the same. For a few sites only, it was found that whilst the basic horizon shape stays the same (in terms of dips and troughs) it appears to have slipped around the compass somewhat in an attempt to include as many of the landscape cues as possible, for instance, the ability to view the winter Sun and southern standstill Moon for their entire travels over the horizon (remembering that in winter the Sun travels at a much lower angle across the sky, as does the full Moon at the southern standstill in summer). Thus, for example, a site 
could be chosen where distant and/or low horizons were available in the required direction. The occurrence of reverse sites, especially those in the vicinity of one or more classic sites which contain opposite topographical horizon shapes, also upholds a sense of the ideas and observations related to the theme of opposition.

For sites displaying the classic landscape pattern regardless of area, we can see that the celestial phenomena in the south rise up east of the water body and travel closely over it, setting to its west; the northerly phenomena also travel over this body of water. At many reverse sites where water is in view, though, whilst the paths of the celestial bodies still flank either side of the water, the celestial bodies do not actually travel over the water at all (see Fig. 14a, b, Cillchrìosd [ML7] as a typical instance). With the aid of these 3D DTM-derived panoramas it has been far easier to visualise and comprehend the locational relationships of water, astronomical bodies and landscape in this region of western Scotland than was previously possible, especially those relationships between the following phenomena: the specific paths of the Sun and Moon in the sky, the extreme rising and setting points of the Sun at the different annual solstices, and the Moon at the two major and two minor standstills, along with the landscape features.

The questions now are 'why was it important to be able to see all of these different phenomena at each of these sites?' and 'how were they seen?' That is, how did the imagery actually play out in the sky before the people at the sites? How did these events exhibit themselves over time? To answer these questions, two things are required. First it is necessary to have an understanding of some features of nakedeye astronomy or the visible celestial dynamics. Second, a description of the events must be created for the reader so they can understand how these events would have unfolded in real time in these settings before the viewers, that is, as the viewers of 4000-2500 years ago would have experienced them. For this a descriptive narrative is provided, which integrates information by using the building blocks of the previous visual descriptions and transforms them into representations of complex experiences. It is specifically in this way, as stated above, that the archaeological data, in the form of standing stones, can go from being a barely interpreted source to an informative construct (Gooding 2008, pp. 2, 9, 17).

\section{Celestial Movement Seen by the Naked Eye}

For this part of the interpretation, like Ruggles' work (see Ruggles 1999, pp. 118-123), we have chosen to focus on the hypothesis that the alignments on the Moon (whether for the major or minor standstill) were likely oriented to the Moon's rising and setting when it was full (as opposed to a half, quarter or dark phase). The reasoning behind this is that such a phase is often more majestic visually, and also, as there are a number of sites where the Moon travels along the horizon or possibly glimmers in various notches, these events would be both more noticeable and more visually striking when the Moon is full. It is also much easier to align to a large, rising circular body at night than, perhaps, a first quarter Moon rising around noon in broad daylight and not well visible on the horizon. By analysing the lunar cycles in some detail, Smith deduced the possible phases of the Moon in which the 
builders of the monuments may have been interested. In so doing, he provided links between season, solar movement, lunar movement and lunar phase (Smith, pers. comm.). Smith explains that there is no simple relationship between the solar and lunar cycles, so the phase of the Moon could be anything at all at a solstice, and this will vary from year to year. Regardless, a full Moon must always occur within two weeks of a solstice and, since the Sun is moving slowly around the time of the solstice, the relative movement of the Sun and the Moon remain largely unchanged throughout this period. If the Sun is at or near the summer solstice (in the north), the full Moon, which must be directly opposite the Sun, must be somewhere in the vicinity of the winter solstice point (in the south): the direction in which about half of distant horizons occur and monument orientations face. The converse is true in the winter: when the Sun is at or near the winter solstice point (in the south), the full Moon must be at or near the summer solstice point (in the north), where about half of the closest horizons occur.

As the time of the summer solstice draws near, the difference between the Sun's rising positions along the horizon from one day to the next gradually decreases, until ultimately the Sun appears to stop. The same is true of the Sun's setting points. During the week or so prior to the actual solstice, the day-to-day difference in rising (or setting) positions is so small that it is almost imperceptible to the unaided eye. References on the horizon (such as trees, peaks and notches) will help an observer track the Sun's rising and setting in this time. These observations of the Sun are also true at the winter solstice.

The day will come, though, when the summer Sun slows down its movement towards the north, and then eventually slowly accelerates southward. The actual turning point is the summer solstice. How this phenomenon appears to the naked eye is as follows: the Sun is seen to slow down its movement towards the north by the observation of the location of its rising and setting points. The Sun's motion over the day or two either side of the solstice is so slow that, to the unaided eye, it will appear to stop altogether. As the Sun's southward motion gathers pace it becomes apparent that it now rises southward of the solstice points, where a solstice point is the farthest northern location on the horizon that the Sun is seen to rise and/or set.

If one wanted to find a place from where the full Moon and the summer solstice could be observed at the closest coincidence in time (possibly as close as the same day), this could be estimated or closely predicted through observation over approximately one lunar cycle of 18.6 years. The calculation would be made by marking out the maximum rising and setting positions of the Moon for each month using stakes and noting the phases of the Moon during these times. It could take at least three generations, though, to predict these things with any real accuracy.

The description that follows will focus on one site as an example, but note that the main features of the relative celestial movements are set up in the same way at every single site, so that similar events were visible at each of the stone sites on Mull. Also the relationship between the basic celestial dynamics and the general landscape profiles are highly comparable across the sites, as evidenced above. Importantly, differences in detail would be brought about by specific landscape shape (e.g. altitude in a certain direction) or the number of inter-visible sites or stones and their visible relationship with each other. An understanding of the celestial dynamics, along with the 
example given below, indicates very clearly that what people can observe is dependent upon when they are looking (i.e. time of day, time of year, point in a cycle). The interplay of the celestial bodies is intimately tied to the seasons, the landscape, the monument location and alignments and, all together, these create a visual spectacle (whether or not the event was to be repeatedly observed).

\section{Descriptive Narrative}

The example used to highlight the complexity of site set-up in relation to the land- and skyscapes is again the site of Gruline (ML16). Remember that this is made up of two standing stones, approximately $250 \mathrm{~m}$ apart, where the thick slab (Stone A; Fig. 12a) is oriented across the line joining the two stones. The other stone is lozenge-shaped (Stone B; Fig. 12b). Here we have the example of those reverse landscapes found in Mull where the most distant horizon is found in the north, and the closest and visually dominant occurs in the south. The actual shape of the horizon remains the same and water is still in view. Gruline is impressive for a number of reasons. As well as participating in an alignment with Killichronan (ML15) with an orientation upon the glimmer of the rising Moon at the major standstill, the site Gruline itself contains two significant orientations, created by the alignment of the Stones 'A' and 'B': one towards the setting of the Sun at the summer solstice and the other towards the rising of the northern minor lunar standstill. What we have at Gruline in mid-Mull is the locational pairing of single stones that create the visual pairing of alignments: one on the Sun and one the Moon, similar to the neighbouring stone rows of Dervaig in the north.

The description of the events seen at this site will be based upon real astronomical events that were indicated by the sites' locations and orientation occurring at the summer solstice. This narrative also incorporates activities that people would have to conduct at this site to observe these visible events. It is written to maintain the theoretical visual concepts: (i) the viewing point is the place upon the Earth at which a person existed and looked out; and (ii) this is a person-centred world which has thus become a more contextualised place through the action of seeing. This ultimately means that the entire viewscape from the monuments creates the context.

\section{The Reconstructed Narrative of the Summer Solstice}

(All references to astronomical events and landscape locations are real physical events or real 'places'.)

It is summer. Wherever observers stand on the greatest or smallest isles, they can see that the differences between the Sun's rising and setting positions along the horizon are getting less and less each day. They now know that the great event of the summer Sun approaches, the summer solstice. Soft light is 
now continuous through the night and, after the Sun drops below the horizon, it is still light enough to carry out ordinary domestic activities for some hours. At this time, some individuals/groups travel to a designated place on a specified island where some are able to stand with the Gruline Stone A closest to the sea in the west (ML16a; Fig. 12a) and the others with the Gruline Stone B (ML16b; Fig. 12b) closest to the highest mountains in the east. Each night over the next few days, participants stand at these assigned places watching the Sun and the Moon move closer to their anticipated positions. On the marked day, they can see the Sun rising in the northeast and, with this, morning twilight passes. Unlike those at 16a, those standing with the sea-facing 'witness' stone (ML16b towards 16a; Fig. 11b) can see the Sun rise out of the dominant northern mountain chain and run along its edges for a short while (c.f. Fig. 11a, b). As time goes by, all observers may turn to watch the daily progress of the Sun: firstly towards the east then towards the south; and then southwest as it traverses the sky and moves across the water and peaks; later, observers can turn to face the west and northwards again to watch the Sun set into the dominant range in the northwest. However, it is only those standing with the sea-facing stone (16b) that are clearly directed towards the exact and appropriate setting position of the summer solstice Sun. The people standing here can look along the line that runs westward between the sea- and mountain-facing stones and out towards the precise hilltop upon which the Sun will set behind the sea, and witness the point at which the Sun touches the Earth (Fig. 11b). These observers then look east, in anticipation of the next imperative encounter.

The people standing by Gruline Stone A (ML16a), the one that effectively 'witnesses' the intersite events on the mountain, may now look along the line drawn between this stone and the sea-facing one towards the east (Fig. 11a). Specifically, these observers are guided by the two stones to watch the most distant mountains in the southeast, hoping for the full Moonrise (at the years of Minor Standstill). Almost immediately, the full face of the Moon appears, large and bright; it then begins to roll along the nearby southern horizon. Initially the twilight is broken on the horizon and across the landscape in the direction opposite: the participants in the event are surrounded by light, though the amphitheatre directly under the hill still contains 'darkness'. Those present do not have to move, as they can follow the progression of the Moon from rising to setting by merely rotating their heads. However, it is only those located at the mountain-facing stone that can watch the lunar disc as it travels in its entirety over the dominant range of mountains in the south: from there the disc is never seen to fall below the horizon. They can witness the Moon's unbroken trail during its lowest and most southerly path in the sky, when the Moon appears to caress the Earth.

At this point, all observers, would be aware that the setting of this summer Sun would signal the start of the return of coldness and darkness, and thus the next cycle of life. The night would appear alive with light with the Moon coming 
into contact with the Earth for the last time this night on the highest mountain-top. In the morning observers can see the turning of the Sun, waiting and looking along the line made by the 'witness' stones, towards the horizon. As the Sun creeps into view, it will be clear that it has made its way slightly further east around the horizon and a little higher up the slope towards its winter home; it has begun the journey towards the direction of the inferrably possible eternal night, when evenings lengthen and the winter solstice approaches. So here people have experienced complementary positioning, for in the pairing of the stones, the stone closest to the mountain witnesses the sea and the Sun, and that closest to the sea witnesses the mountain and the Moon.

\section{Understanding the Experience and Meaning of Winter Solstice at Gruline}

(C.f. with Hough and Barrapol on Coll and Tiree in Higginbottom et al. 2015, pp. 636-640.) For the winter solstice, there are two obvious visual experiences at reverse sites that are essentially the opposite of what is experienced at the summer solstice, namely the Sun rises and sets in its southernmost position, with a possible full Moon appearing in its northernmost. This is all the more striking because of the Moon's occurrence in deeply dark skies on the longest nights of the solar year. In winter, a full Moon can bring light for a far greater time than the Sun because the Moon travels above the horizon for longer, over greater distances, for, in these latitudes, winter has only about six hours of daylight. However, Gruline, along with most other reverse sites on the Isle of Mull (6/7), is distinct because, unlike at the classic sites, you cannot see the full Moon at the time of the major standstill travelling in the south at mid summer at all. Further, Gruline itself is exceptional, because the Sun in winter is hardly ever seen, creating even more striking visual effects. There could be Sun glow, but the body itself is rarely visible.

At this site at and around the summer solstice, the brightest days contrast and herald the approaching darkness of winter. For the people in charge of the site of Gruline, this is a grim possibility, for when the Sun returns to its winter home, it might keep moving southwards, never to return, and the World would freeze over and come to an end. The way that the viewscape has been set up allows the landscape and cosmological bodies to play out this possibility at Gruline-a play of cosmological magnitude with the force of a threat and the removal of that threat. This is seen in six acts of 'the play' and can happen, be seen, or understood as follows below.

The scene: midwinter: the solstitial Sun only appears from two notches in the mountains in the south, one on the east side of the mountains and one on the west side. Fascinatingly, both of these can only be viewed from megalith ' $A$ ' (our stone of 'the Mountain and the Moon'). At Stone 'B', the Sun can only be seen once, in the southeast. 
Act one: as the winter solstice draws near, the valley is still in twilight, even though more than half the morning has passed. The Sun suddenly glimmers brightly from a notch in the closest mountain range as it ascends in the east, never breaking away fully from the hills. Then, suddenly, it disappears and the valley is veiled once more in twilight, which quickly becomes darker. The Sun has been taken from the World.

Act two: much of the day has gone by and the valley continues to be veiled in gloom. Observers can watch a notch on the west side of the mountain and hope for the Sun's return.

Act three: the Sun suddenly reappears moving away from the mountains and filling the valley with light and warmth for about thirty minutes before it naturally descends and sets.

Act four: observers wait and watch. The Sun has appeared to follow the above pattern for some days. Will this pattern be broken? Will the Sun stop reappearing from the behind the mountain? Or will it keep reappearing? In doing so, will it reappear and begin to rise and set away from the south and towards the north and bring promise of the summer to come? Will the Sun turn? Will it break away from the mountain of darkness?

Act five: at last, the next day the Sun rises more easterly within the notch, the Sun has begun to turn and this brings with it the assurance of summer, but then it disappears again into the mountain, the answer is unclear. But each new day offers more hope as the Sun stays up longer in the morning and in the late afternoon/evening.

Act six: after some days of this pattern, eventually the Sun leaves the mountain of darkness and rises and sets freely across the sky at Gruline, all threats have passed. The World begins here.

However, there is more than one play per season, for the Universe is complex and the bodies of the sky and the light are interwoven in a cosmological dance that seems to go on forever, with repetition and variation, and as one pulls, the other pushes and as one appears, one can disappear. Thus, dramatically, if there is a new Moon at the winter solstice, and this Moon is at the major lunar standstill, it will be hidden behind the southern range along with the Sun. Thus at this site you can also have the darkest of days and the blackest of nights, where the body of the winter Sun is barely seen and the Moon neither rises nor glows above the horizon. Perhaps this actually plays out the ending of a World, creating a time of alternating twilight and darkness or at least a time of edging towards an end. So the positioning of the bodies in this play could potentially play out even more dramatically than the example play above.

And so we can see that Gruline, a reverse site, is likely also associated with winter, darkness, and threats, but also the possibility of a future and summer and with that the continuation of life. Here we have seen the turning of the Sun at the winter 
solstice. This was likely a well-observed and eminently significant event, for, as it approaches the turnaround point, as stated above, the audience would wonder if the Sun would choose to return to its travels in the north and bring with it longer, warmer days. Then the cycle and the World begins again (as observed by the existence of other natural events like winter crocus and late winter/early spring bulbs). Thus, at this site, the arrival and departure of the winter solstice Sun and the alignments with Sun and the minor Moon at the Summer solstice are key reasons for its existence.

\section{What We Have Seen at Gruline}

Both the summer and winter solstices are relevant for this site. From Gruline in summer, for instance, we have seen that the Sun could be observed reaching its highest point in the entire year and its most northern points along the horizon. Further, the Sun travels along its longest path across the sky, keeping it above the horizon for the longest time, and with the rising of the full Moon, bright light never leaves the Earth on the longest day. The minor Moon in the south and north is tied to the Sun's motion by being observed within the boundaries of the rising and setting points of the Sun at the summer and winter solstices. In summer, whilst Stone 'B' (ML16b) has strong visual ties to the Sun at the solstice, this is only through the indication of the Sun through the alignment with Stone 'A' (ML16b to M16a), which tells one where to look. Also Stone 'A' has selected, powerful visual connections with the Moon, through the indication of the Moon via the alignment with Stone 'B' (ML16a to ML16b). Each of these megaliths, then, represents a particular celestial body as well as the stages of the interplay of these bodies with the Earth.

Further, it is only from the Stone of the Mountain and the Moon (Stone A) that one can observe a clear focus on the Moon rather than the Sun, in relation to the intersite alignments. For, from Stone 'A' one can see the minor standstill Moon rising as the primary celestial body near the tops of the prominent range in the NE, whereas the summer Sun is seen instead to rise out of a much lower peak to the north of the minor standstill Moon. Further, the equinoctial Sun appears on the lower flanks of the northeastern-eastern range. This further suggests that this stone is more directly connected to the Moon than the Sun (Fig. 11a, b). At this place of monumental alliance, it is clear that people could come together to participate in this cosmic cycle, and possibly see the force of both the Sun's and Moon's powers in one day at either of the extreme seasonal 'points' of the solstice. The rising and setting points of both of these bodies are vitally connected to the combined locations of the mountains as well as the shape and distance of the horizon.

\section{Discussion: Interpretation of Monument Context}

Ultimately, as for the work done on Coll and Tiree, at each of these sites we have the coming together of the liminal properties of morning and evening, the horizon, and of twilight, where the moments of the rising and setting of the solstitial Sun 
occur, with the summer and winter solstice themselves liminal occurrences prior to the Sun's turning and returning to its sojourn towards the south or north. Here we can also see the continual theme of opposition at work: levels of light and darkness, morning and evening, turning southwards at the summer solstice and then towards its opposite northwards at the winter solstice, the Sun rising within one half of the sky and setting in the other, stillness and activity, extremities of farther and closerall of which are embedded with various notions of beginnings and endings (Higginbottom et al. 2015, p. 638).

Obviously many of these oppositions are created through the natural interplay of celestial geometry and the dynamic phenomena. What is relevant is: (i) that it is the phenomena at the extremes that were of the greatest interest (like the solstices: the Sun's most southerly and northerly rising and setting points); (ii) that it is at these extremes that the interplay of opposites is most noticeable; and (iii) that such interplay was the focus of human contemplation in the second millennium BC. Indeed, if the point at these sites was not to regularly observe, but primarily to create a material connection with this cosmic order, this too has been done.

We know that numerous cosmological plays can occur and that each extreme season potentially contains the power of the other, for their cycles can be said to contain the opposing cosmological forces that provide the balance of existence on different levels of being (c.f. Sims, in press). What we have here, at these Late Bronze Age sites, is strikingly similar to the Scottish great circles, as well as the Stonehenge enclosure, namely a solar-lunar cosmological system (Higginbottom and Clay 2016a; c.f. Pollard and Ruggles 2001, p. 19; Sims, in press).

Thus, for these Scottish sites at least, most of what goes on does not appear mutually exclusive. For there is indeed a suite of shared ideas expressed through a wide variety of practices, where the variety of practices here could mean the creation of superficially different monuments (c.f. Bradley 1991 in Pollard and Ruggles 2001, p. 19; Gillings 2015, p. 227). Yet this does not disqualify a host of different ideas and beliefs being also 'expressed through a restricted repertoire of shared practices' that we can also see across these various sites (c.f. Gillings 2015, p. 227). Rather, we could be seeing a type of balance-a creation of harmony of 'opposites' and/or 'converses' (q.v. Higginbottom et al. 2015; c.f. Sims 2006). Only further work, including excavation in western Scotland, will deepen our understanding.

Ultimately, both the architecturally simpler monuments and the great stone circles, are connected to an ideology of working with the environment as a whole (land, water, sky, and the bodies in the sky: Higginbottom and Clay 2016a; Higginbottom et al. 2015 and see above), even to the point that they share an interest in the same ones - their locational choices and their alignment foci. Where they differ is in the visual detail of the show created at local, individual sites. This difference occurs because of the combination of the entire horizon profile at each site (which cannot be repeated exactly across every site) with the solar calendar and/or the lunar calendar. These combinations affect what other bodies and events can be seen and will therefore dictate the unique views of all astronomical 
bodies and lighting effects found at individual sites (Higginbottom and Mom 2018, 2020).

Earlier in this paper, it was noted that the orientation on north and south might indicate the times of day at the solstices or standstills, for these positions indicate midday or midnight, as described for sites on Coll and Tiree in Higginbottom et al. (2015, pp. 625-626, 632). Very recent work done in Stellarium supports this idea, for not only did we find the Sun's glow at cardinal north at midnight at and around the summer solstice, but it was also found that certain constellations or celestial bodies reached particular points (like north, east or south, or in line with the orientation), at particular times of day such as midnight, during the epoch around 1500 BC (Higginbottom and Mom 2018, 2020). The most striking of these is the constellation of Ursa Major, which lay horizontally at midnight on the summer solstice over north and in winter stands vertical just west of north at $9 \mathrm{pm}$, which, due their high vertical position, can be seen at all sites. At Ardnacross, this was actually directly in line with one of the stone rows.

The results of past and present work by the current author show that the megalith builders were 'observational astronomers' in the broadest sense, and that they understood the paths of the Sun and the Moon and other bodies through their complete cycles. For this reason, it is clear that the builders could not have failed to observe these visible astronomical patterns that divided the day into half, quarters and so on, making the occurrence of alignments to cardinal north and south all the more likely.

It is of interest that the Maya are said to have equated cardinal north with zenith and up or above, and cardinal south with nadir, down or below (Mendez et al. 2014, p. 63), and thus the indications connect to a multi-layered understanding of the astronomy, which are then interwoven with applied mythological law and understandings of their world order and the greater cosmos (Aveni and Hartung 1986, p. 8, cited in Mendez et al. 2014). Such connections also applied to the Inka (Farrington 2013, pp. 325-358). This paper takes on these same interpretations for the standing stones of Scotland. For Scotland, as for these American groups, the astronomical information gained and represented by the architecture of a site replicated the 'cosmic principles of ... order' that possibly formed the basis of religious thought (Aveni and Hartung 1986, p. 8). In this way, then, this paper argues that standing stones linked the cosmos to earthly events as a powerful affirmation of the divine or other-worldly in a place and time (Mendez et al. 2014), where the timing can be a mythological time, large cycles of observable years (like the 18.6 year cycle of the Moon), a divided year, or within a day. In the case of standing stones, the cosmic principles of their builders were acknowledged to lie above, upon and below the Earth. Thus all these times and places were indicated by the locations of the standing stones and their alignments, where the 'up-ness' and 'down-ness' of the cosmos is actualised by the paths and the travels of the astronomical bodies, stones driven into the earth and standing above it, the 'geography' or cardinal points of the horizon, and the relative positions of the living and the dead. These notions link well with Gillings' ideas: 
That active concerns with reversal and inversion had broader currency during the second millennium BC is strongly suggested by sites such as the Holme timber circle (Brennand et al. 2003). This opens up a very different reading of the Porlock Circle, where the surviving fabric hints at alternations between stones set upright and down - in effect two circles interwoven; this perhaps mediated by a third involving the larger sloping stones we now know were deliberately set in angled stone holes (Fig. 14, stones 1, 4, 17 and Feature 6). Rather than a single circular motif embedding a single metaphorical meaning, we have potentially three, very different circles perhaps coming together to create something far more than the sum of the individual parts; all expressed through the same basic practice of stone erection. ... Where researchers have identified strong topographic and lunar significance in the organization of monumental structures in other parts of the country (e.g. Bradley 2005), the results from Porlock suggest that a strong chthonic element may also have been in play in the southwest if not more broadly, and as well as looking up (to the heavens) and across (to the surrounding landscape) we also need to consider looking down (Gillings 2015, p. 227).

The conscious interpretation, or consideration, of one's widest environment is no trivial act, for it means that 'ordinary thinking (of a human being) is given over to contemplation of something patently beyond, and greater than, itself', in this case the sky and land (Davidson 1985, p. 9). It is clear from the placement of the megaliths across western Scotland that such contemplation has occurred and is mirrored by the creation and erection of these stones. In particular, as intimated above, ideas and notions linked to the complex forces of transformation and opposition are apparent across all sites. In the views to the north and south of the megalithic monuments we encounter transformation at many of its most fundamental levels, and these transformations are expressed as topographical positions of liminality. We have the edges of the World nominated by the horizons upon which the various transformations of the Sun and the Moon are witnessed (q.v. Helskog 1999 cited in Bradley and Nimura 2013, p. 14).

\section{Conclusion: Interpretation of Monument Context}

As quoted in Higginbottom et al. (2015), it is still uncommon for "prehistorians to move beyond generalised statements and toward the detailed interpretation of particular beliefs and ceremonial practices' (Harding et al. 2006, p. 27) or indeed towards deep reflective considerations of what the cosmological systems might be, in particular within British archaeology (exceptions include Bradley 2012, 2013; Bradley and Nimura 2013; Burl 1981; Darvill 1997, 2016; Gillings 2015; Parker Pearson and Ramilisonina 1998; Parker Pearson et al. 2011; Pollard and Ruggles 2001; Richards 1996b, 2013a, b, c; Sims 2009, in press; Whittle 1997; Whittle et al. 1999). However, it is clear that, with apparently simpler standing stones at least, we can now move beyond very simple statements when 
we consider the new evidence above, including most recently that revealed by the use of Stellarium (Higginbottom and Mom 2018, 2020) as well as that found previously for Coll and Tiree (Higginbottom et al. 2015). As explained earlier in this paper, it was previously argued that likely Bronze Age free-standing megalithic monuments were the materialization and acknowledgement of past people's cosmology and cosmological forces, as indicated by the stones' location and their various associations (Higginbottom et al. 2015, pp. 639-40). These forces are various and rely on many site components each playing a role, where the standing stones were considered living witnesses to the very cosmological order upheld by the builders of the monuments. It was argued that this was understood and manifested by the creators of the sites. It was further speculatively argued that through the combined 'power' and juxtaposition of the special cosmological events (like the extreme points of the Sun and Moon's positions on the horizon before they turned back, the full or new Moon at these times, or even eclipses) and the transformed dead (cremations), the stones were given the power to see what the living could (Higginbottom et al. 2015, p. 639). It is here, then, that the work done on Coll and Tiree is now clearly reinforced by that done on Mull, Argyll and Kintyre. It should be noted that the astronomical-landscape patterns have been noticed but not yet fully investigated on Uist (Higginbottom and Clay 2016a) and Islay and Jura. Together the outcomes for these close regions clearly continue to dovetail with Kirchner (1955), Cooney (2000) and Taçon's (1994) earlier ideas. In particular, this work on western Scotland further underscores what the actual belief systems of the creators of the standing stone are likely to be.

Significantly, in a similar way to Bradley's (1998) argument about the circularity of the Late Neolithic and Early Bronze Age monuments of the British Isles, this paper examines archetypes, both in monument forms and landscape choices (1998, pp. 101-115). It is these archetypes, or repeated patterns, that imply a possible shared cosmological worldview. Further, it has been shown, that with the horizon as a continued focus in the creation of monumental places, circularity continues to be of importance. For in the Late Bronze Age, it is the horizon that defines and creates the realm of the theatre of action and upon which the acts of Nature are played out.

What has not been shown is whether it was necessary to keep observing these displays over the years, or whether the mere connection between the astronomical body and the monument or site was the entire or main point of the construction (q.v. Pollard and Ruggles 2001). Our field investigations into the presence or absence of heavy foliage in and around the monuments, or even the regions in general, will assist us in our consideration of these matters as well as the design of the models themselves. Geophysical surveys, excavation, and pollen and soil analyses are seen as the next major steps. Specifically, it is necessary to recover dating evidence and material culture, both of which are lacking compared to the number of standing stones; and from pollen and microscopic charcoal analyses, it is important to determine things like tree cover and land use around the monuments to better contextualise the monuments and add this information to the $3 \mathrm{D}$ panorama models. 
It can be argued that, from a Heideggerian point of view, having been created by a community, the megalithic monuments themselves gather, focus, direct and manifest the self-interpretations of that same group. The monuments have been used to both appropriate and disclose the events and objects in the landscape in order to define and display what is meaningful to the creators. The creators of these monuments have demonstrated the meaningful presence these things have for them through material production, and through this have defined their own 'meaning of Being' and that of the monuments (Heidegger 1971, p. 86). The meaning of these monuments for the people that built them and those who come after will continually be defined and redefined. Most importantly, we have seen that these places engendered the power of life and death, of acting out the greater cosmological world, as well as observing it. Through creating the opportunity to observe it ourselves, we can see that this World was understood as a series of oppositions and a continuity of cycles. People created places that embodied their universal laws, illustrating how the World worked (q.v. Gianoi et al. 2011, p. 402), 'along with the sense of "timelessness" and unchanging order of the universe' (Pollard and Ruggles 2001, p. 19).

Through the results of this work, as mooted in Past Considerations and Interpretations above, we might be coming closer to Hodder's idea of entanglement and an understanding of how this might play out. These past peoples are inextricably and co-incidentally intertwined, ensnared and entrapped by the things they make, as well as the things around them, funnelling the people towards a future not entirely of their own making from which there is fundamentally no clear escape (Hodder 2012, 2016, pp. 8-12). What is important here is not what they are funnelling towards (which is an important concern for Hodder) but rather 'why?'. This paper tentatively suggests that perhaps we are ensnared because we are not separate from things but are things, a materiality, and it is this that actually provides traction for our entrapment. Further, past peoples likely recognised this, and we can see dualist understandings taking shape, as discussed above, which were perhaps created to escape such entrapments; a belief that, by becoming 'immaterial' in some way or having 'immateriality' in your belief system, you could now overcome the entrapment and prevent the funnelling towards a future not entirely of your own making. This recognition of the constraints of their material existence is highlighted by the symbols of transformation and opposition at the sites, as well as, perhaps, a recognition of their hope for the existence of the divisibility of existence in order to escape the entrapment. Hence their belief systems include notions of the unbounded-where non-material sides of reality are believed to coexist with the material, and through these possibilities break the chains of the material world. It is speculatively suggested that cremation is one way people tried to escape these material constraints. Conversely, or in opposition to this, to have an unbounded world around you was dangerous.

Through the construction of stone, water, the land, the cremated dead, and specific astronomical phenomena, these builders of monuments produced dramatic bounded visual events in time, played out using a spectacular show based on light and darkness, and-manipulating these through positioning-demonstrated the significance of the Sun and its connection to life, and the connection of its 
absence to death. Thus, for the creators of the standing stone monuments of western Scotland, these sites embody the fundamental knowledge of Being or existence, and the opposite of these: places that pronounce the World begins here, the World ends here.

Acknowledgements I am particularly indebted to Andrew Smith and Roger Clay, both of the University of Adelaide. Andrew Smith invented and constructed the 2D and 3D panoramic software that enabled the work to be done in the first place and fascinating discoveries to be made, as well as offering consulting assistance over many years in astronomy, statistics and research generally. Roger Clay was there to advise and supervise much of the scientific method when the project began as a $\mathrm{PhD}$ project and again today. It was he who suggested investigating the circular statistical method originally developed for cosmic-ray physics. Through this, and other tests, the breadth of interest in astronomical bodies by people across prehistoric Scotland was discovered and quantitatively confirmed. I am indebted to Clive Ruggles and the work he has done; we have used his raw data to assist us in making these discoveries. A special thank you to Thomas Whitley who read some earlier versions of this work and offered helpful advice, along with producing the attractive panoramic photographs. I am grateful for the hard work of the reviewers of my paper as well as that of the editors of this volume (Timothy Taylor, Editor-in-Chief and Sarah Wright, Managing Editor; especially Sarah, whose attention to detail was phenomenal). I would like to thank those who gave us permission to use their photographs for publication in this work: Douglas Scott, Drew Parsons, Ewen Rennie, Chris Bickerton and Joanne Wright. Any remaining errors are my own. This project has received funding from the European Union's Horizon 2020 research and innovation programme under the Marie Skłodowska-Curie grant agreement SHoW No 800236.

Open Access This article is licensed under a Creative Commons Attribution 4.0 International License, which permits use, sharing, adaptation, distribution and reproduction in any medium or format, as long as you give appropriate credit to the original author(s) and the source, provide a link to the Creative Commons licence, and indicate if changes were made. The images or other third party material in this article are included in the article's Creative Commons licence, unless indicated otherwise in a credit line to the material. If material is not included in the article's Creative Commons licence and your intended use is not permitted by statutory regulation or exceeds the permitted use, you will need to obtain permission directly from the copyright holder. To view a copy of this licence, visit http://creativecommons.org/licen ses/by/4.0/.

\title{
Appendix
}

\author{
See Tables 1 and 2.
}




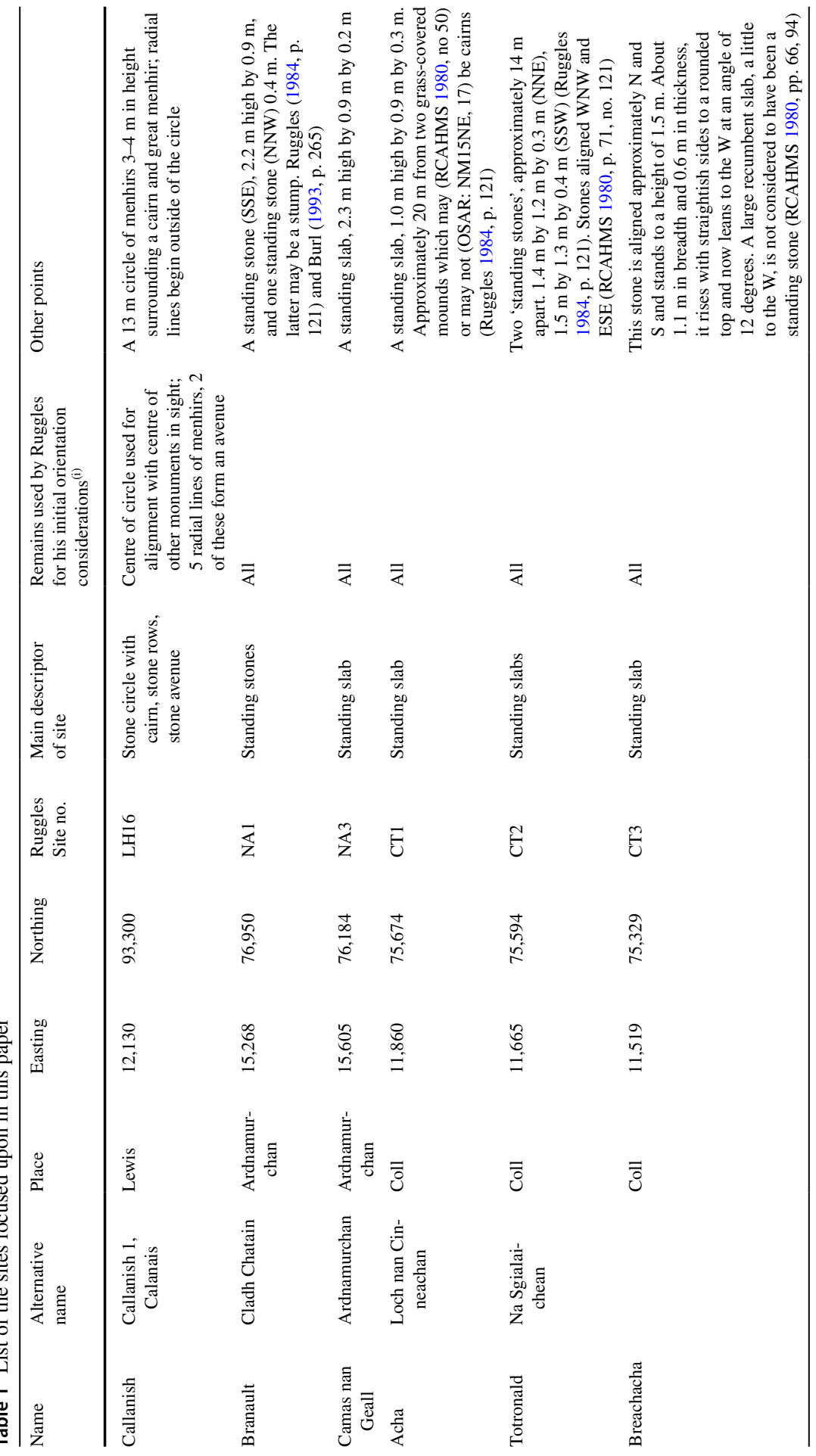




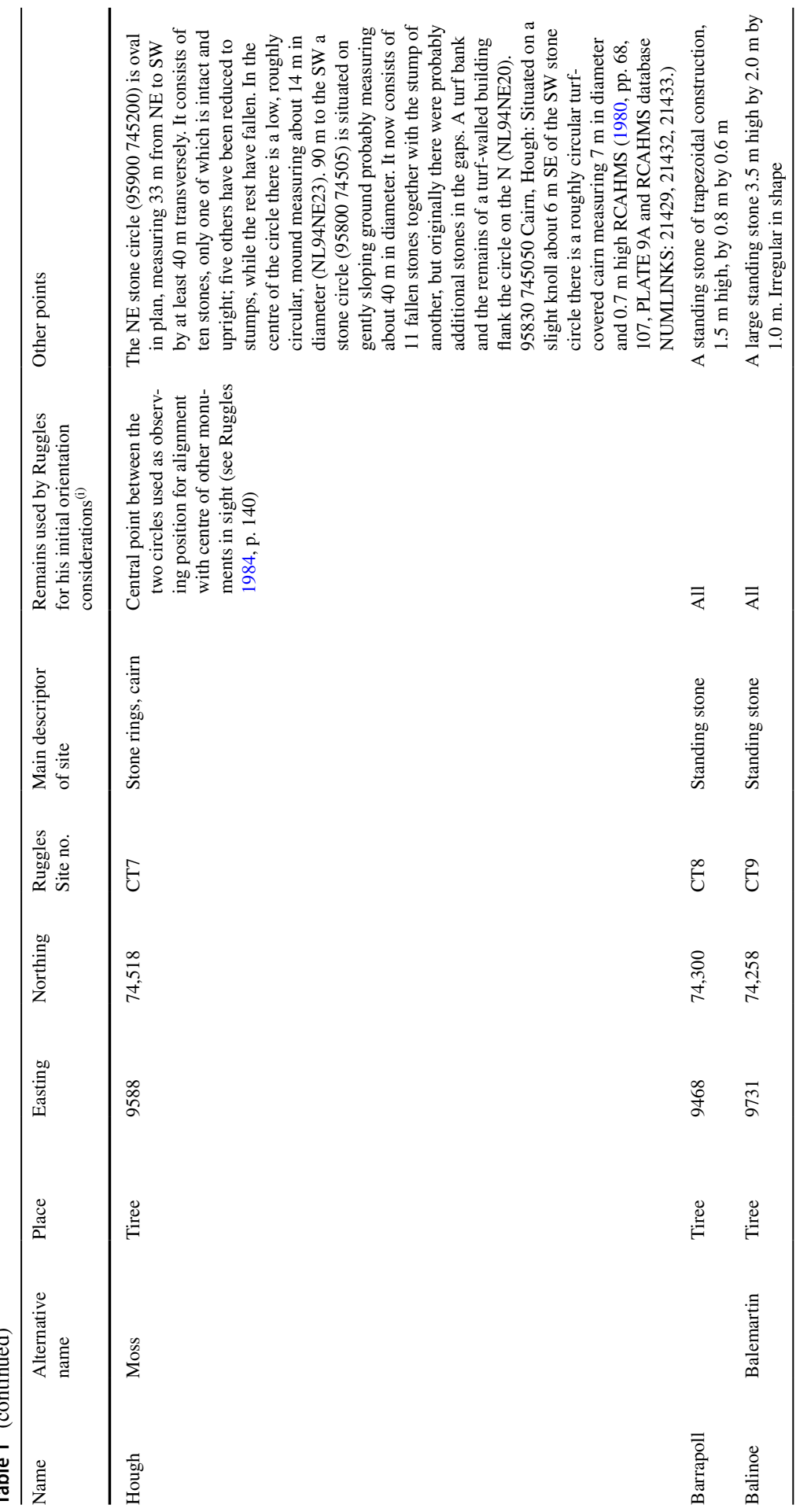




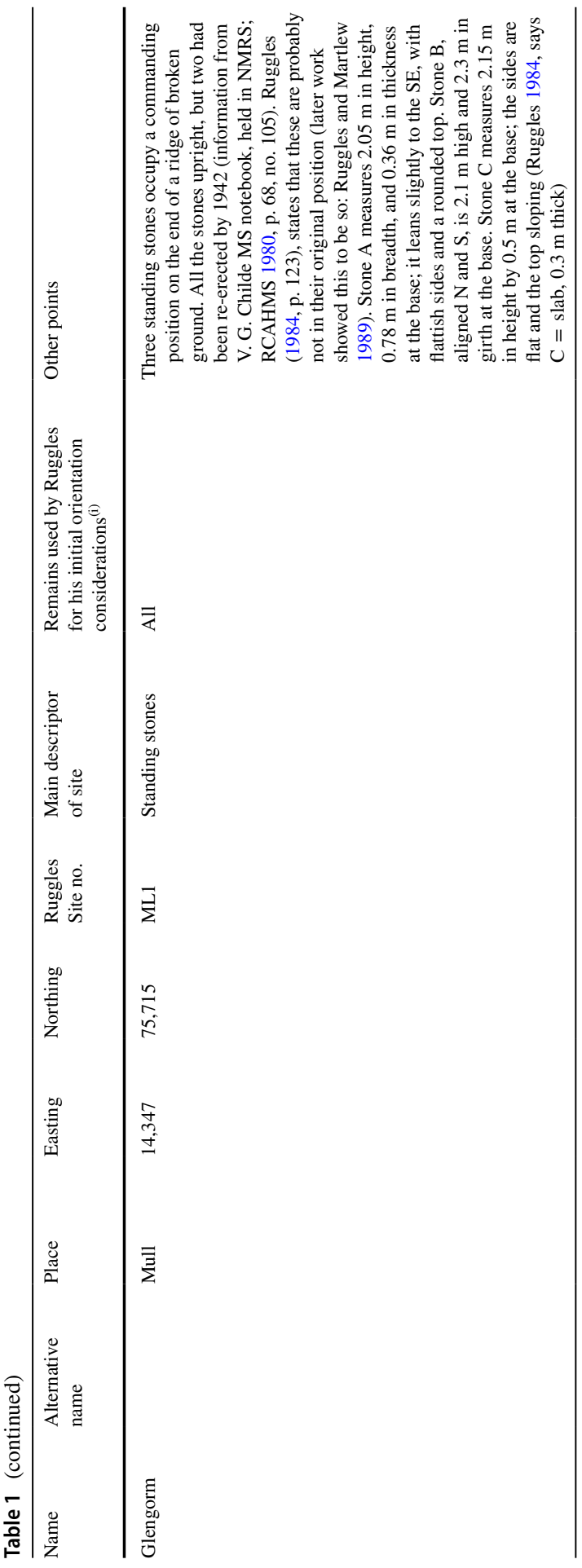




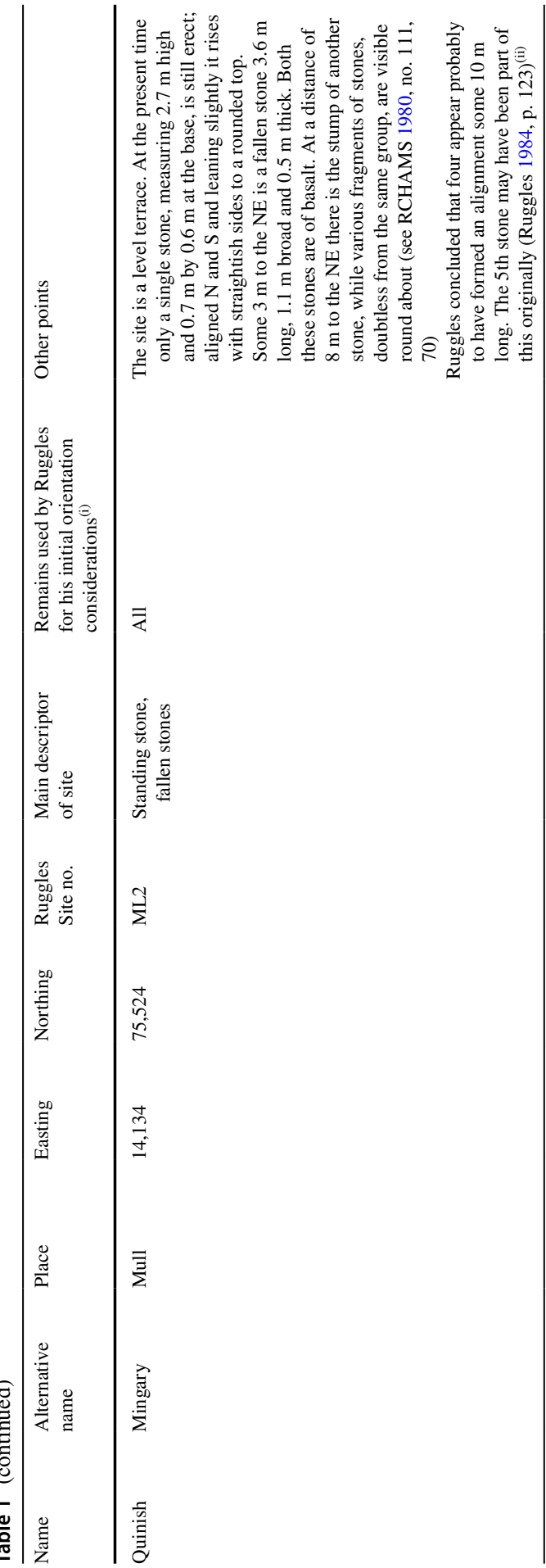




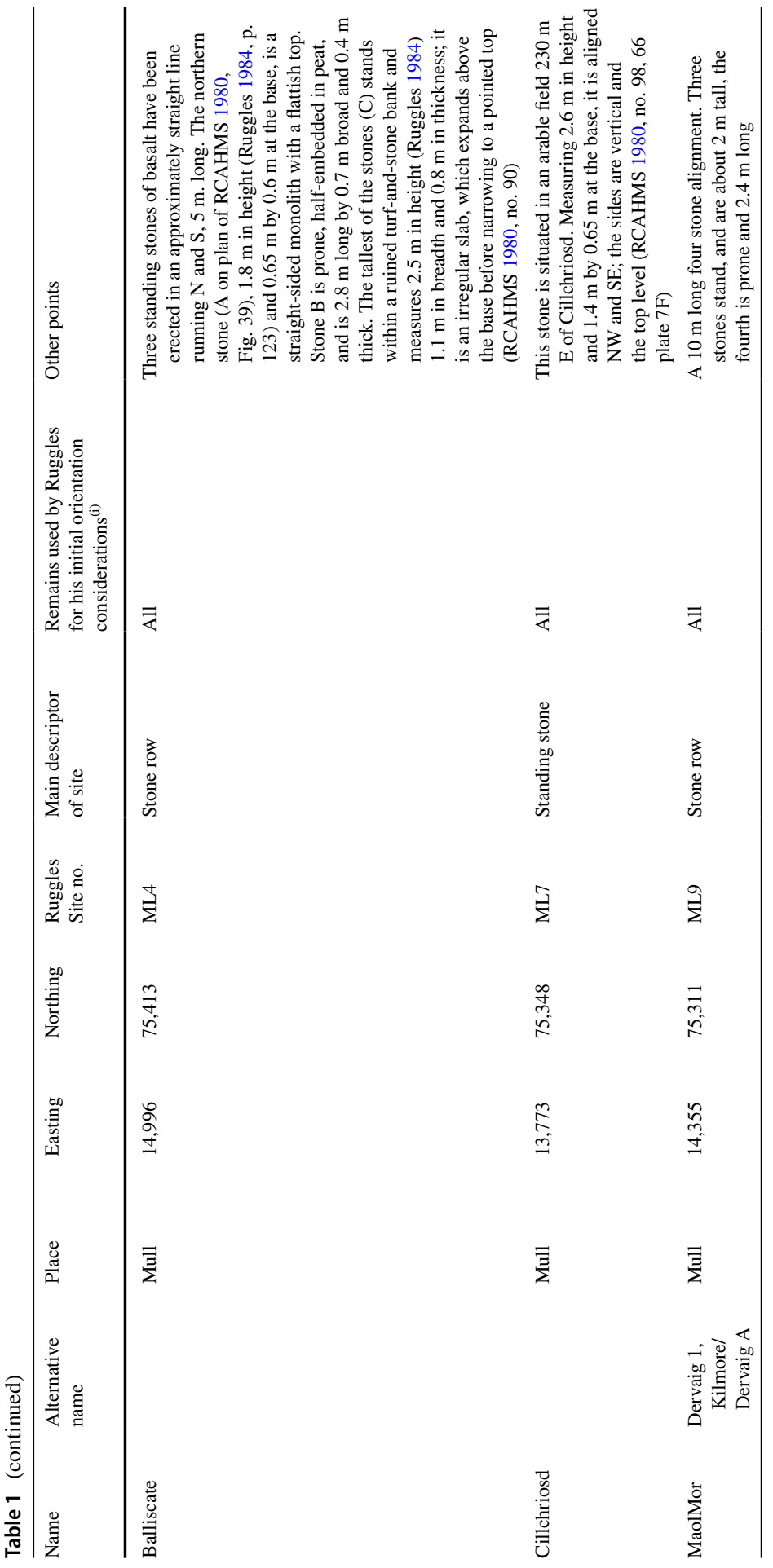




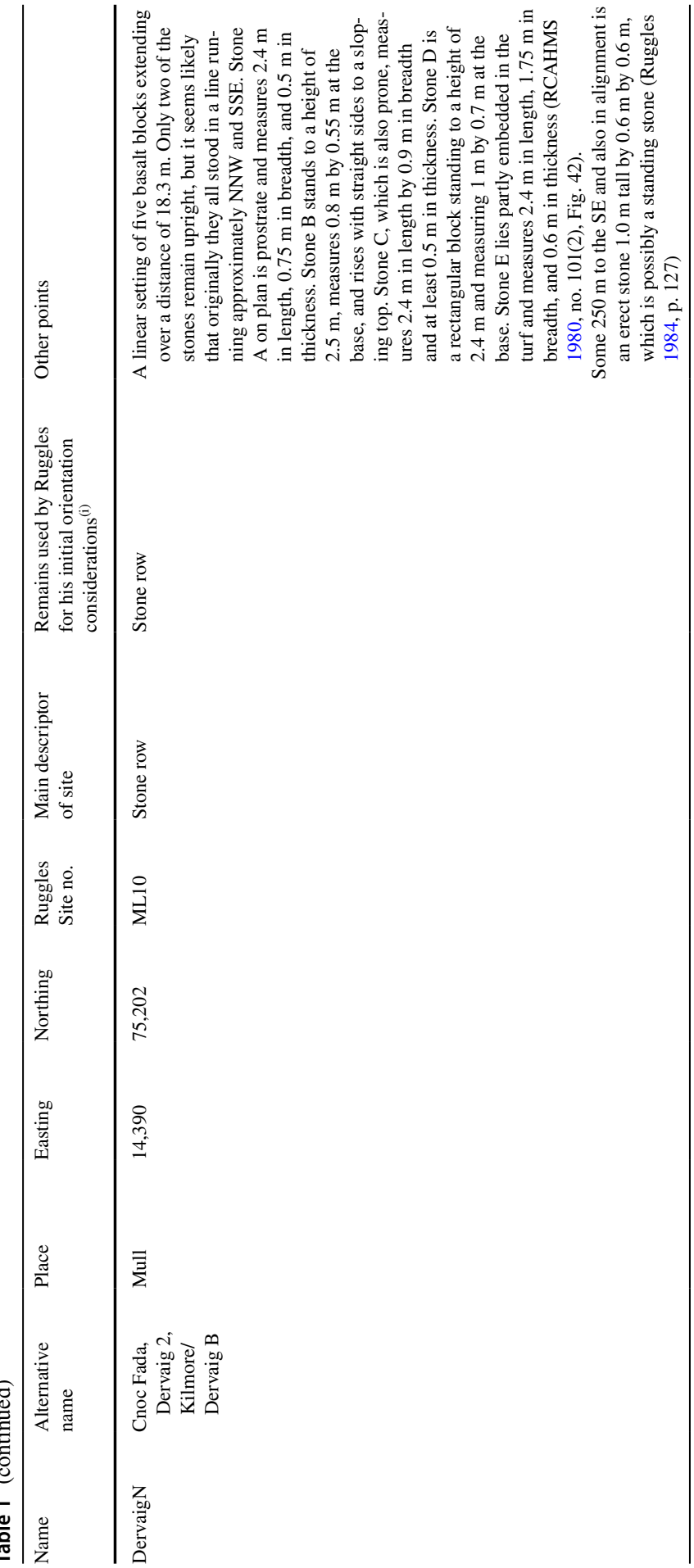




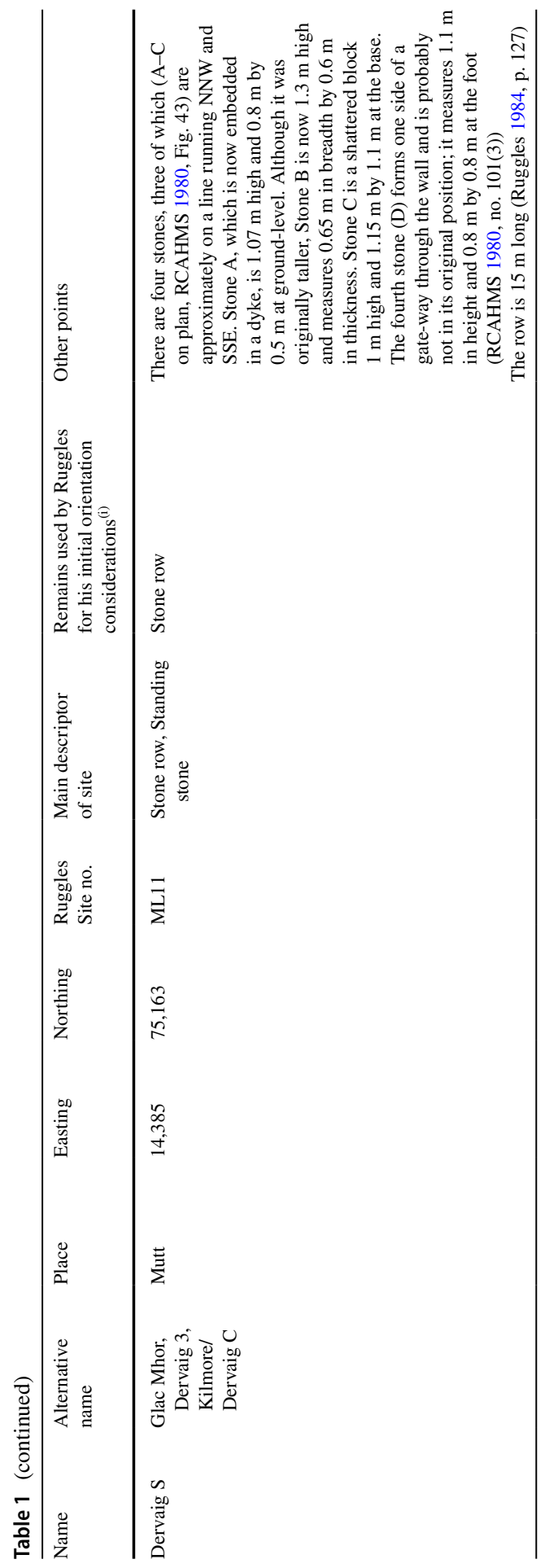




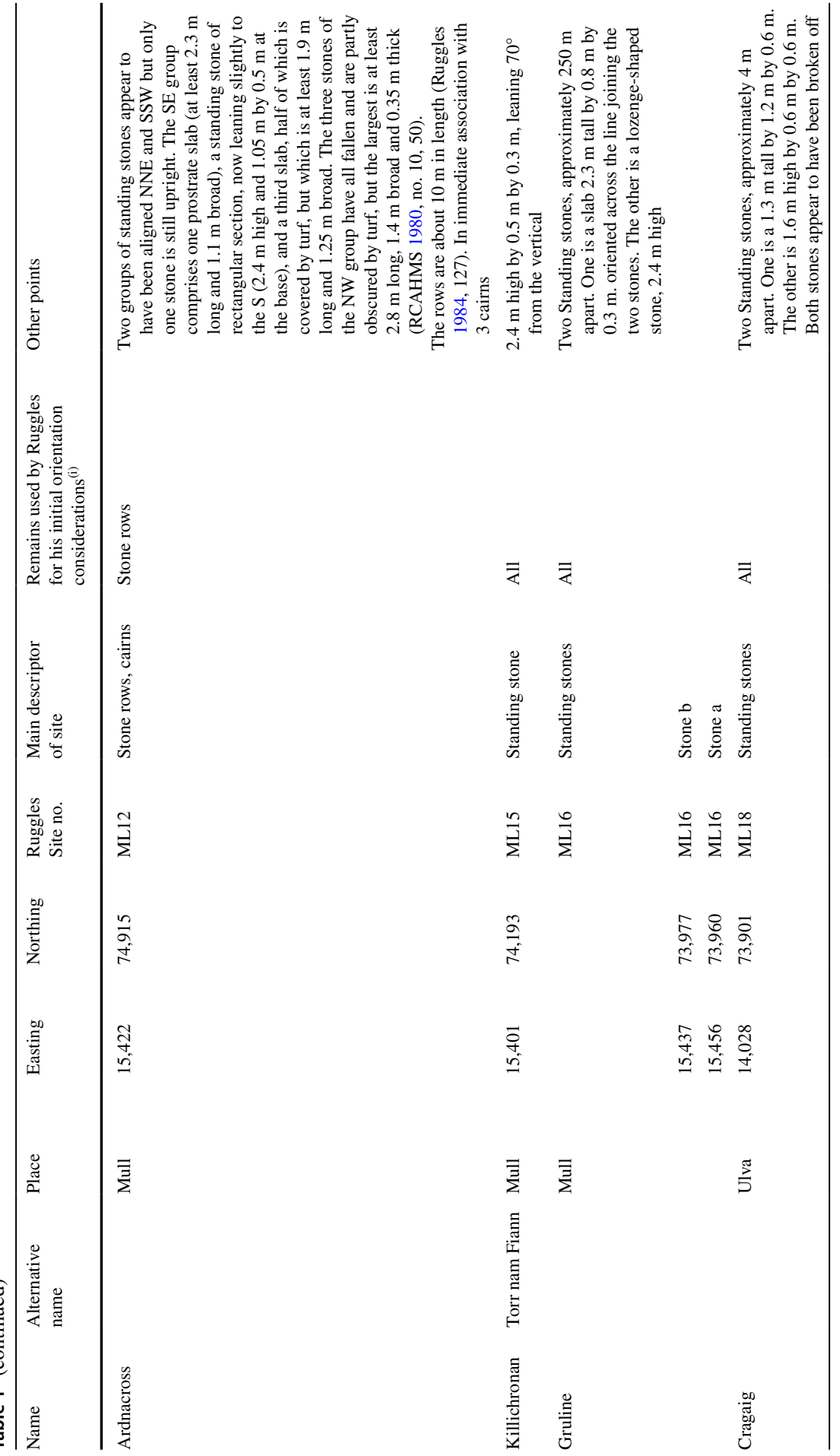




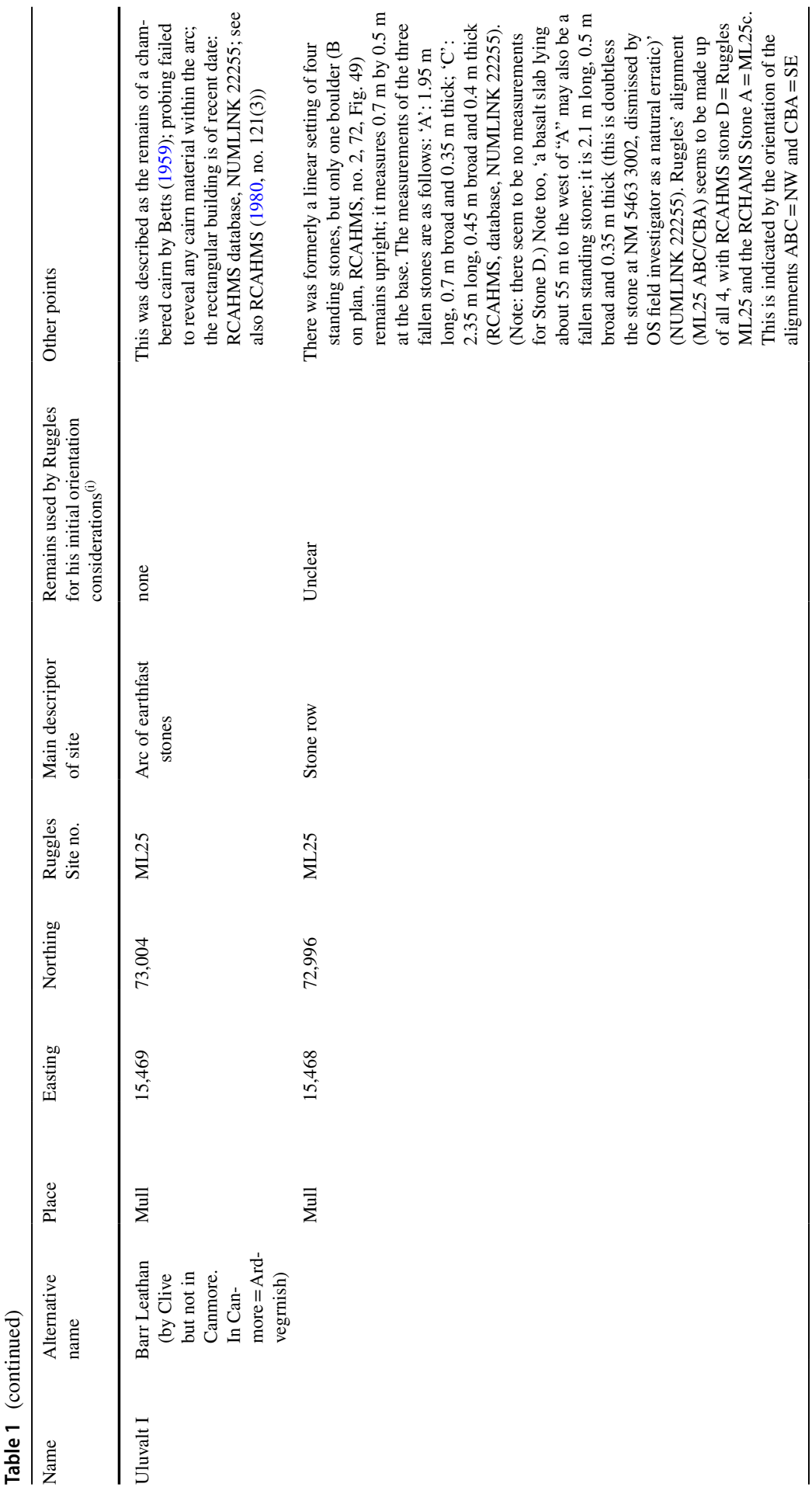




\begin{tabular}{|c|c|c|c|c|c|}
\hline 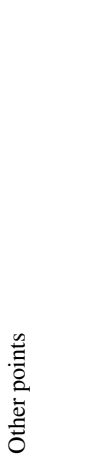 & 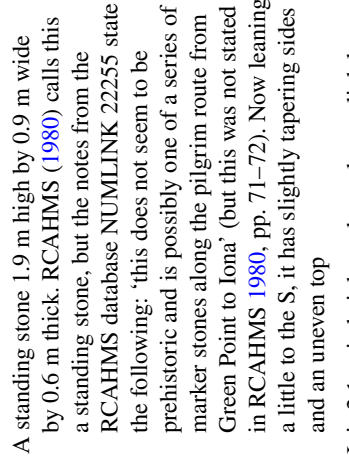 & 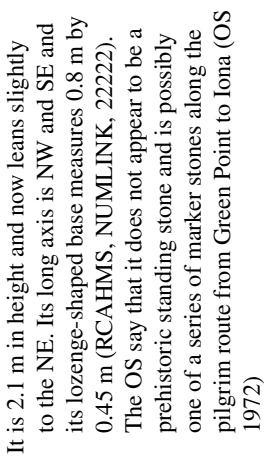 & 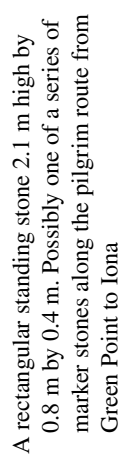 & 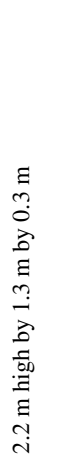 & 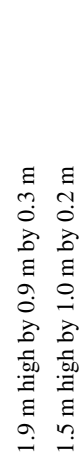 \\
\hline 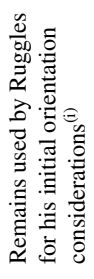 & $\stackrel{\mathscr{\Xi}}{\Xi}$ & $\bar{\varangle}$ & $\bar{z}$ & . & ॠ \\
\hline 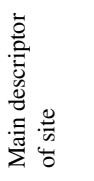 & 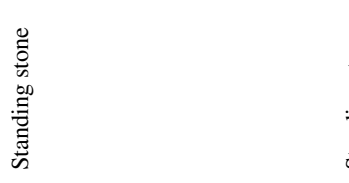 & 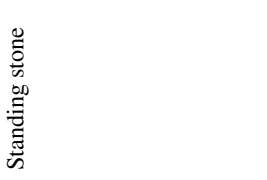 & 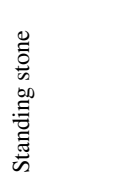 & 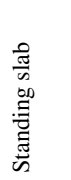 & 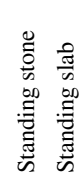 \\
\hline 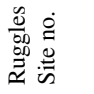 & $\stackrel{\text { İ }}{\mathrm{z}}$ & $\stackrel{\widehat{J}}{\xi}$ & 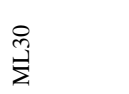 & $\overrightarrow{\tilde{3}}$ & 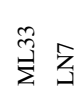 \\
\hline 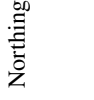 & $\begin{array}{l}\text { à } \\
\text { î }\end{array}$ & $\begin{array}{l}\text { î } \\
\text { i. } \\
\text { i }\end{array}$ & $\begin{array}{l}\text { ते } \\
\text { ते }\end{array}$ & $\begin{array}{l}\vec{\varpi} \\
\vec{\nabla}\end{array}$ & \begin{tabular}{ll}
$\infty$ & 0 \\
$\infty$ & 0 \\
$\infty$ & $\infty$ \\
\hdashline & 1
\end{tabular} \\
\hline 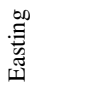 & $\begin{array}{l}n \\
\vdots \\
\mathfrak{2} \\
2\end{array}$ & 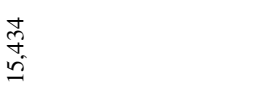 & $\begin{array}{l}\text { ڤે } \\
\text { ભે }\end{array}$ & $\begin{array}{l}\circ \\
\stackrel{2}{g}\end{array}$ & 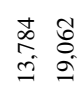 \\
\hline$\frac{\mathscr{\Xi}}{\mathscr{a}}$ & $\bar{\Xi}$ & $\bar{\Xi}$ & $\bar{\Xi}$ & $\bar{\Xi}$ & $\bar{\Xi}$ \\
\hline 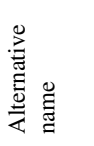 & & 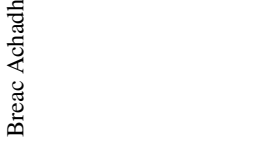 & 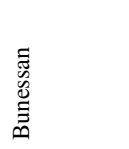 & 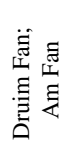 & \\
\hline छ్ & & $\begin{array}{l}\text { चू } \\
0 \\
0 \\
0\end{array}$ & 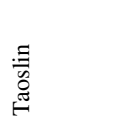 & 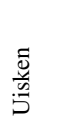 & 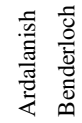 \\
\hline
\end{tabular}




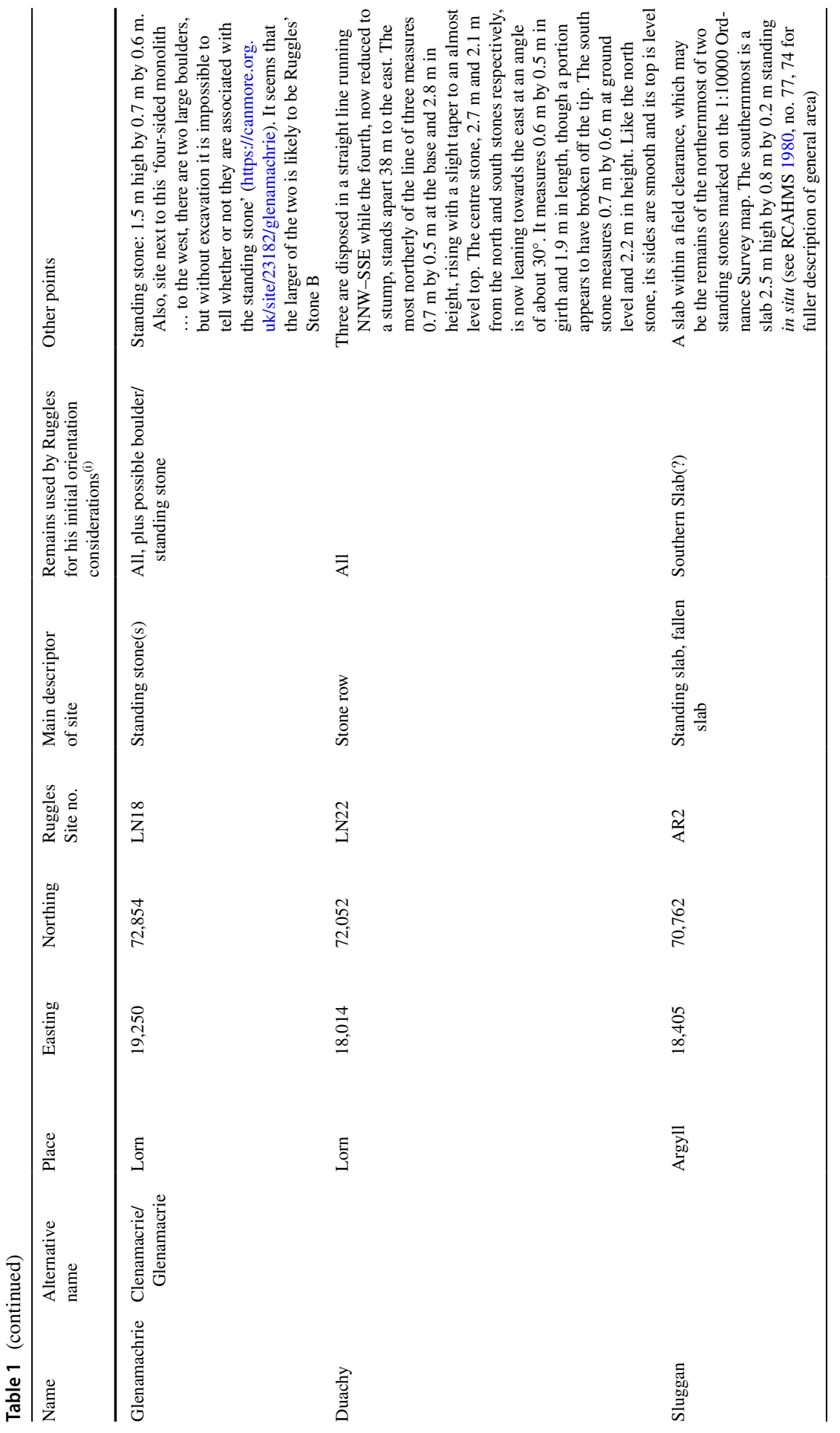




\begin{tabular}{|c|c|c|c|c|c|}
\hline 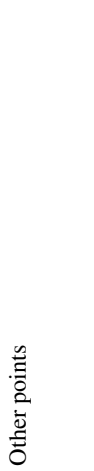 & 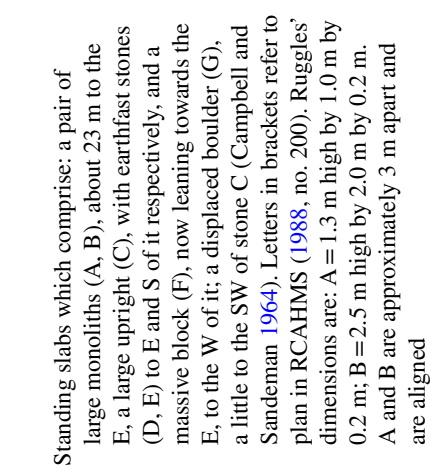 & 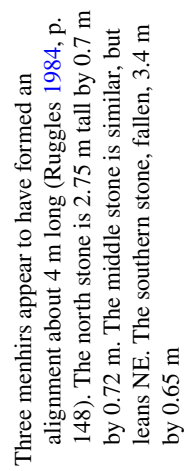 & 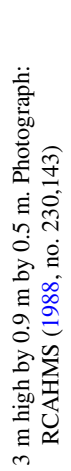 & 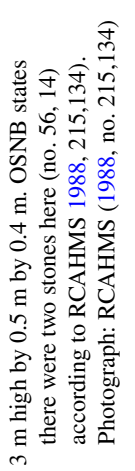 & 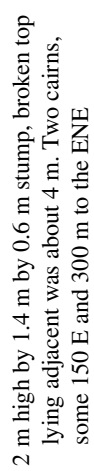 \\
\hline 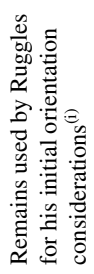 & 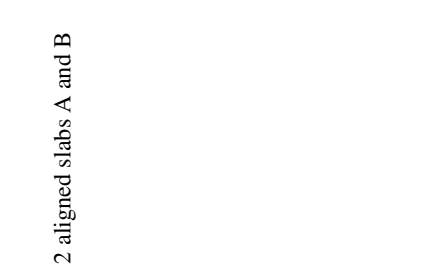 & $\bar{\psi}$ & \& & $\bar{\psi}$ & $\bar{\psi}$ \\
\hline 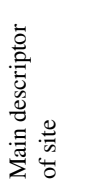 & 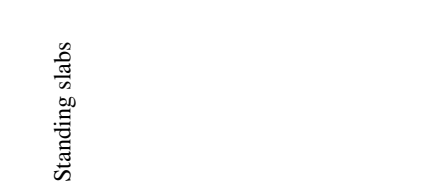 & 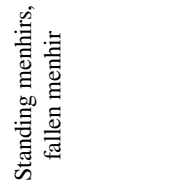 & 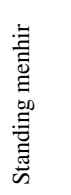 & 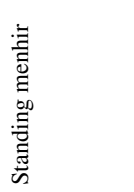 & 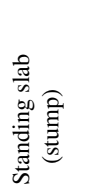 \\
\hline 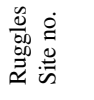 & $\stackrel{\approx}{4} \stackrel{\widetilde{\alpha}}{4}$ & $\frac{2}{4}$ & $\bar{q}$ & $\begin{array}{l}\infty \\
\stackrel{\alpha}{<}\end{array}$ & ڤे \\
\hline $\begin{array}{l}\text { 量 } \\
\text { 章 } \\
\text { Zे }\end{array}$ & 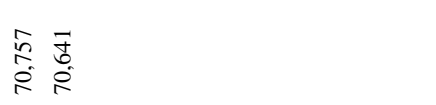 & $\begin{array}{l}m \\
\stackrel{q}{q} \\
\stackrel{2}{r}\end{array}$ & $\begin{array}{l}\infty \\
\infty \\
+\infty \\
0 \\
0\end{array}$ & $\begin{array}{c}m \\
\stackrel{m}{R}\end{array}$ & $\frac{n}{n}$ \\
\hline 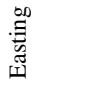 & $\begin{array}{ll}m & n \\
\hat{+} & m \\
\infty & \infty \\
\infty & \infty\end{array}$ & $\begin{array}{l}\mathscr{q} \\
o+ \\
\infty \\
\infty\end{array}$ & $\begin{array}{l}\infty \\
\stackrel{\infty}{\infty} \\
\stackrel{\infty}{-}\end{array}$ & $\begin{array}{l}\infty \\
\stackrel{0}{0} \\
\infty \\
\infty\end{array}$ & $\begin{array}{l}n \\
\hat{n} \\
\infty \\
\infty\end{array}$ \\
\hline$\frac{\mathscr{E}}{\tilde{L}}$ & 原 & $\begin{array}{l}\overline{7} \\
\frac{70}{4}\end{array}$ & 窎 & 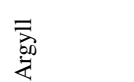 & $\begin{array}{l}\text { 䆜 } \\
\text { 妾 }\end{array}$ \\
\hline 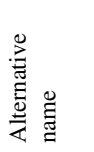 & & & & 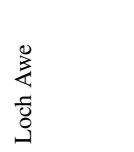 & 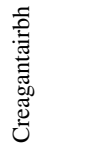 \\
\hline छ్ & 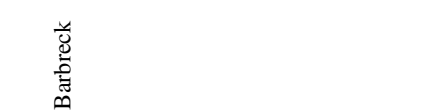 & 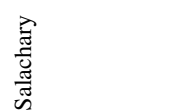 & 劳 & 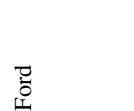 & $\begin{array}{l}\text { Z } \\
\text { : } \\
\text { 芯 }\end{array}$ \\
\hline
\end{tabular}




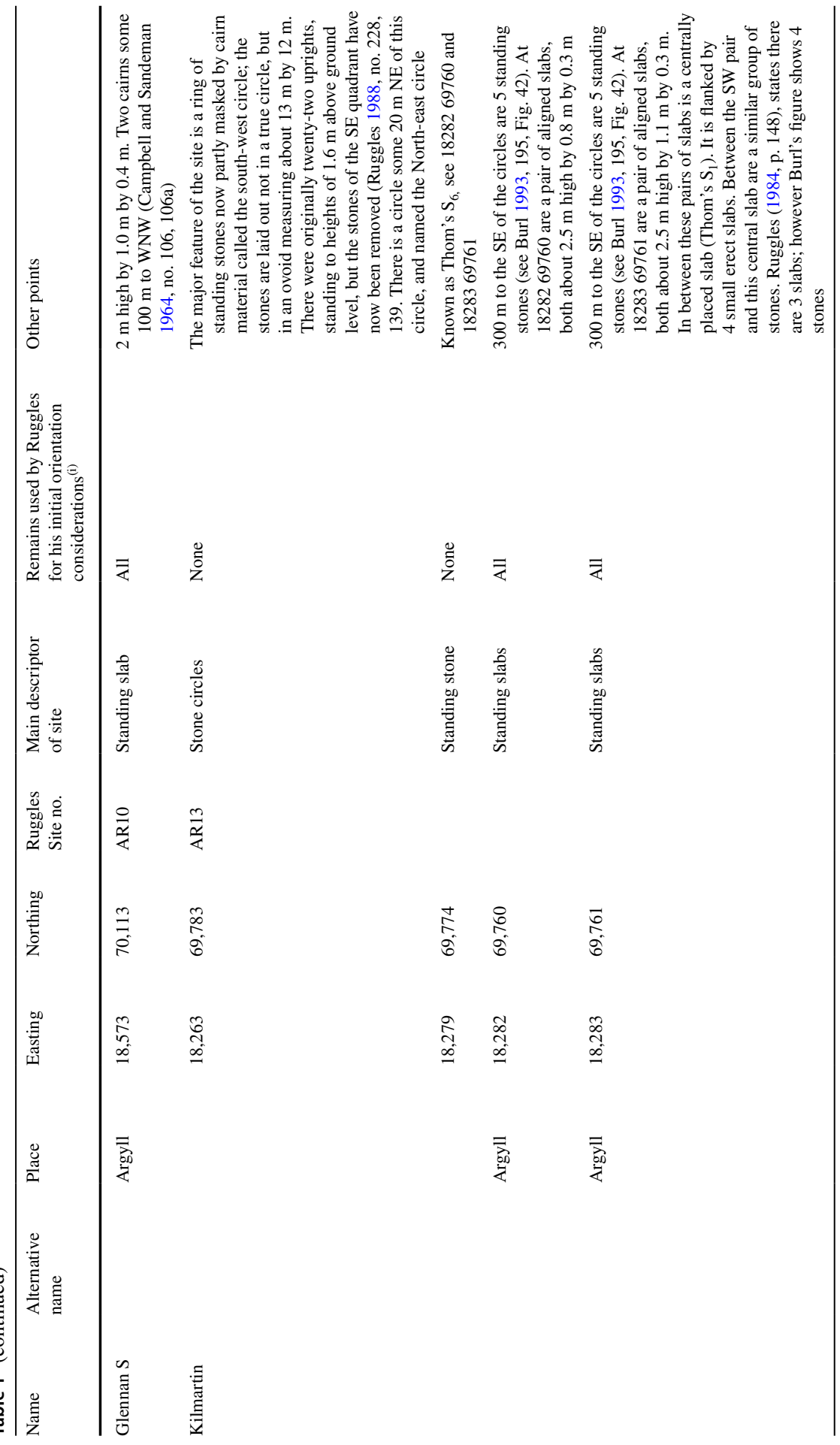




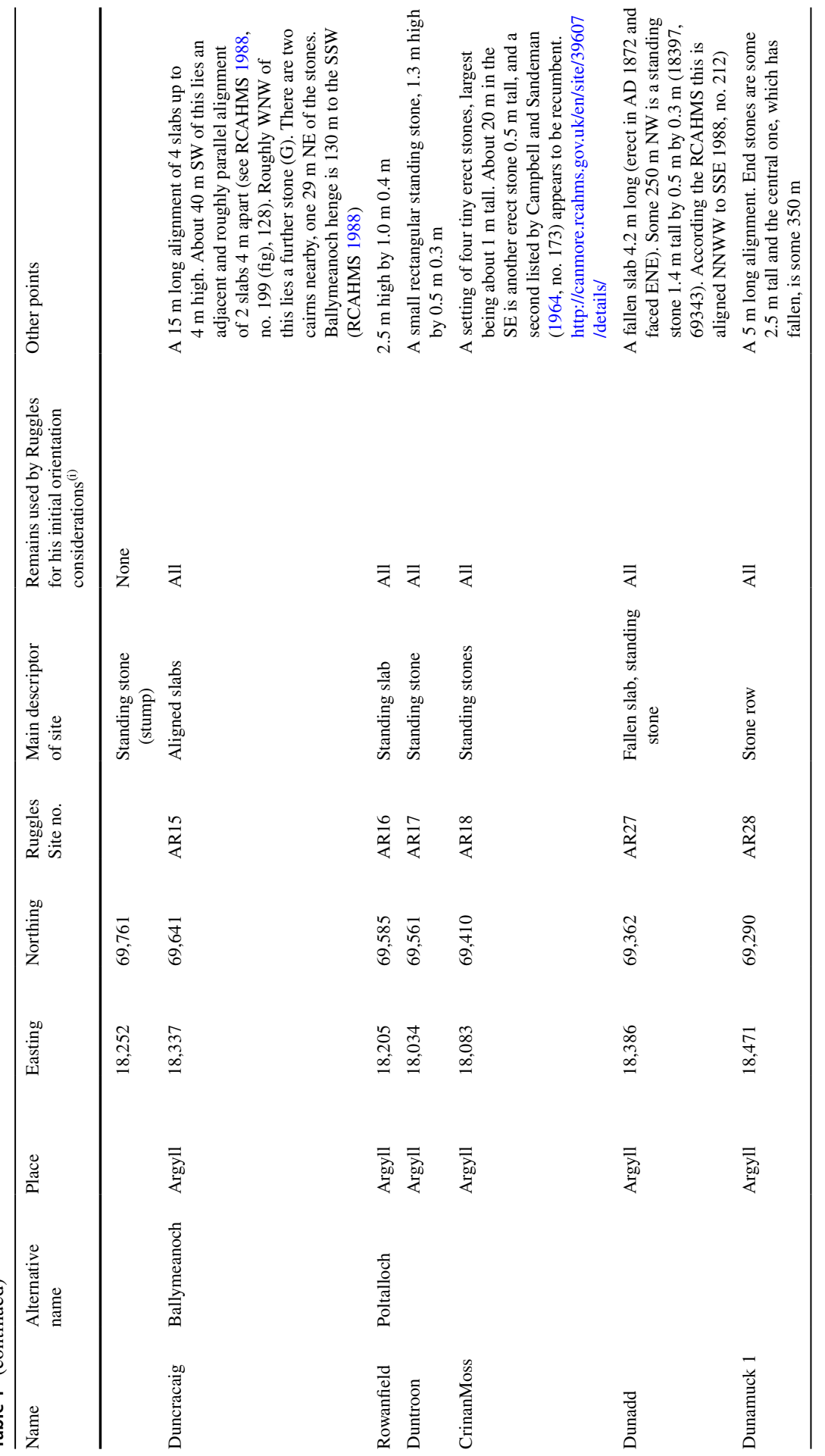




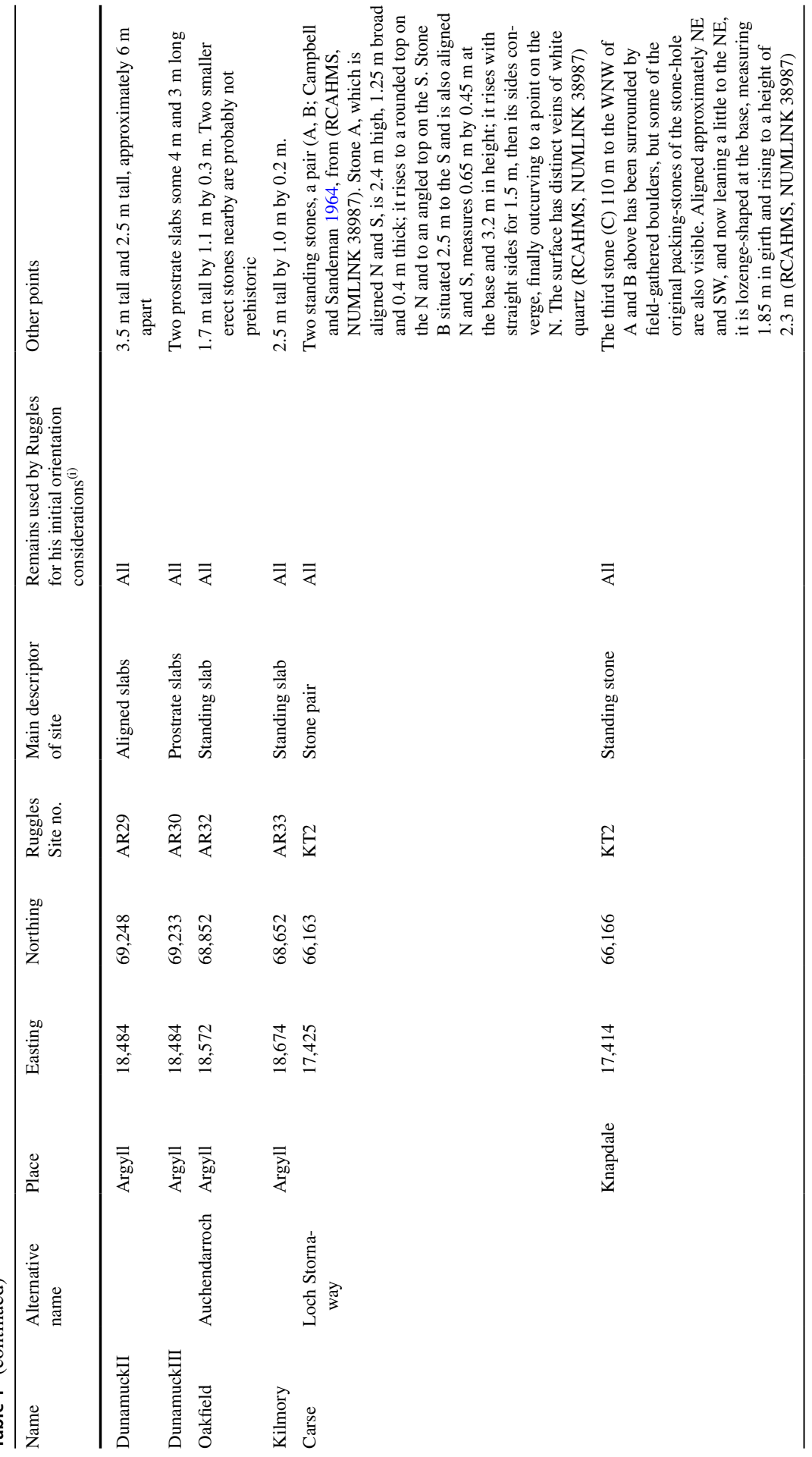




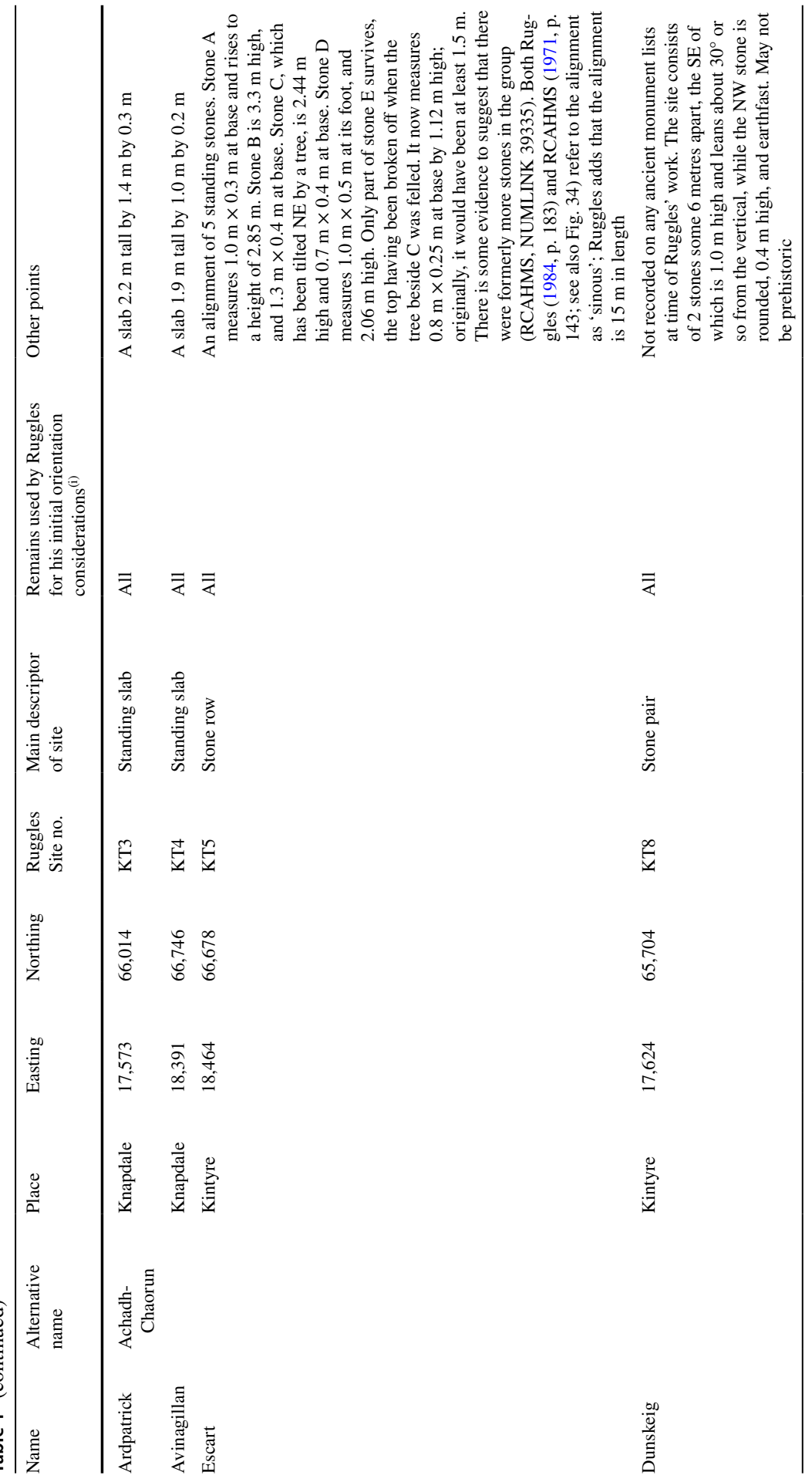




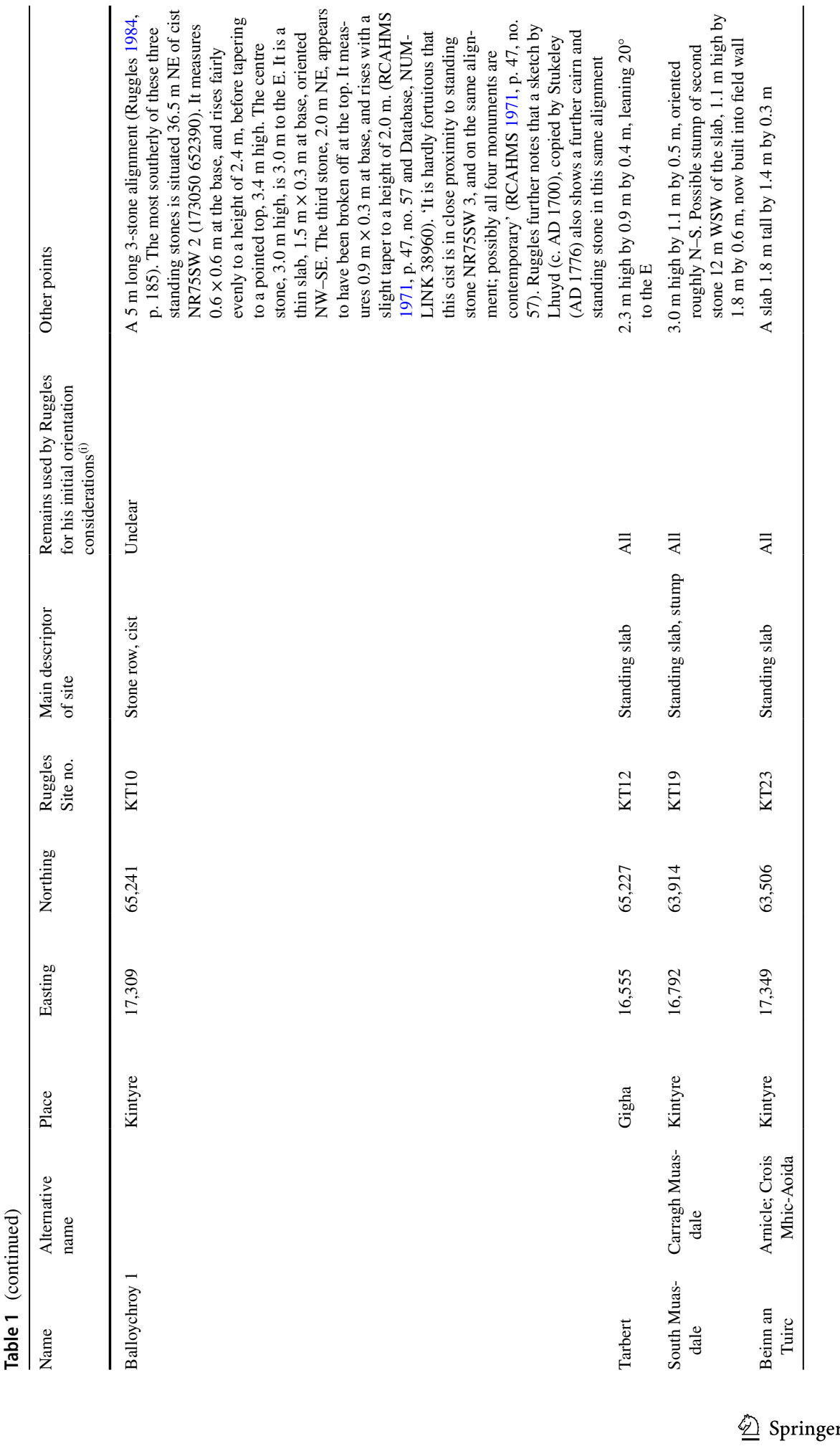




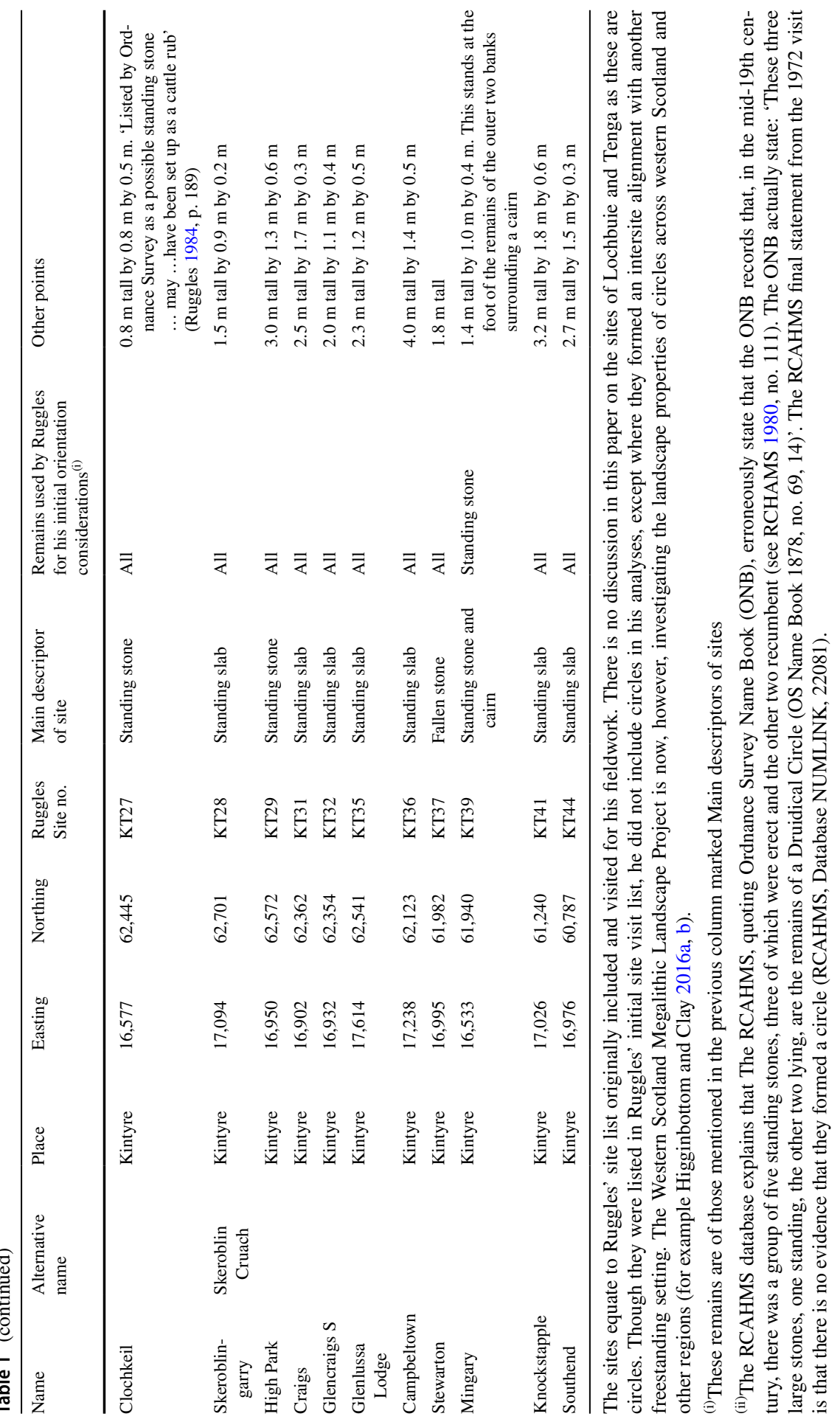




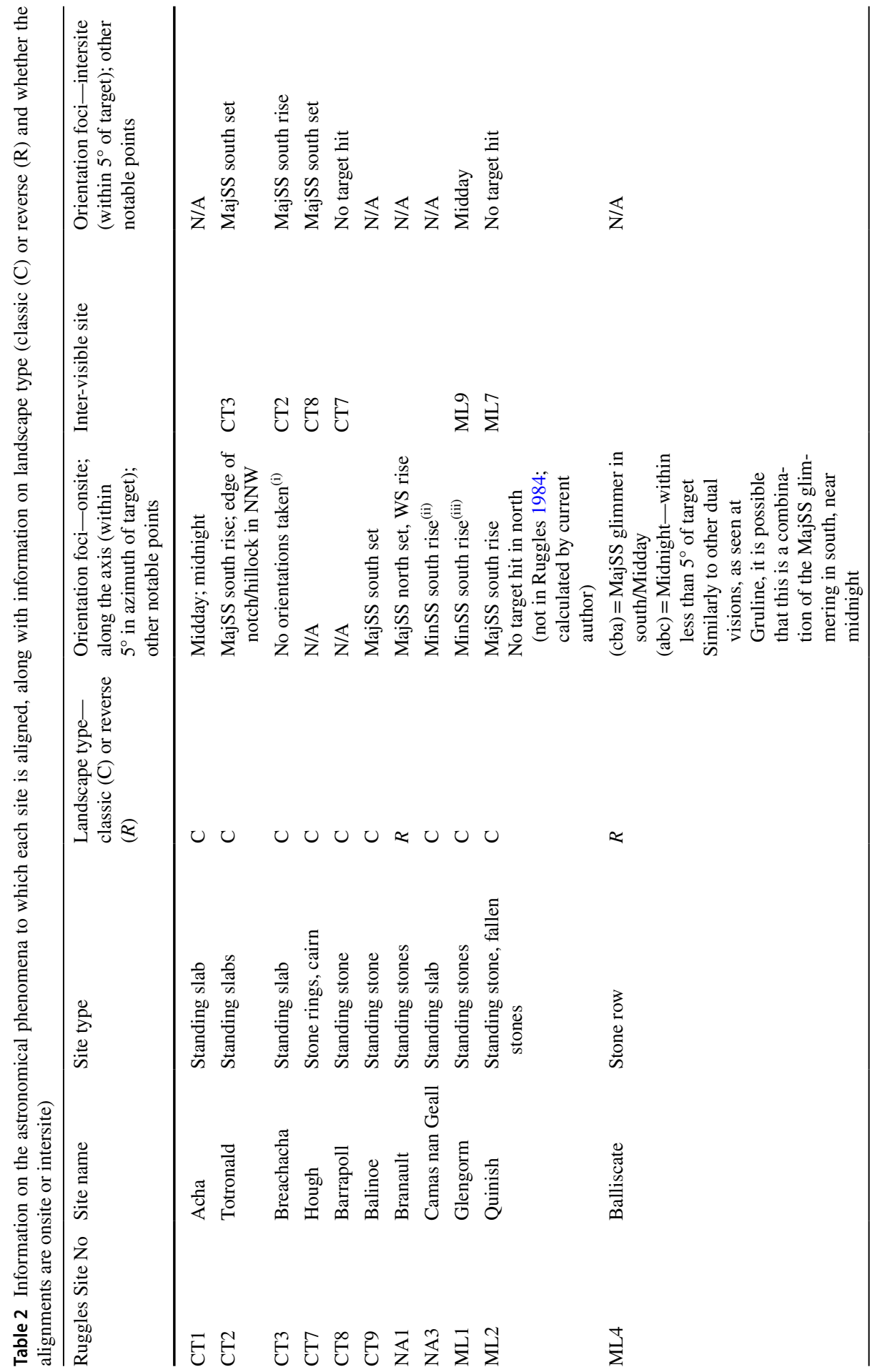




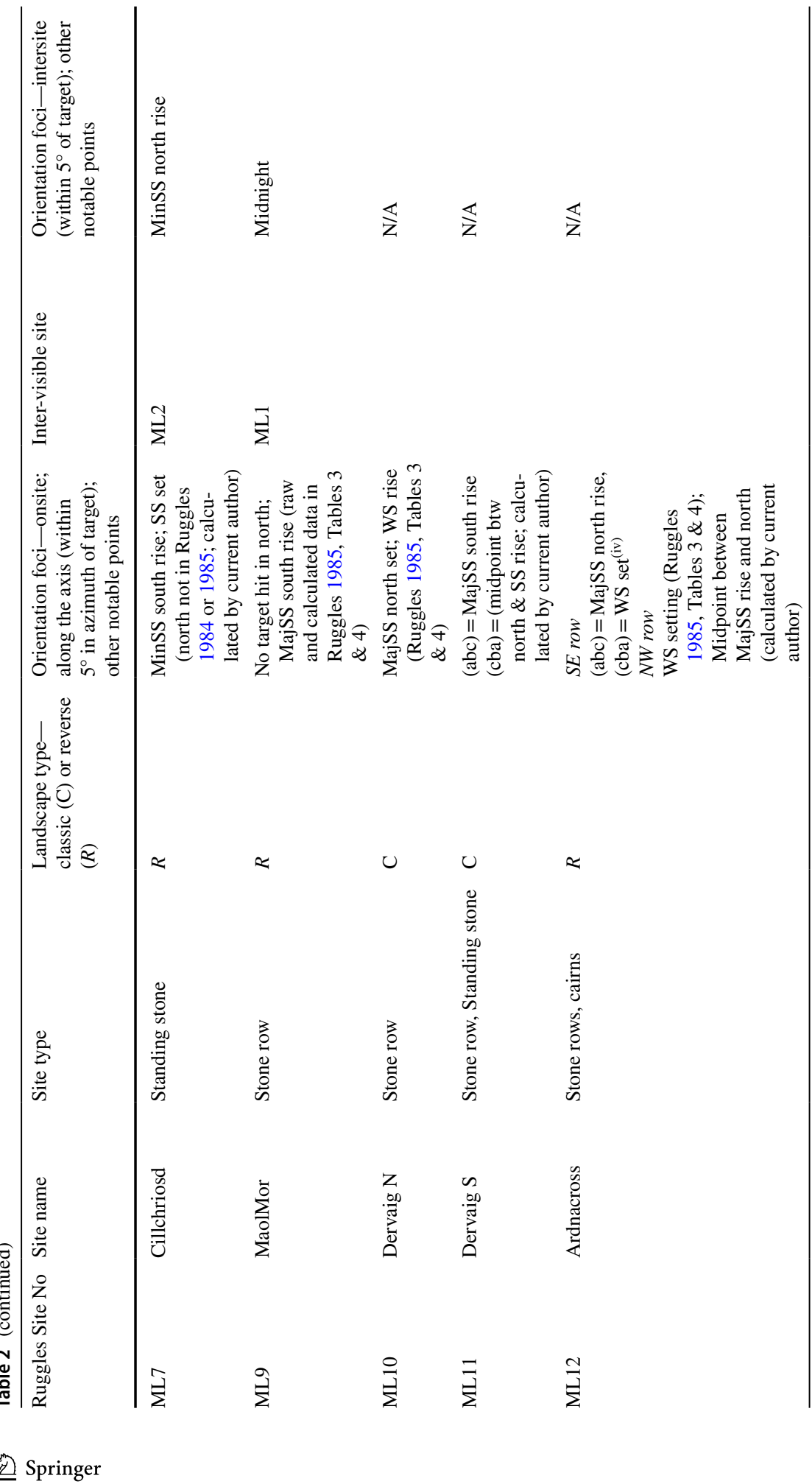




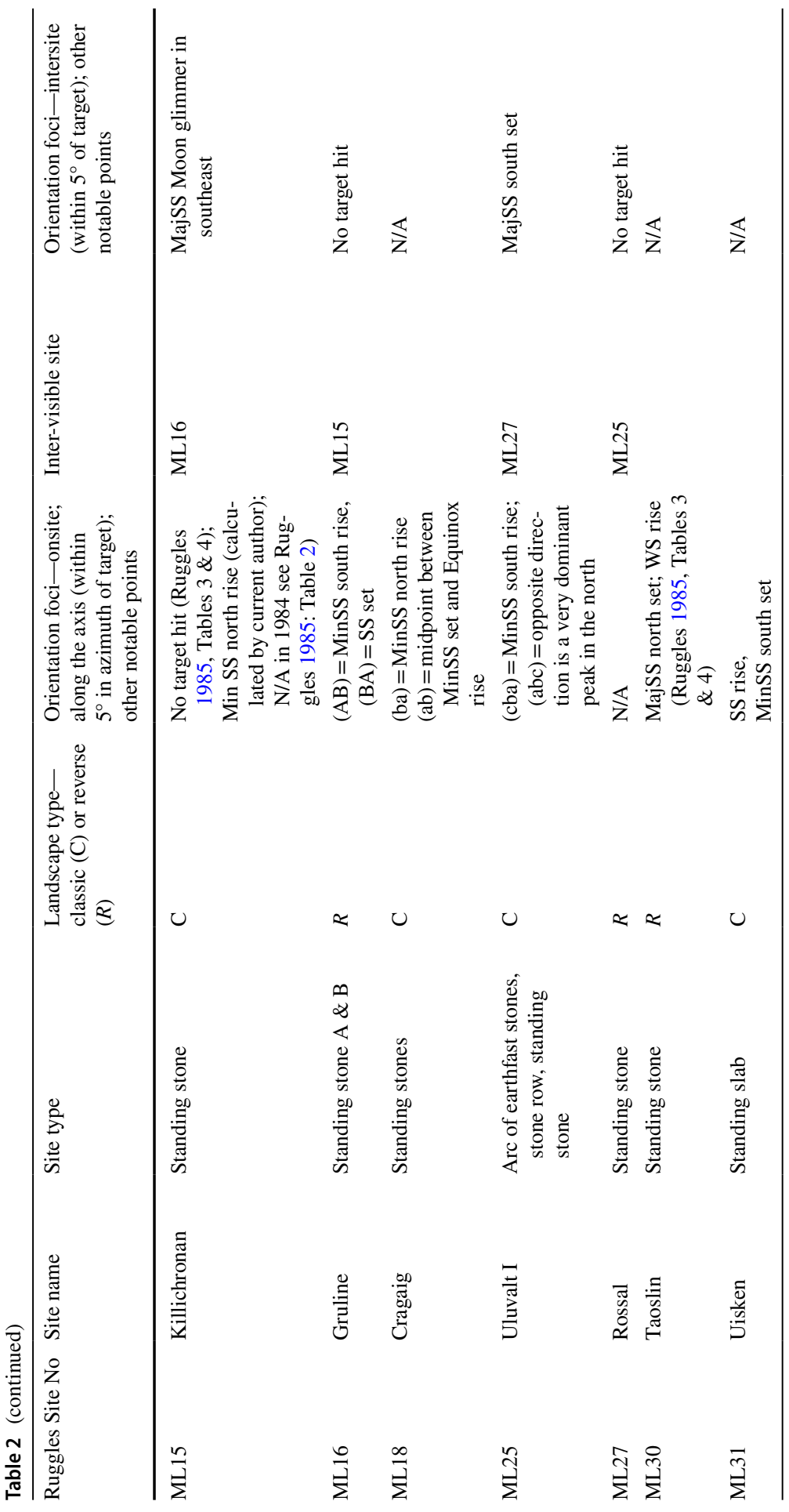




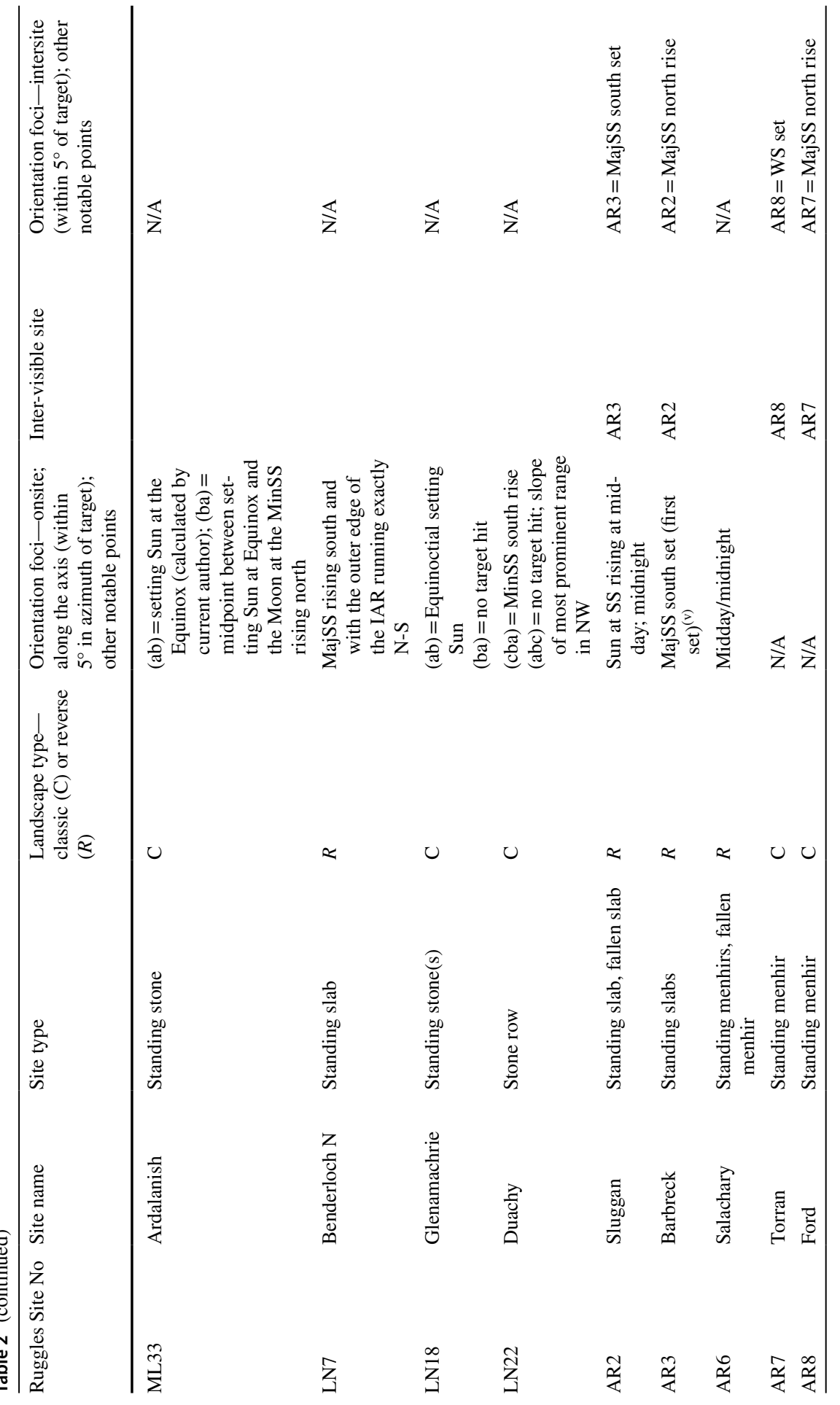




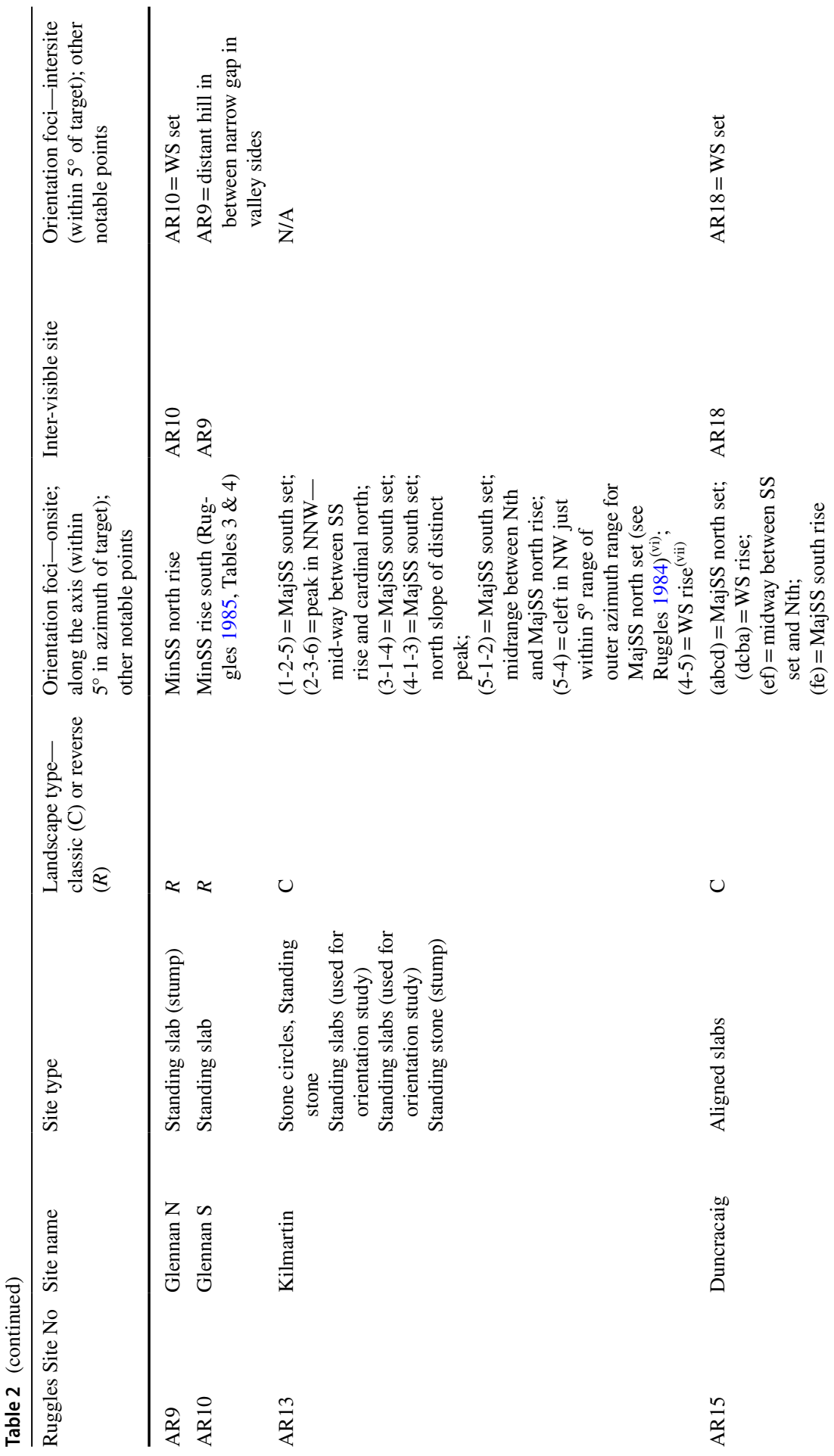




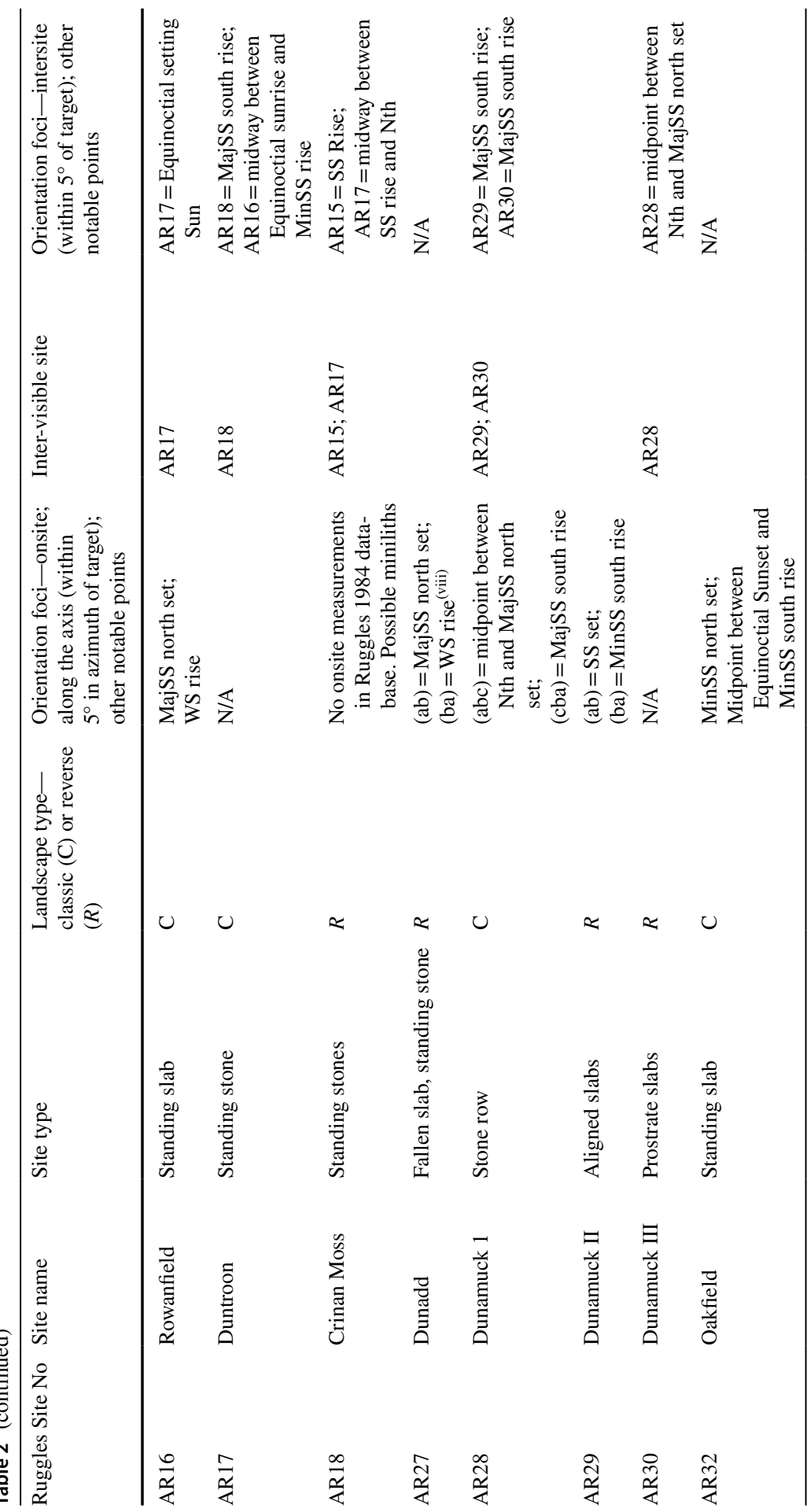




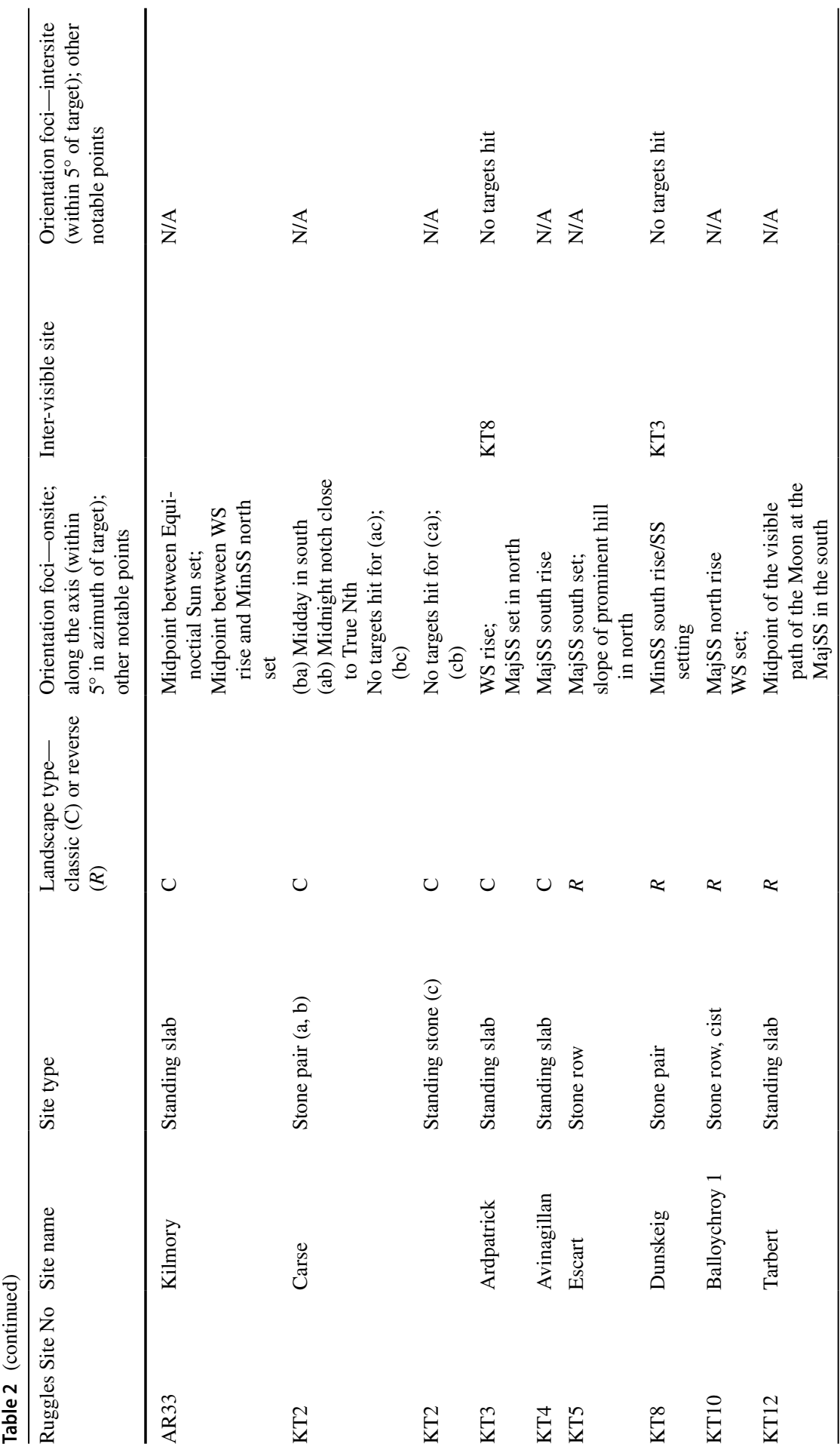




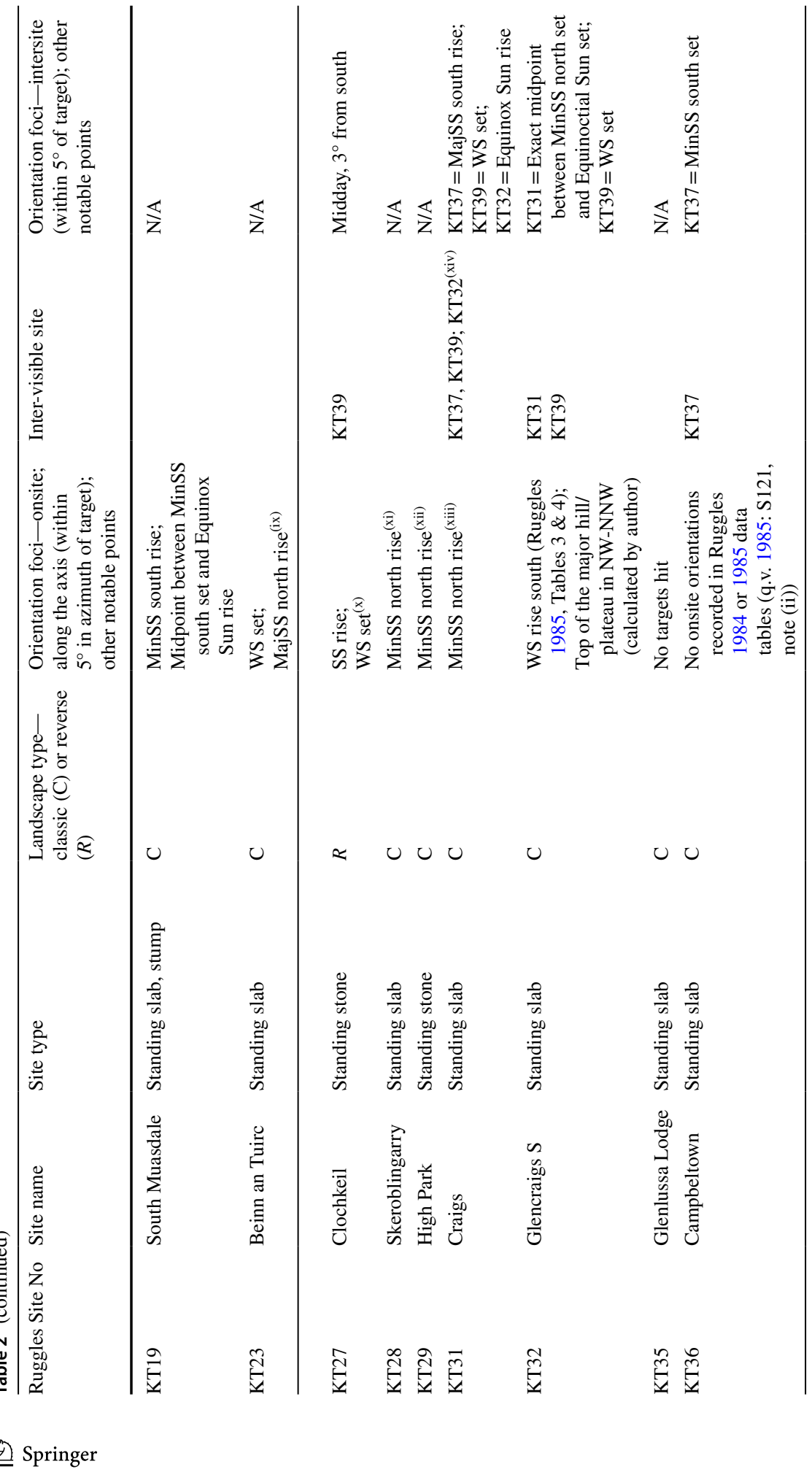




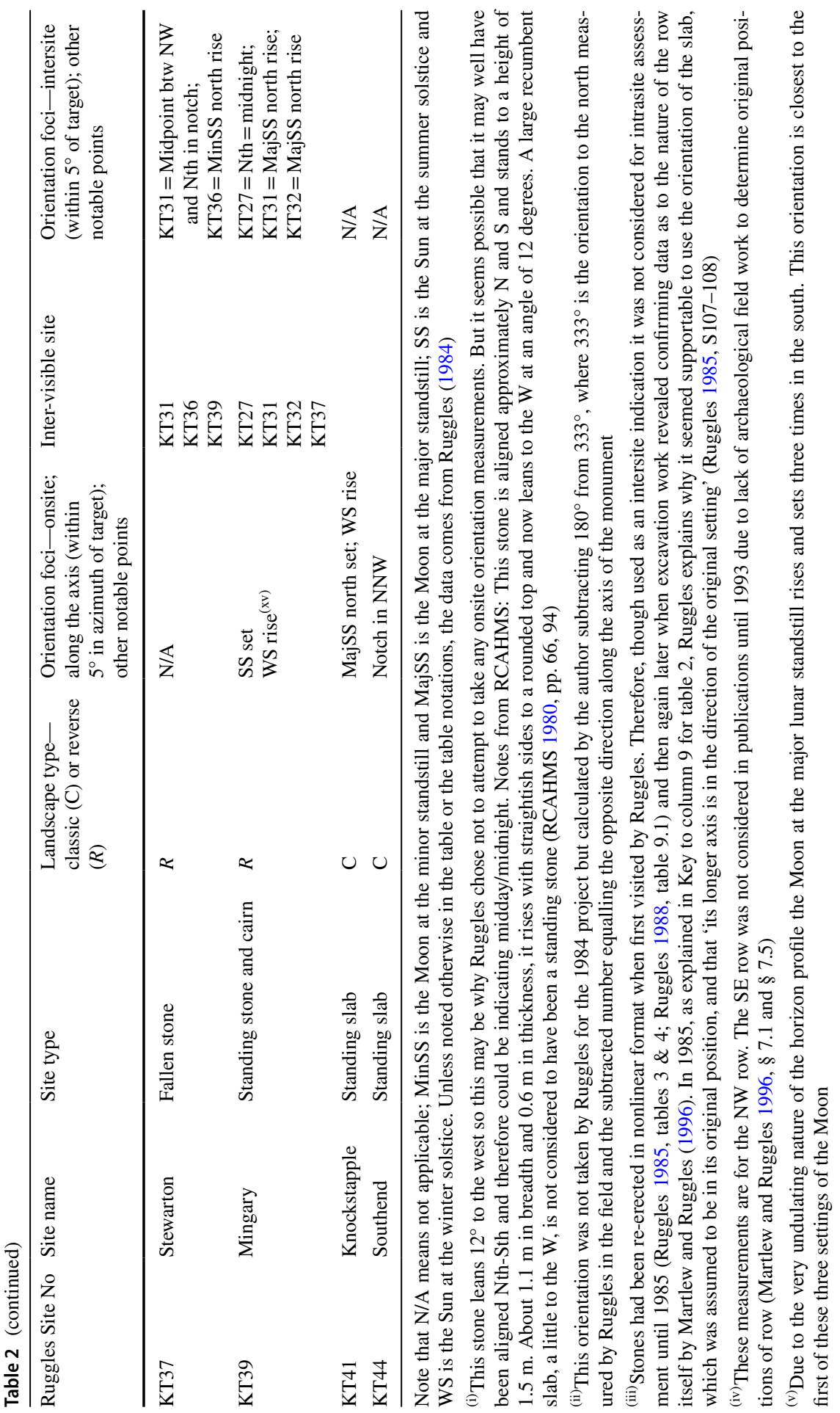




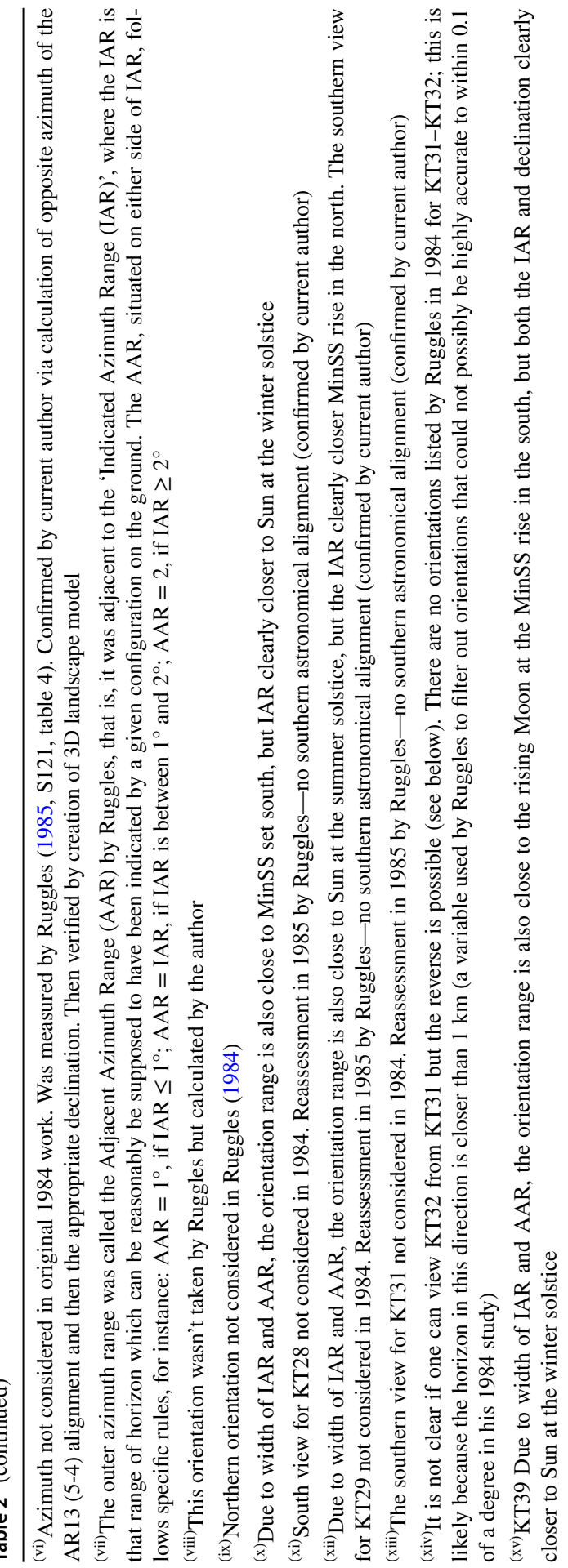




\section{References}

Allentoft, M. E., Sikora, M., Sjögren, K. G., Rasmussen, S., Rasmussen, M., Stenderup, J., et al. (2015). Population genomics of Bronze Age Eurasia. Nature, 522, 167-172. https://doi.org/10.1038/natur e14507.

Angeletaki, A., \& Carrozzino, M. (2017). Mubil: A library-based immersive virtual environment for situated historical learning. In A. Benardou, E. Champion, C. Dallas, \& L. Hughes (Eds.), Cultural heritage, infrastructures in digital humanities. London: Routledge. https://doi.org/10.4324/97813 15575278.

Ashmore, P. J. (1999). Radiocarbon dating: Avoiding errors by avoiding mixed samples. Antiquity, 73(279), 124-130.

Ashmore, P. J. (2016). Calanais survey and excavation 1979-1988. With contributions by T. Ballin, S. Bohncke, A. Fairweather, A. Henshall, M. Johnson, I. Maté, A. Sheridan, R. Tipping \& M. Wade Evans. Edinburgh: Historic Environment Scotland.

Aveni, A. F., \& Hartung, H. (1986). Maya city planning and the calendar. Transactions of the American Philosophical Society, 76(7).

Baines, A., Brophy, K., \& Pannett, A. (2003). Yarrows Landscape Project/Battle Moss Stone Rows (Wick parish): Multiple stone rows; kerb cairn; lithic scatter. Discovery Excavation Scotland, 4, 94-95.

Barber, J. (1978). The excavation of the holed-stone at Ballymeanoch, Kilmartin, Argyll. Proceedings of the Society of Antiquaries of Scotland, 109, 104-111.

Barnatt, J. (1989). Stone circles of Britain: Taxonomic and distributional analyses and a catalogue of sites in England, Scotland and Wales. BAR British Series, 215. Oxford: British Archaeological Reports.

Barnatt, J., \& Pierpoint, S. (1983). Stone circles: Observatories or ceremonial centres. Scottish Archaeological Review, 2, 101-116.

Barrett, J. (1987). Contextual archaeology. Antiquity, 61(233), 468-473.

Beier, H. J. (1991). Die megalithischen, submegalithischen und pseudomegalithischen Bauten sowie die Menhire zwischen Ostsee und Thüringer Wald. Beiträge zur Ur-und Frühgeschichte Mitteleuropas 1. Wilkau-Haßlau: Beier \& Beran.

Beier, H. J. (1992). Die megalithischen, submegalithischen und pseudomegalithischen Bauten sowie die Menhire in den fünf neuen ostdeutschen Bundesländern (ehemals DDR): Eine Bestandsaufnahme. Ethnographisch-Archäologische Zeitschrift, 33, 416-438.

Bennett, K. D., Simonson, W. D., \& Peglar, S. M. (1990). Fire and man in post-glacial woodlands of eastern England. Journal of Archaeological Science, 17, 635-642.

Betts, U. V. G. (1959). Uluvalt. Discovery and Excavation in Scotland, 1959, 9-10.

Birks, H. J. B., \& Madsen, B. J. (1979). Flandrian vegetational history at Little Loch Roag, Isle of Lewis, Scotland. Journal of Ecology, 67, 825-842.

Birks, H. J. B., \& Williams, W. (1983). Late Quaternary vegetational history of the Inner Hebrides. Proceedings of the Royal Society of Edinburgh, 83B, 269-292.

Birks, J. B. H. (1991). Floristic and vegetational history of the Outer Hebrides. In J. R. Pankhurst \& J. M. Mullin (Eds.), Flora of the Outer Hebrides (pp. 32-37). London: Pelagic Publishing.

Bocksberger, O.-J. (1964). Découvertes archéologiques récentes à l'ouest de Sion: Nouvelles données sur le néolithique valaisan. Bulletin de la Murithienne, 81, 141-151.

Bohncke, S. (1988). Vegetation and habitation history of the Callanish area, Isle of Lewis, Scotland. In H. H. Birks, H. J. B. Birks, P. E. Kaland, \& D. Moe (Eds.), The cultural landscape: Past, present and future (pp. 445-462). Cambridge.

Brace, S., Diekmann, Y., Booth, T. J., van Dorp, L., Faltyskova, Z., Rohland, N., et al. (2019a). Ancient genomes indicate population replacement in Early Neolithic Britain. Nature Ecology \& Evolution, 3(5), 1. https://doi.org/10.1038/s41559-019-0871-9.

Brace, S., Diekmann, Y., Booth, T. J., van Dorp, L., Faltyskova, Z., Rohland, N., et al. (2019b). Author correction: Ancient genomes indicate population replacement in Early Neolithic Britain. Nature Ecology \& Evolution, 3, 1-2. https://doi.org/10.1038/s41559-019-0912-4.

Bradley, R. (1997). Rock art and the prehistory of Atlantic Europe: Signing the land. London: Routledge.

Bradley, R. (1998). The significance of monuments: On the shaping of human experience in Neolithic and Bronze Age Europe. London and New York: Routledge.

Bradley, R. (1993). Altering the Earth: Origins of monuments in Britain and continental Europe. Edinburgh: Society of Antiquaries of Scotland. 
Bradley, R. (Ed.). (2000). The good stones: A new investigation of the Clava Cairns. Edinburgh: Society of Antiquaries of Scotland.

Bradley, R. (Ed.). (2005). The Moon and the bonfire: An investigation of three stone circles in Northeast Scotland. Edinburgh: Society of Antiquaries of Scotland.

Bradley, R. (2011a). Stages and screens: An investigation of four henge monuments in northern and northeastern Scotland. Edinburgh: Society of Antiquaries of Scotland.

Bradley, R. (2011b). Passage graves, statues and standing stones. In M. Furholt, F. Lüth, \& J. Müller (Eds.), Megaliths and identities: Early monuments and Neolithic societies from the Atlantic to the Baltic. Frühe Monumentalität und soziale Differenzierung 1 (pp. 47-52). Bonn: Habelt Dr. Rudolf $\mathrm{GmbH}$

Bradley, R. (2012). The idea of order: The circular archetype in prehistoric Europe. Oxford: Oxford University Press.

Bradley, R. (2013). An archaeology of natural places. London and New York: Routledge.

Bradley, R. J. (1991). Ritual, time and history. World Archaeology, 23, 209-219.

Bradley, R., \& Nimura, C. (2013). The earth, the sky and the water's edge: Changing beliefs in the earlier prehistory of Northern Europe. World Archaeology, 45(1), 12-26. https://doi.org/10.1080/00438 243.2012.759515.

Brennand, M., Taylor, M., Ashwin, T., Bayliss, A., Canti, M., Chamberlain, A., et al. (2003). The survey and excavation of a Bronze Age timber circle at Holme-next-the-Sea, Norfolk, 1998-9. Proceedings of the Prehistoric Society, 69, 1-84. https://doi.org/10.1017/S0079497X00001250.

Brophy, K., Pannett, A., \& Baines, A. (2013). Megalithic overkill: The multiple stone rows of Caithness and Sutherland. Edinburgh: Society of Antiquaries of Scotland.

Burl, A. (1976). The stone circles of the British Isles. New Haven: Yale University Press.

Burl, A. (1981). By the light of the cinerary Moon: Chambered tombs and the astronomy of death. In C. L. N. Ruggles \& A. W. R. Whittle (Eds.), Astronomy and society in Britain during the period 4000-1500 BC. BAR British Series 88 (pp. 243-274). Oxford: British Archaeological Reports.

Burl, A. (1982). Pi in the sky. In D. C. Heggie (Ed.), Archaeoastronomy in the Old World (pp. 141-169). Cambridge: Cambridge University Press.

Burl, H. A. W. (1993). From Carnac to Callanish: The prehistoric stone rows and avenues of Britain, Ireland and Brittany. New Haven and London: Yale University Press.

Burl, H. A. W. (2000). The stone circles of Britain, Ireland and Brittany. New Haven: Yale University Press.

Burri-Wyser, E., Falquet, C., Terrier, F., \& Wüthrich, S. (2012). D'un megalithe à l'autre: Entre YverdonLes-Bains VD et Hauterive NE. Yverdon-Les-Bains: Musée d'Yverdon et Région.

Calado, M. (2002). Standing stones and natural outcrops: The role of ritual monuments in the Neolithic transition of the Central Alentejo. In C. Scarre (Ed.), Monuments and landscape in Atlantic Europe: Perception and society during the Neolithic and Early Bronze Age (pp. 17-35). London: Routledge.

Campbell, M., \& Sandeman, M. (1964). Mid Argyll: An archaeological survey. Proceedings of the Society of Antiquaries of Scotland, 95, 1-125.

Carter, S., Dalland, M., \& Long, D. (2005). Early land-use and landscape development in Arisaig. Edinburgh: SAIR. http://www.sair.org.uk.

Carnes, A. (2014). The evolution of Neolithic and Bronze Age landscapes: From Danubian longhouses to the stone rows of Dartmoor and Northern Scotland. Oxford: Archaeopress.

Cassen, S., Blain, S., Guibert, P., Querré, G., \& Chaigneau, C. (2013). Les pierres dressées de la forêt du Gâvre (Loire-Atlantique): Nature et origine des matériaux, premiers éléments de chronologie (14C, OSL). ArchéoSciences, 37(1), 173-188. https://www.cairn.info/revue-archeosciences-20131-page-173.htm.

Cooney, G. (2000). Landscapes of Neolithic Ireland. London: Routledge.

Criado-Boado, F., Santos-Estévez, M., \& Villoch-Vázquez, V. (2001). Forms of ceremonial landscapes in Iberia from the Neolithic to Bronze Age: Essay on an archaeology of perception. In P. F. Biehl, F. Bertemes, \& H. Meller (Eds.), The archaeology of cult and religion. Budapest: Archaeolingua.

Criado-Boado, F., \& Villoch-Vázquez, V. (1998). La monumentalización del paisaje: Percepción Y sentido original en el megalitismo de la Sierra De Barbanza (Galicia). Trabajos De Prehistoria, 55, 63-80.

Criado-Boado, F., \& Villoch-Vázquez, V. (2000). Monumentalizing landscape: From present perception to the past. Meaning of Galacian megalithism. European Journal of Archaeology, 3(2), 188-216. 
Cummings, V. (2002). Between mountains and sea: A reconsideration of the Neolithic monuments of Southwest Scotland. Proceedings of the Prehistoric Society, 68, 125-146.

Cummings, V., \& Richards, C. (2013). The peristalith and the context of Calanais: Transformational architecture in the Hebridean early Neolithic. In C. Richards (Ed.), Building the great stone circles of the north (pp. 186-200). Oxford: Windgather Press.

Cummings, V., \& Whittle, A. (2004). Places of special virtue: Megaliths in the Neolithic landscapes of Wales. Oxford: Oxbow.

D’Anna, A., \& Pinet, L. (2006). Les pierres dressées des montagnes à la mer Méditerranée (Standing stones from the Alps to the Mediterranean sea). In R. Joussaume, L. Laporte, \& C. Scarre (Eds.), Origine et développement du mégalithisme de l'ouest de l'Europe: Colloque international: international conference (Origin and development of the megalithic monuments of western Europe) (pp. 577-602). Niort: Conseil Général des Deux Sèvres.

Darvill, T. (1997). Ever increasing circles: The sacred geographies of Stonehenge and its landscape. Proceedings of the British Academy, 92, 167-202.

Darvill, T. (2016). Houses of the holy: Architecture and meaning in the structure of Stonehenge, Wiltshire, UK. Time and Mind, 9(2), 89-121. https://doi.org/10.1080/1751696X.2016.1171496.

Davidson, N. (1985). Astronomy and the imagination: A new approach to Man's experience of the stars. London: Routledge \& Kegan Paul.

Davies, A. L., \& Tipping, R. (2005). Sensing small-scale human activity in the palaeoecological record: Fine spatial resolution pollen analyses from west Glen Affric, northern Scotland. The Holocene, 14, 233-245.

Dean, J., Gumerman, G. J., Epstein, J. M., Axtell, R. L., Swedlund, A. C., Parker, M. T., et al. (1999). Understanding Anasazi culture change through agent-based modelling. In T. A. Kohler \& J. G. Gummerman (Eds.), Dynamics in human and primate societies: Agent-based modeling of social and spatial processes (pp. 179-207). Oxford: Oxford University Press.

DeMarrais, E. (2012). The materialization of culture. In E. DeMarrais, C. Gosden, \& C. Renfrew (Eds.), Rethinking materiality (pp. 11-22). Cambridge: McDonald Institute.

DeMarrais, E., Castillo, L., \& Earle, T. (1996). Ideology, materialization, and power strategies. Current Anthropology, 37, 15-31.

Dowd, A. S., \& Milbrath, S. (Eds.). (2015). Cosmology, calendars, and horizon-based astronomy in ancient Mesoamerica. Boulder: University Press of Colorado.

Downes, J., Richards, C., Brown, J., Cresswell, A. J., Ellen, R., Davis, A. D., et al. (2013). Investigating the great Ring of Brodgar. In C. Richards (Ed.), Building the great stone circles of the north (pp. 90-118). Oxford: Windgather Press.

Droysen, J. G. (1977). Historik: Rekonstruktion der ersten vollständigen Fassung der Vorlesungen (1857), Grundriss der Historik in der ersten handschriftlichen (1857/1858) und in der letzten gedruckten Fassung (edited by P. Leyh). Stuttgart-Bad Cannstatt: Frommann-Holzboog.

Droysen, J. G. (1986). History and the historical method. In K. Mueller-Vollmer (Ed.), The hermeneutics reader (8th ed., pp. 119-124). Oxford: Blackwell.

Duffy, P. R. J. (2010). Excavations at Dunure Road, Ayrshire: A Bronze Age cist cemetery and standing stone. Proceedings of the Society of Antiquaries of Scotland, 137, 69-116.

Farrington, I. (2013). Cusco. Urbanism and archaeology in the Inka world. Ancient cities of the New World Series. Gainesville: University Press of Florida.

Fergusson, J. (1872). Rude stone monuments in all countries; their age and uses. London: John Murray.

Firth, C. R., \& Stewart, I. S. (2000). Postglacial tectonics of the Scottish glacio-isostatic uplift centre. Quaternary Science Reviews, 19, 1469-1493.

Forte, M. (2008). Virtual archaeology: Communication in 3D archaeological thinking. In B. D. Frischer \& A. Dakouri-Hild (Eds.), Beyond illustration: $2 D$ and $3 D$ digital technologies as tools for discovery in archaeology. BAR International Series 1805 (pp. 75-119). Oxford: Archaeopress.

Fossitt, J. A. (1990). Holocene vegetation history of the Western Isles, Scotland. Unpublished PhD, University of Cambridge.

Fossitt, J. A. (1996). Late Quaternary vegetation history of the Western Isles of Scotland. New Phytologist, 132, 171-196.

Fraser, D. (1983). Land and society in Neolithic Orkney. BAR British Series 117. Oxford: British Archaeological Reports.

Fraser, D. (1988). The orientation of visibility from the chambered cairns of Eday, Orkney. In C. L. N. Ruggles (Ed.), Records in stone: Papers in memory of Alexander Thom (pp. 325-336). Cambridge: Cambridge University Press. 
Fraser, S. M. (1996). Physical, social and intellectual landscapes in the Neolithic: Contextualizing Scottish and Irish Megalithic architecture. Unpublished $\mathrm{PhD}$ thesis, University of Glasgow.

Fraser, S. M. (2004). Metaphorical journeys: Landscape, monuments and the body in a Scottish Neolithic. The Proceedings of the Prehistoric Society, 70, 129-151.

Furholt, M., \& Müller, J. (2011). The earliest monuments in Europe: Architecture and social structures (5000-3000 cal BC). In M. Furholt, F. Lüth, \& J. Müller (Eds.), Megaliths and identities: Early monuments and Neolithic societies from the Atlantic to the Baltic. Frühe Monumentalität und soziale Differenzierung 1 (pp. 15-32). Bonn: Dr. Rudolf Habelt GmbH.

Gianoi, C., Mañana-Borrazás, P., Criado-Boado, F., \& López-Romero, E. (2011). Deconstructing Neolithic monumental space: The Montenegro enclosure in Galicia (Northwest Iberia). Cambridge Archaeological Journal, 21(3), 391-406.

Gibson, A. (2010). Dating Balbirnie: Recent radiocarbon dates from the stone circle and cairn at Balbirnie, Fife, and a review of its place in the overall Balfarg/Balbirnie site sequence. Proceedings of the Society of Antiquaries of Scotland, 140, 51-79.

Gillings, M. (2015). Betylmania? Small standing stones and the megaliths of southwest Britain. Oxford Journal of Archaeology, 34(3), 207-233.

Gillings, M., \& Pollard, J. (2004). Avebury. London: Duckworths.

Gillings, M., Pollard, J., \& Taylor, J. (2010). The miniliths of Exmoor. Proceedings of the Prehistoric Society, 76, 297-318.

Giot, P.-R., Monnier, J.-L., \& L’Helgouach, J. (1998). Préhistoire de le Bretagne. Rennes: Ouest-France.

González-García, A. C., \& Belmonte, J. A. (2014). Sacred architecture orientation across the Mediterranean: A comparative statistical analysis. Mediterranean Archaeology and Archaeometry, 14(2), 95-113.

Gooding, D. C. (2008). Envisioning explanation: The art in science. In B. D. Frischer \& A. Dakouri-Hild (Eds.), Beyond illustration: $2 D$ and $3 D$ digital technologies as tools for discovery in archaeology. BAR International Series 1805 (pp. 1-20). Oxford: Archaeopress.

Graham, A. (1977). The development of Scottish antiquarian records: 1600-1800. Society of Antiquaries of Scotland, 106(1974), 183-190.

Grau Bitterli, M.-H., Leuvrey, J.-M., \& Rieder, J. (2002). Deux nouveaux espaces mégalithiques sur la rive nord du lac de Neuchâtel. Archéologie Suisse, 25, 20-30.

Harding, J., Johnson, B., \& Goodrick, G. (2006). Neolithic cosmology and the monument complex of Thornborough, North Yorkshire. Archaeoastronomy: Journal of Astronomy in Culture, 20, 28-53.

Heggie, D. C. (1981). Megalithic science: Ancient mathematics and astronomy in Northwest Europe. London: Thames \& Hudson.

Heidegger, M. (1971). Poetry, language, thought. A. Hofstadter, Trans. New York: Harper \& Row.

Heidegger, M. (1982). The basic problems of phenomenology. A. Hofstadter, Trans. Bloomington: Indiana University Press.

Helskog, K. (1999). The shore connection: Cognitive landscape and communication with rock carvings in northenmost Europe. Norwegian Archaeological Review, 32(2), 73-94.

Hermon, S. (2008). Reasoning in 3D: A critical appraisal of the role of 3D modelling and virtual reconstructions in archaeology. In B. D. Frischer \& A. Dakouri-Hild (Eds.), Beyond illustration: $2 D$ and $3 D$ digital technologies as tools for discovery in archaeology. BAR International Series 1805 (pp. 36-45). Oxford: Archaeopress.

Higginbottom, G. (2003). Interdisciplinary study of megalithic monuments in western Scotland. Unpublished $\mathrm{PhD}$ thesis, University of Adelaide.

Higginbottom, G. (2005). https://www.academia.edu/42778668/EAA2005_PP_Presentation_-_Const ruction_of_the_Observers_of_time_on_the_inner_isles_of_western_Scotlands. Accessed 18 Apr 2020 .

Higginbottom, G. (2014). Intangible heritage: Cultural heritage management. In C. Smith (Ed.), Encyclopaedia of global archaeology (pp. 3918-3921). New York: Springer.

Higginbottom, G. (2020). Perception creates worlds: Meaning and experience in the erection of the standing stones of western Scotland. In L. Dunbar, R. Parkes, C. Gant-Thompson, \& D. Tybussek (Eds.), Yachay Wasi: The House of Knowledge of I. S. Farrington. Oxford: BAR Publishing.

Higginbottom, G. (in prep.). Megaliths in Argyll: Integrating landscape formations and astronomical knowledge in the creation of place in the Bronze Age. Draft retrieved December 2018 at https://anuau.academia.edu/GailHigginbottom.

Higginbottom, G., \& Clay, R. (1999). Reassessment of sites in northwest Scotland: A new statistical approach. Archaeoastronomy, 24, S1-S6. 
Higginbottom, G., \& Clay, R. (2016a). Origins of standing stone astronomy in Britain: New quantitative techniques for the study of archaeoastronomy. Journal of Archaeological Science: Reports, 9, 249-258. https://doi.org/10.1016/j.jasrep.2016.05.025.

Higginbottom, G., \& Clay, R. (2016b). Connections: The relationships between Neolithic and Bronze Age megalithic astronomy in Britain. In F. Silva, K. Malville, T. Lomsdalen, \& F. Ventura (Eds.), The materiality of the sky. Lampeter: Sophia Centre Press.

Higginbottom, G., \& Mom, V. (2018). Place: The physical embodiment of collective information. In J. B. Glover, J. M. Moss, \& D. Rissolo (Eds.), Digital archaeologies, material worlds. Tübingen: University of Tübingen Press.

Higginbottom, G., \& Mom, V. (2020). Illuminating time: The visibility of temporality in prehistory. In C. Papadopoulos \& H. Moyes (Eds.), The Oxford handbook of light in archaeology. Oxford: Oxford University Press.

Higginbottom, G., Simpson, K., \& Clay, R. (2002). Using viewsheds wisely: Developing sound methodologies from spatial analyses of megalithic monuments in western Scotland. In G. Burenhult \& J. Arvidsson (Eds.), Archaeological informatics: Pushing the envelope. BAR International Series 1016 (pp. 53-62). Oxford: Archaeopress.

Higginbottom, G., Smith, A. G. K., Simpson, K., \& Clay, R. (2000). Gazing at the horizon: Heavenly phenomena and cultural preferences within northwest Scotland? In C. Esteban \& J. A. Belmonte (Eds.), Astronomy and cultural diversity (pp. 43-50). Tenerife: Organismo autónomo de Museos del Cabildo.

Higginbottom, G., Smith, A. G. K., Simpson, K., \& Clay, R. (2001). Incorporating the natural environment: Investigating landscape and monument as sacred space. In M. Gojda \& T. Darvill (Eds.), One land, many landscapes. BAR International Series 987 (pp. 97-104). Oxford: Archaeopress.

Higginbottom, G., Smith, A., Simpson, K., \& Clay, R. (2003). More than orientation: Placing monuments to view the cosmic order. In A. Maravelia (Ed.), Ad Astra per Aspera et per Ludum: European archaeoastronomy and the orientation of monuments in the Mediterranean Basin. British Archaeological Reports, International Series S1154 (pp. 39-52). Oxford: Archaeopress.

Higginbottom, G., Smith, A. G. K., \& Tonner, P. (2011). https://www.academia.edu/42784873/A_Recreation_of_an_Embodied_Engagement_and_the_Revelation_of_World_Views_in_Bronze_Age_ Scotland. Accessed 18 Apr 2020.

Higginbottom, G., Smith, A. G. K., \& Tonner, P. (2015). A re-creation of visual engagement and the revelation of world views in Bronze Age Scotland. Journal of Archaeological Method and Theory, 22, 584-645. https://doi.org/10.1007/s10816-013-9182-7. Published online 2013.

Higginbottom, G., \& Tonner, P. (2010). The geographies of values. In S. Koerner \& I. Russell (Eds.), The unquiet past: Theoretical perspectives on archaeology and cultural heritage (pp. 291-303). Oxon: Ashgate.

Hodder, I. (2012). Entangled: An archaeology of the relationships between humans and things. Malden: Wiley-Blackwell.

Hodder, I. (2016). Studies in human-thing entanglement. CIan Hodder. Creative Commons Attribution (CC BY 4.0) license.

Hoskin, M. (2009). Orientations of dolmens in Western Europe. In Proceedings of the International Astronomical Union, 5, Symposium S260 (pp. 116-126).

Hunt, D. (1987). Early farming communities in Scotland: Aspects of economy and settlement, 4500-1250 $B C$. BAR British Series 117. Oxford: British Archaeological Reports.

Husserl, E. (1913 [1982]). Ideas Ppertaining to a pure phenomenology and to a phenomenological philosophy; first book: General introduction to a pure Pphenomenology. F. Kersten, Trans. The Hague: Nijhoff.

Johnsen, H., \& Olsen, B. (1992). Hermeneutics and archaeology: On the philosophy of contextual archaeology. American Antiquity, 57(3), 419-436. https://doi.org/10.2307/280931.

Jones, R. (1997). Mull in the making. Aros: Craigmore.

Jones, A. M., Freedman, D., O’Connor, B., Lamdin-Whymark, H., Tipping, R., \& Watson, A. (2011). An animate landscape: Rock art and the prehistory of Kilmartin, Argyll, Scotland. Oxford: Windgather Press.

Kirchner, H. (1955). Die Menhire in Mitteleuropa und der Menhirgedanke. Wiesbaden: F. Steiner.

Kitchin, R., \& Blades, R. (2002). The cognition of geographic space. London: I. B. Taurus.

Kohler, T. A. (2012). Complex systems and archaeology. In I. Hodder (Ed.), Archaeological theory today (pp. 93-123). Hoboken: Wiley. 
Kohler, T. A., \& van der Leeuw, S. (Eds.). (2007). Model-based archaeology of socionatural systems. Santa Fe: School of Advanced Research.

Lee, E. J., Makarewicz, C., Renneberg, R., Harder, M., Krause-Kyora, B., Müller, S., et al. (2012). Emerging genetic patterns of the European Neolithic: Perspectives from a Late Neolithic Bell Beaker burial site in Germany. American Journal of Physical Anthropology, 148, 571-579.

Le Roux, C.-T. (1984). A propos des fouilles de Gavrinis (Morbihan): Nouvelles données sur l'art mégalithique armoricain. Bulletin de la société préhistorique française, 81, 240-245.

Le Roux, C.-T. (1992). The art of Gavrinis presented in its Armorican context and in comparison with Ireland. Journal of the Royal Society of Antiquaries of Ireland, 122, 79-108.

Lockyer, N. (1906). Stonehenge and other British stone monuments astronomically considered. London: MacMillan \& Co.

Macklin, M., Bonsall, C., Davies, F. M., \& Robinson, M. R. (2000). Human-environment interactions during the Holocene: New data and interpretations from the Oban area, Argyll, Scotland. The Holocene, 10, 109-121.

Macnab, P. (1995). Mull and Iona. Newton Abbot: David \& Charles/Pevensey.

Martinsson-Wallin, H., \& Wehlin, J. (2017). Stones in the South: Decoding Bronze Age ritual practices on Gotland. Current Swedish Archaeology, 25, 227-256. Retrieved from http://urn.kb.se/resol ve?urn=urn:nbn:se:uu:diva-371255

Martlew, R., \& Ruggles, C. (1996). Ritual and landscape on the west coast of Scotland: An investigation of the stone rows of northern Mull. Proceedings of the Prehistoric Society, 62, 117-131. https:// doi.org/10.1017/S0079497X00002760.

McFadyen, L. (2008). Building and architecture as landscape practise. In B. David \& J. Thomas (Eds.), Handbook of landscape archaeology (pp. 307-314). Walnut Creek: Left Coast Press.

Mendez, A., Karasik, C., Barnhart, E. L., \& Powell, C., (2014). The astronomical architecture of Palenque's Temple of the Sun. In G. Aldana y Villalobos \& E. L. Barnhart (Eds.), Archaeoastronomy and the Maya (pp. 57-76). Oxford: Oxbow.

Merleau-Ponty, M. (2012). Phenomenology of perception (D. Landes, Trans.). London: Routledge. (Original work published 1945).

Miller, J., \& Page, S. (2007). Complex adaptive systems: An introduction to computational models of social life. Princeton Studies in Complexity. Princeton: Princeton University Press.

Mitchell, M. E. C. (1933). The prehistoric antiquities of Benderloch and Appin. Proceedings of the Society of Antiquaries of Scotland, 67, 320.

Mithen, S. (Ed.). (2000). Hunter-gatherer landscape archaeology: The Southern Hebrides Mesolithic Project 1988-1998. Volume 1: Project development, palaeoenvironmental studies and archaeological fieldwork on Islay. Cambridge: McDonald Institute for Archaeological Research.

Mörner, N.-A. (2012). Strict solar alignment of Bronze Age rock carvings in SE Sweden. Journal of Archaeological Science, 39, 3301-3305. https://doi.org/10.1016/j.jas.2012.05.027.

Mörner, N.-A. (2015). Ales stones in SE Sweden: A solar calendar from the Late Bronze Age. Journal of Archaeological Science Reports, 2, 437-448. https://doi.org/10.1016/j.jasrep.2015.04.002.

Müller, J. (2014). 4100-2700 BC: Monuments and ideologies in the Neolithic landscape. In J. F. Osborne (Ed.), Approaching monumentality in archaeology (pp. 181-217). Albany: University of New York Press.

Mueller-Vollmer, K. (1986). The hermeneutics reader (English ed.). Oxford: Blackwell.

Myatt, L. (2003). The stone rows of northern Scotland. In C. L. N. Ruggles (Ed.), Records in stone: Papers in memory of Alexander Thom (pp. 277-318). Cambridge: Cambridge University Press.

Noble, G., \& Brophy, K. (2011). Ritual and remembrance at a prehistoric ceremonial complex in central Scotland: Excavations at Forteviot. Perth and Kinross. Antiquity, 85(329), 787-804.

Noble, G., \& Brophy, K. (2014). Construction, process, environment: Altering the landscape in Neolithic lowland Scotland. In D. Mischka, M. Furholt, M. Hinz, G. Noble, \& D. Olausson (Eds.), Landscapes, histories and societies in the northern European Neolithic (pp. 65-80). Kiel: Kiel University.

Noble, G., \& Brophy, K. (2015). Transforming place and architecture through cremation: Cremation traditions at the third millennium BC monument complex at Forteviot, central Scotland. In K. Brink, S. Hyden, K. Jennbert, L. Larsson, \& D. Olousson (Eds.), Neolithic diversities: Perspectives from a conference in Lund, Sweden. Acta Archaeologica Lundisia Series in $8^{\circ}$, No. 65 (pp. 164-172). New York: Taylor \& Francis.

Olalde, I., Brace, S., Allentoft, M. E., Armit, I., Kristiansen, K., Booth, T., et al. (2018). The Beaker phenomenon and the genomic transformation of northwest Europe. Nature, 555, 190-196. 
Parker Pearson, M., Pollard, J., Richards, C., Thomas, J., Tilley, C., \& Welham, K. (2008). The Stonehenge Riverside Project: Exploring the Neolithic landscape of Stonehenge. Documenta Praehistorica, 35, 153-166.

Parker Pearson, M., Pollard, J., Richards, C., Thomas, J., Tilley, C., \& Welham, K. (2011) Stonehenge and early Bronze Age cosmology. In H. Meller \& F. Bertemes (Eds.), Der Griff nach den Sternen: Wie Europas Eliten zu Macht und Reichtum kamen (pp. 397-416). Halle, DE: Landesamt für Denkmalpflege und Archäologie Sachsen-Anhalt/Landesmuseum für Vorgeschichte.

Parker Pearson, M., \& Ramilisonina, (1998). Stonehenge for the ancestors: The stones pass on the message. Antiquity, 72(276), 308-326.

Patrick, J., \& Freeman, P. (1985). A cluster analysis of astronomical orientations. In C. L. N. Ruggles (Ed.), Records in stone: Papers in memory of Alexander Thom (pp. 251-261). Cambridge: Cambridge University Press.

Pollard, J., \& Ruggles, C. (2001). Shifting perceptions: Spatial order, cosmology, and patterns of deposition at Stonehenge. Cambridge Archaeological Journal, 11, 69-90. https://doi.org/10.1017/S0959 $77430100004 \mathrm{X}$.

RCAHMS. (1971). The Royal Commission on the ancient and historical monuments of Scotland. Argyll: An Inventory of the Ancient Monuments, Volume 1, Kintyre. Edinburgh: HMSO.

RCAHMS. (1980). The Royal Commission on the ancient and historical monuments of Scotland. Argyll: an inventory of the monuments. Volume 3: Mull, Tiree, Coll and Northern Argyll (excluding the early medieval and later monuments of Iona). Edinburgh: HMSO.

RCAHMS. (1988). The Royal Commission on the ancient and historical monuments of Scotland. Argyll: An Inventory of the Ancient Monuments, Volume 6, Mid Argyll and Cowal: Prehistoric and Early Medieval Monuments. Edinburgh: HMSO.

Rennie, A. F. (2006). The role of sediment supply and sea level changes on a submerging coast: Past changes and future management implications. University of Glasgow. Unpublished PhD Thesis.

Rennie, A. F., \& Hansom, J. D. (2011). Sea level trend reversal: Land uplift outpaced by sea level rise on Scotland's coast. Geomorphology, 125, 193-202.

Richards, C. (1996a). Monuments as landscape: Creating the centre of the world in Late Neolithic Orkney. World Archaeology, 28, 190-208.

Richards, C. (1996b). Henges and water: Towards an elemental understanding of monumentality and landscape in Late Neolithic Britain. Journal of Material Culture, 1(3), 313-336.

Richards, C. (2005). Dwelling among the monuments: The Neolithic village of Barnhouse, Maeshowe passage grave and surrounding monuments at Stenness, Orkney. Cambridge: McDonald Institute for Archaeological Research.

Richards, C. (Ed.). (2013a). Building the great stone circles of the north. Oxford: Windgather Press.

Richards, C. (2013b). Interpreting stone circles. In C. Richards (Ed.), Building the great stone circles of the north (pp. 2-30). Oxford: Windgather Press.

Richards, C. (2013c). Wrapping the hearth: Constructing house societies and the tall Stones of Stenness, Orkney. In C. Richards (Ed.), Building the great stone circles of the north (pp. 64-89). Oxford: Windgather Press.

Richards, C., Challands, A., \& Welham, K. (2013). Erecting stone circles in a Hebridean landscape. In C. Richards (Ed.), Building the great stone circles of the north (pp. 201-223). Oxford: Windgather Press.

Richards, C., \& Wright, J. (2013). Monuments in the making: The stone circles of Western Scotland. In C. Richards (Ed.), Building the great stone circles of the north (pp. 31-63). Oxford: Windgather Press.

Richmond, A. (1999). Preferred economies: The nature of the subsistence base throughout mainland Britain during prehistory. British Archaeological Reports, British Series 290. Oxford: Archaeopress.

Ritchie, J. N. G. (1974). The excavation of a stone circle and cairn at Balbirnie, Fife. Archaeological Journal, 131, 1-32.

Ritchie, J. N. G. (1976). The Stones of Stenness, Orkney. Proceedings of the Society of Antiquities of Scotland, 107, 1-60.

Robb, J. (2009). People of stone: Stelae, personhood, and society in prehistoric Europe. Journal of Archaeological Method and Theory, 16(3), 162-183.

Rodriguez, G., \& Marchesi, H. (Ed.). (2015). Statues-menhirs et pierres levées du Néolithique à aujourd'hui: Actes du $3^{e}$ Colloque international sur la statuaire mégalithique, Saint-Pons-deThomières, du 12 au 16 septembre 2012. Montpellier \& Saint-Pons-de-Thomières: Direction régionale des affaires culturelles Languedoc-Roussillon \& Groupe archéologique du Saint-Ponais. 
Ruggles, C. (1999). Astronomy in prehistoric Britain and Ireland. London: Yale University Press.

Ruggles, C. L. N., \& Martlew, R. D. (1989). The north mull project (1): Excavations at glengorm 198788. Archaeoastronomy, 14, S137-S149.

Ruggles, C., \& Martlew, R. (1992). The north Mull project, 3: Prominent hill summits and their astronomical potential. Archaeoastronomy, 17, S1-S13.

Ruggles, C., \& Medyckyj-Scott, J. D. (1996). Site location, landscape visibility, and symbolic astronomy: A Scottish case study. In H. D. G. Maschner (Ed.), New methods, old problems: Geographic Information Systems in modern archaeological research. Center for Archaeological Investigations Occ. Paper No. 23 (pp. 127-146). Carbondale: Southern Illinois University.

Ruggles, C. L. N. (1981). A critical examination of the megalithic lunar observatories. In C. L. N. Ruggles \& A. W. R. Whittle (Eds.), Astronomy and society in Britain during the period 4000-1500 BC. BAR British Series 88 (pp. 153-209). Oxford: British Archaeological Reports.

Ruggles, C. L. N. (1982a). Megalithic astronomical sightlines: Current reassessment and future directions. In D. C. Heggie (Ed.), Archaeoastronomy in the Old World (pp. 83-105). Cambridge: Cambridge University Press.

Ruggles, C. L. N. (1982b). A reassessment of the high precision megalithic lunar sightlines, 1: Backsights, indicators and the archaeological status of the sightlines. Archaeoastronomy, 4, S21-S40.

Ruggles, C. L. N. (1983). A reassessment of the high precision megalithic lunar sightlines, 2: Foresights and the problem of selection. Archaeoastronomy, 5, S1-S36.

Ruggles, C. L. N. (1984). Megalithic astronomy: A new archaeological and statistical study of 300 western Scottish sites. BAR British Series 123. Oxford: British Archaeological Reports.

Ruggles, C. L. N. (1985). Linear settings of Argyll and Mull. Archaeoastronomy, 16, S105-S130.

Ruggles, C. L. N. (1988). The stone alignments of Argyll and Mull. In C. L. N. Ruggles (Ed.), Records in stone: Papers in memory of Alexander Thom (pp. 325-336). Cambridge: Cambridge University Press.

Ruggles, C. L. N. (1996). The stone rows of southwest Ireland [part 2]. Journal for the History of Astronomy. Archaeoastronomy Supplement, 19, S55-S71.

Ruggles, C. L. N., \& Burl, A. (1985). A new study of the Aberdeenshire recumbent stone circles, 2: Interpretation. Archaeoastronomy, 8, S25-S60.

Ruggles, C. L. N., Martlew, R. D., \& Hinge, P. (1991). The north Mull project 2: The wider astronomical potential of the sites. Archaeoastronomy, 16, S51-S75.

Ruzicka, D. (2015). Is there evidence for the observation and use of astronomy at the Harris site in the Mimbres Valley? PhD Thesis. University of Nevada.

Sartre, J.-P. (1956). Being and nothingness: An essay on phenomenological ontology (H. E. Barnes, Trans.). New York: Philosophical Library. (Original work published 1943).

Scarre, C. (Ed.). (2005). Monuments and landscape in Atlantic Europe: Perception and society during the Neolithic and Early Bronze Age. London: Routledge.

Scarre, C., \& Oosterbeek, L. (Eds.) (2019). Megalithic tombs in Western Iberia: Excavations at the Anta da Lajinha. Oxford: Oxbow Books.

Schuldt, E. (1972). Die mecklenburgischen Megalithgräber: Untersuchungen zu ihrer Architektur und Funktion. Beiträge zur Ur- und Frühgeschichte der Bezirke Rostock, Schwerin und Neubrandenburg, 6. Berlin: Deutscher Verlag der Wissenschaften.

Schulting, R., Sheridan, R., Crozier, R., \& Murphy, E. (2010). Revisiting Quanterness: New AMS dates and stable isotope data from an Orcadian chamber tomb. Proceedings of the Society of Antiquaries Scotland, 140, 1-50.

Schulz Paulsson, B. (2017). Time and stone: The emergence and development of megaliths and megalithic societies in Europe. Oxford: Archaeopress.

Shennan, I., \& Horton, B. P. (2002). Holocene land- and sea-level changes in Great Britain. Journal of Quaternary Science, 17, 511-526.

Sheridan, J. A. (2008a). Towards a fuller, more nuanced narrative of Chalcolithic and Early Bronze Age Britain 2500-1500 BC. Bronze Age Review: The International Journal of Research into the Archaeology of the British and European Bronze Age, 1, 57-78.

Sheridan, J. A. (2008b). Radiocarbon dates arranged through the National Museums of Scotland Archaeology Department during 2007/8. Discovery and Excavation in Scotland, 9, 201-205.

Sheridan, J. A. (2012). Contextualising Kilmartin: Building a narrative for developments in western Scotland and beyond, from the Early Neolithic to the Late Bronze Age. In A. M. Jones, J. Pollard, M. J. Allen, \& J. Gardiner (Eds.), Image, memory and monumentality: Archaeological engagements 
with the material world. A celebration of the academic achievements of Professor Richard Bradley. Prehistoric Society Research Paper No. 5 (pp. 163-183). Oxford: Oxbow.

Sims, L. (2006). The 'Solarization' of the Moon: Manipulated knowledge at Stonehenge. Cambridge Archaeological Journal, 16, 191-207. https://doi.org/10.1017/S0959774306000114.

Sims, L. (2009). Entering, and returning from, the Underworld: Reconstituting Silbury Hill by combining a quantified landscape phenomenology with archaeoastronomy. The Journal of the Royal Anthropological Institute, 15, 386-408. Retrieved April 8, 2020, from https://www.jstor.org/stable/20527 714.

Sims, L., \& Fisher, D. (in press). Through the dark vale: Interpreting the Stonehenge palisade through inter-disciplinary convergence. Journal of Skyscape Archaeology, 6, 1.

Smith, A. G. K. (2013). Horizon user guide and implementation notes. Documentation Version 0.12728 December 3, 2013. http://www.agksmith.net/horizon. Retrieved Dec 2019.

Smith, D. E. (2005). Evidence for secular sea surface level changes in the Holocene raised shorelines of Scotland, UK. Journal of Coastal Research, 42, 26-42.

Smith, D. E., Hunt, N., Firth, C. R., Jordan, J. T., Fretwell, P. T., Harman, M., et al. (2012). Patterns of Holocene relative sea level change in the North of Britain and Ireland. Quaternary Science Reviews, 54(26), 58-76.

Sofaer, A., Sinclair, R. M., \& Doggett, L. E. (1982). Noon markings on Fajada Butte, Chaco Canyon, New Mexico. Bulletin of the American Astronomical Society, 14, 872.

Somerville, B. (1912). Prehistoric monuments in the Outer Hebrides, and their astronomical significance. The Journal of the Royal Anthropological Institute of Great Britain and Ireland, 42, 23-52.

Spence, M. (1894). Standing stones and Maeshowe of Stenness. Paisley and London: Gardner.

Spence, M. (1906). Reports of district secretaries: Renovation and preservation of the standing stones, Stenness. London: Saga Book of the Viking Club.

Šprajc, S., \& Sánchez Nava, P. F. (2015). Astronomía en la arquitectura de Chichén Itzá: Una reevaluación. Estudios de Cultura Maya, 41(41), 31-60. https://doi.org/10.1016/S0185-2574(13)71376 -515 .

Taçon, P. S. C. (1994). Socializing landscapes: The long term implications of signs, symbols and marks on the land. Archaeology in Oceania, 29, 117-129. https://doi.org/10.1002/arco.1994.29.3.117.

Tan, H., WilsonIan, A., \& Olver, I. (2009). Ricoeur's theory of interpretation: An instrument for data interpretation in hermeneutic phenomenology. The International Journal of Qualitative Methods, 8, 1-15. https://doi.org/10.1177/160940690900800401.

Thom, A. (1955). A statistical examination of the megalithic sites in Britain. Journal of the Royal Statistical Society. Series A General, 118(3), 275-295.

Thom, A. (1967). Megalithic sites in Britain. Oxford: Clarendon Press.

Thom, A. (1971). Megalithic lunar observatories. Oxford: Clarendon Press.

Thom, A. (1973). A megalithic lunar observatory in Orkney. Journal for the History of Astronomy, 4, $169-173$.

Thom, A. (1979). The standing stones in Argyllshire. Glasgow Archaeological Journal, 6, 5-10. https:// doi.org/10.3366/gas.1979.6.6.5.

Thom, A. (1984). The two major Megalithic observatories in Scotland. Journal for the History of Astronomy, 15, 129-148.

Thom, A., \& Thom, A. S. (1978). Megalithic remains in Britain and Brittany. BAR British Series 81. Oxford: British Archaeological Reports.

Thom, A., \& Thom, A. S. (1980). A new study of all megalithic lunar lines. Archaeoastronomy, 2, S78-S89.

Thom, A., Thom, A. S., \& Burl, A. (1980). Megalithic rings. BAR British Series 81. Oxford: British Archaeological Reports.

Thom, A., Thom, A. S., \& Burl, A. (1990). Stone rows and standing stones. BAR International Series 560. Oxford: British Archaeological Reports.

Thom, A. S. (1981). Megalithic lunar observatories: An assessment of 42 lunar alignments. Astronomy and society. In C. L. N. Ruggles \& A. W. R. Whittle (Eds.), Britain during the period 4000-1500 BC. BAR British Series 88 (pp. 14-61). Oxford: British Archaeological Reports.

Thomas, J. (2006). The great dark book: Archaeology, experience, and interpretation. In J. Bintliff (Ed.), A companion to archaeology (pp. 20-36). Oxford: Blackwell.

Tipping, R. (1994). The form and fate of Scotland's woodlands. Proceedings of the Society of Antiquaries of Scotland, 124, 1-54.

Tonner, P. (2010). Heidegger, metaphysics and the univocity of Being. New York: Continuum. 
Toren, C. (1999). Mind, materiality and history: Explorations in Fijian ethnography. London: Routledge.

Trevarthen, D. (2000). Illuminating the monuments: Observation and speculation on the structure and function of the cairns at Balnuaran of Clava. Cambridge Archaeological Journal, 10, 295-315.

Welfare, A. (2011). Great crowns of stone: The recumbent stone circles of Scotland. Edinburgh: Royal Commission on the Ancient and Historical Monuments of Scotland.

Whittle, A. (1997). Remembered and imagined belongings: Stonehenge in its traditions and structures of meaning. In B. Cunliffe \& C. Renfrew (Eds.), Science and Stonehenge (pp. 145-166). Oxford: Oxford University Press.

Whittle, A., Pollard, J., \& Grigson, C. (1999). The harmony of symbols: The Windmill Hill causewayed enclosure, Wiltshire. Oxford: Oxbow.

Wilkins, D. A. (1984). The Flandrian Woods of Lewis (Scotland). Journal of Ecology, 72(1), 251-258.

Willis, C., Marshall, P., McKinley, J., Pitts, M., Pollard, J., Richards, C., et al. (2016). The dead of Stonehenge. Antiquity, 90, 337-356. https://doi.org/10.15184/aqy.2016.26.

Wright, J. (2007). The standing stones on the Western Isles of Scotland. Unpublished PhD Thesis, University of Manchester.

Wüthrich, S. (2007). L'émergence du mégalithisme au 5emillénaire sur la rive nord du lac de Neuchâtel (Suisse): Un phénomène lié à l'organistion socio-économique des premières communautés agricoles? In M. Besse (Ed.), Sociétés néolithiques: des faits archéologiques aux fonctionnements socio-économiques: Actes du $27^{e}$ colloque interrégional sur le Néolithique (Neuchâtel, 1 et 2 octobre 2005) (pp. 295-301). Lausanne: Cahiers d'archéologie romande.

Publisher's Note Springer Nature remains neutral with regard to jurisdictional claims in published maps and institutional affiliations. 